Universidade de São Paulo

Instituto de Física

\title{
O papel da virulência na evolução da adaptabilidade de uma população de parasitas
}

\author{
Fernando Goldenstein Carvalhaes \\ Orientadora : Carla Goldman
}

Dissertação de mestrado apresentada ao

Instituto de Física da USP para a obtenção

do título de Mestre em Ciências.

Comissão Examinadora

Profa. Dra. Carla Goldman (IFUSP)

Profa. Dra. Carmen Pimentel Cintra do Prado (IFUSP)

Prof. Dr. Marcus Aloizio Martinez de Aguiar (UNICAMP)

São Paulo

2005 


\section{FICHA CATALOGRÁFICA}

Preparada pelo Serviço de Biblioteca e Informação do Instituto de Física da Universidade de São Paulo

Carvalhaes, Fernando Goldenstein

O Papel da Virulência na Evolução da Adaptabilidade de uma População de Parasitas.

São Paulo - 2005.

Dissertação (Mestrado) - Universidade de São Paulo Orientador: Profa. Dra. Carla Goldman

Instituto de Física - Departamento de Física Geral Área de Concentração: Física

Unitermos:

1. Biofísica;

2. Dinâmica de populações;

3. Fenomenologia;

4. Fenômenos biológicos;

5. Virologia. 
A meus pais 



\section{Conteúdo}

Capítulo 1. Introdução 1

Capítulo 2. Sobre Dinâmica de Populações $\quad 9$

2.1. Um pouco sobre a história dos modelos para dinâmica de populações $\quad 9$

2.2. Sobre os conceitos biológicos utilizados ao longo do trabalho 18

2.3. O trabalho experimental contemplado 24

2.4. Interpretação dos procedimentos experimentais e da relação dos resultados com o processo de crescimento Malthuseano 31

2.5. Análise das primeiras propostas de descrições teóricas do experimento. 34

Capítulo 3. Desenvolvimento Teórico 43

3.1. Modelo não-linear para a evolução do fenótipo de uma quasi-espécie de vírus 43

3.2. Soluções da equação

$\begin{array}{lll}\text { Capítulo 4. Discussão dos resultados } & 79\end{array}$

4.1. Soluções Analíticas $\quad 80$

4.2. Soluções Numéricas $\quad 95$

4.3. Comparação com os dados experimentais 102

$\begin{array}{lll}\text { Capítulo 5. Conclusões } & 107\end{array}$

$\begin{array}{ll}\text { Apêndice A } & 111\end{array}$

$\begin{array}{ll}\text { Apêndice B } & 115\end{array}$

Apêndice C 133

$\begin{array}{ll}\text { Referências } & 137\end{array}$ 



\section{CAPíTULO 1}

\section{Introdução}

Quando ainda não havia uma tradição de investigação científica que tratasse da diversidade da vida na Terra, a maior parte das pessoas do ocidente, por mais ilustradas que fossem, acreditava na teoria criacionista, aceitando a versão bíblica de que os seres são permanentes e imutáveis, criados pelo desígnio de deus.

O trabalho de Darwin sobre a origem das espécies, datado de 1859 [Darwin 1979, Darwin 2002], é um dos trabalhos pioneiros nesta temática. É, também, um dos maiores exemplos da enorme resistência que os conceitos profundamente arraigados na sociedade oferecem à aceitação da ciência, no caso, biologia da evolução.

A tese de Darwin sobre a origem das espécies sofreu inúmeras críticas, principalmente pela religiosidade da sociedade na época. O próprio autor hesitou por mais de dez anos, e apenas percebeu que era hora de publicar seu trabalho quando recebeu de Alfred Russel Wallace, em 1858, uma carta com a descrição de seu manuscrito intitulado "Sobre a tendência das variedades se afastarem indefinidamente a partir do ponto original".

Como talvez já esperasse, sua tese foi muito mal aceita, tanto pela sociedade quanto pela comunidade científica.

Com o tempo, tornou-se claro, principalmente com as descobertas de fósseis, que os animais realmente "evoluíam", ou seja, transformavam-se; ficou evidente, também, que em um tempo remoto existiram outras formas de vida, agora extintas.

A maior parte destes primeiros trabalhos evolucionistas era qualitativa, feitos através da comparação morfológica entre fósseis e animais vivos, como, por exemplo, a enorme semelhança entre mamutes e elefantes, ou entre os próprios animais vivos, por exemplo entre os diversos tipos de pombos. 
O trabalho pioneiro de Darwin traz muitos conceitos importantes para o estudo da biologia da evolução. Com eles, ficou claro que cada variação (seja dentro ou fora de uma espécie) está mais ou menos adaptada àquele ambiente em que habita [Darwin 1979].

Por mais que este fato tenha parecido óbvio com o tempo, quantificar o quanto um indivíduo ou espécie está adaptado a um determinado ambiente (o que designaremos por fitness), até os dias atuais, mostra-se extremamente complicada.

Esta dificuldade existe por diversas razões.

A primeira reside na própria definição do conceito, que costuma variar dependendo do objeto de estudo.

Segundo, porque o procedimento de avaliação do fitness de um determinado indivíduo (ou espécie) não pode ignorar que este depende de sua relação com o meio, e invariavelmente o meio se transforma no decorrer de sua vida, ou na de seus descendentes.

Terceiro, porque na natureza fenômenos aleatórios são responsáveis por grande parte do processo evolutivo das populações. As mutações podem ser consideradas aleatórias, já a seleção não é. Isto significa que se fossemos medir o fitness de dois indivíduos idênticos (clones), tomando como indicadores o tempo de vida, fertilidade, ou número de descendentes por exemplo, provavelmente chegaríamos a um resultado diferente para o fitness de cada um deles. Por isso normalmente considera-se o fitness médio de uma população.

Outra dificuldade de medição em biologia da evolução é a "velocidade"com que ocorre a "evolução"dos seres vivos. Em outras palavras, como quantificar a variação do fitness de uma população, indivíduo, ou espécie, em um determinado intervalo de tempo?

O registro fóssil é escasso, e desta forma não se consegue responder à questão de como se dá a modificação, substituição, surgimento e tempo de permanência das diferentes espécies. Darwin percebeu que isto era um grande problema para sua teoria, segundo a qual supunha que as modificações se davam de maneira gradual e contínua: não se consegue acumular evidências suficientes para caracterizar o conjunto de etapas desta gradação. 
Os biologistas da evolução debatem, ainda hoje, sobre a forma com que se dão essas transformações, no chamado debate "Equilíbrio Pontuado x Gradualismo", que foi durante muito tempo presidido por Stephen Jay Gould e Richard Dawkins. Segundo Gould:

"O registro fóssil não oferecia qualquer apoio à mudança gradual: faunas inteiras tinham sido erradicadas durante intervalos de tempo extremamente curtos. As novas espécies apareceram no registro fóssil quase sempre de maneira abrupta, sem elos intermediários aos antepassados nas rochas mais velhas da mesma região"[Gould 2004].

Ao que tudo indica, pelo conjunto de motivos descritos acima, um estudo que meça a variação do fitness de uma espécie in vivo parece ser praticamente impossível.

Porém, os vírus, devido à sua simplicidade intrínseca, que se deve ao fato de se reproduzirem assexuadamente, ter um genoma de tamanho relativamente pequeno, e também à sua grande adaptabilidade a novos ambientes [Holland 1982, Strauss 1988], bem como agilidade (rapidez) para se adaptar, devido principalmente à alta taxa de mutação e grande progênia, oferecem uma oportunidade única para explorar uma dinâmica evolucionária.

É possível que genomas compostos de RNA tenham sido as primeiras formas de vida que constituíram a biosfera, suplantados, posteriormente, por genomas de DNA, mais estáveis. Porém os vírus sobrevivem até hoje, como parasitas de células com genomas de DNA.

Os primeiros microorganismos que foram manipulados em laboratório, desde seu descobrimento por Pasteur no século 19, foram as bactérias. Primeiro isolando e qualificando diferentes tipos, depois criando vacinas que fossem específicas para estas bactérias, possibilitando também a criação de diversos fármacos, como a penicilina, por exemplo, e também abrindo sua utilização para fins comerciais, como com as leveduras para fabricação de cerveja e de fermento - técnicas que aliás já eram conhecidas, mas cujo mecanismo completo de funcionamento demorou ainda mais tempo para ser compreendido, e teve que esperar ainda a descoberta da respiração celular.

Os vírus sempre foram considerados patógenos para o ser humano, e daí a necessidade de entender seu funcionamento e a dinâmica de suas forças evolutivas. 
Atualmente, adiciona-se a isto a possibilidade de utilizar os vírus para fins terapêuticos, através da chamada terapia gênica. Nestes processos, por exemplo, utiliza-se a capacidade dos vírus de transportar moléculas de DNA para o interior das células, com o intuito de reparar partes defeituosas no genoma de um ser vivo. Porém, por não ser ainda inteiramente dominado, a terapia gênica já foi responsável pela morte de pelo menos um ser humano utilizado experimentalmente (cobaia).

Em todos estes procedimentos laboratoriais, populações de vírus são manipuladas, em condições específicas de concentração e recursos. Ser capaz de quantificar o comportamento evolutivo dessas populações é de extrema valia.

Grupos experimentais de virologistas desenvolveram métodos para medir a evolução de uma população de vírus in vitro, e tem estudado extensivamente nos últimos dez anos maneiras de contornar parte das dificuldades encontradas quando da medida do fitness de uma população in vivo [Holland 1991, Clarke 1993, Duarte 1993, Novella 1995a,b e c, Novella 1999].

A grandeza medida nestes experimentos é a concentração de vírus em uma determinada amostra. A taxa de replicação da população é atribuída posteriormente, através do pressuposto de que estas populações se replicam exponencialmente.

Estes trabalhos preocupam-se em quantificar a dinâmica do fitness das populações de vírus, principalmente em situações de rotina dos laboratórios (onde normalmente grandes populações de vírus são manipuladas), que raramente coincidem com aquelas que os vírus encontrariam quando em infecções in vivo.

Em nosso trabalho, iremos propor um modelo teórico para a avaliação da evolução de uma população de vírus in vitro, tal como é observado em uma série de experimentos [Novella 1995a, Novella 1999, Holland 1991], tendo como objetivo prever a evolução da taxa de replicação desta população.

Os experimentos são compostos basicamente de duas etapas: uma onde ocorre a evolução da população de vírus, nas chamadas "passagens de evolução"(evolving passages), e outro onde ocorre a medida do fitness da população, relativa a cada uma destas "passagens de 
evolução", nas chamadas "passagens de competição"(competition passages). Esta distinção entre as duas etapas do experimento é essencial e faz-se presente em nosso modelo, como veremos a seguir.

Os resultados de tais experimentos são caracterizados por dois regimes para o crescimento da taxa de replicação, e a existência de um limite assintótico para esta.

Para tanto, lembramos que a população de vírus é geneticamente heterogênea (constituída de indivíduos com diferentes genomas), devido principalmente à alta taxa de mutação característica dos vírus. Porém, levamos em conta o fato de que diferentes genótipos podem remeter ao mesmo fenótipo: diferentes genomas podem levar à mesma taxa de replicação, por exemplo.

Experimentalmente, mede-se uma característica "macroscópica"da amostra: a concentração relativa de uma determinada população em relação à uma população padrão, em um determinado instante de tempo, que pode ser avaliada e medida com relativa facilidade.

Nosso modelo teórico descreve a evolução da população de vírus no chamado espaço dos fenótipos, grandeza que está associada ao fitness e à taxa de replicação, e caracterizaremos a população heterogênea através das concentrações $C(x, t)$ de indivíduos com determinado fenótipo $x$ presentes em uma amostra no instante $t$.

Segundo nosso modelo, a função $C(x, t)$ obedece à seguinte equação:

$$
\frac{\partial C(x, t)}{\partial t}=\Gamma \frac{\partial}{\partial x} C(x, t)[(1-2 P)+2 \alpha C(x, t)]
$$

Trata-se de uma equação diferencial parcial de primeira ordem, quasi-linear, de conservação para a evolução da função distribuição das concentrações $C(x, t)$ das sub-populações caracterizadas pelo fenótipo $x$ no instante $t$.

Na primeira parte do trabalho, apresentamos os conceitos biológicos considerados importantes para a descrição de um processo evolutivo de uma população de vírus, tais como fitness, quasi-espécies, pressão de seleção, bottlenecking, e, a seguir, a descrição do experimento que iremos modelar. 
Apresentamos também, nesta primeira parte, as primeiras descrições teóricas [Tsimring 1996, Aafif 1998] que surgiram na literatura, visando modelar este mesmo processo evolutivo, decorrente desta mesma série de experimentos. Estas descrições, entretanto, são calcadas em hipóteses de difícil comprovação e apresentam resultados limitados quanto às predições dos dados experimentais.

Nossas motivações para estudar os resultados experimentais de uma perspectiva teórica, apesar da existência de trabalhos neste âmbito, vem essencialmente da possibilidade de explorar novos aspectos da dinâmica da evolução do fitness em conexão com as condições particulares do experimento.

Mais especificamente, estamos interessados em saber como a cinética observada no regime transiente da variação da taxa de replicação é afetada pelas diferentes condições iniciais; de que maneira a taxa de replicação da população tende a um limite assintótico; quais as possíveis causas e em que condições podemos esperar duas fases distintas para o comportamento da variação da taxa de replicação; e qual é o papel do arranjo experimental e sua relação com a variação intrínseca do fitness da população.

Na segunda parte deste trabalho apresentamos o modelo proposto, seguido da descrição das soluções que obtivemos para a equação acima que é derivada do modelo, usando técnicas analíticas e numéricas.

Obtivemos resultados analíticos utilizando o método das características para certas condições iniciais. Métodos numéricos foram empregados para avaliar as soluções no caso de condições iniciais que não foram possíveis de ser resolvidas analiticamente.

Nossos resultados analíticos contemplam de maneira especial os dados experimentais do comportamento da taxa de replicação da população de vírus, e predizem de maneira correta os dois regimes de crescimento, como observado.

Além disso, nossa solução exibe um limite assintótico para a taxa de replicação, também em acordo com o experimento, que pode ser interpretado em termos de um processo malthuseano. 
Na terceira parte descrevemos como obtivemos o fenótipo médio e a taxa de replicação a partir da solução desta equação; discutimos nossos resultados com maiores detalhes, suas interpretações, as interpretações biológicas dos parâmetros, bem como o ajuste dos resultados experimentais através de nossos resultados analíticos. Discutimos também sobre a possibilidade de sugerir experimentos adicionais que investiguem algumas de nossas predições teóricas, que ainda não podem ser comprovadas com os dados existentes. 



\section{CAPíTULO 2}

\section{Sobre Dinâmica de Populações}

\subsection{Um pouco sobre a história dos modelos para dinâmica de populações}

Anteriormente aos trabalhos de Darwin, já havia inúmeras teorias que buscavam explicações para a origem, para a diversidade e para a dinâmica da evolução da vida na terra.

A linguagem em que se expressavam essas teorias era predominantemente não matemática, o que não impediu a profusão de tratados e estudos escritos sobre evolução.

Parte destes trabalhos levou à criação de conceitos que possibilitaram a formulação de modelos matemáticos que permitem fazer predições para o comportamento temporal de populações.

Um dos primeiros modelos que pode ser chamado de biomatemático foi criado por Fibonacci (1175-1250) para descrever o crescimento de uma população de coelhos [Hofbauer 1988].

Ele assumiu que o número de indivíduos de uma população de coelhos obedeceria a seguinte série:

$$
a_{n}=a_{n-1}+a_{n-2}
$$

Com:

$a_{n}$, número de coelhos no mês $n$,

$a_{n-1}$, número de coelhos no mês anterior a $n$,

$a_{n-2}$, número de coelhos 2 meses antes do mês $n$.

O processo começa com um par de coelhos $\left(a_{0}=a_{1}=1\right)$, e os números que se seguem formam a famosa seqüência de Fibonacci: 


$$
1,1,2,3,5,8,13 \ldots
$$

É claro que este modelo deve ser considerado extremamente simplificado, uma vez que não leva em conta inúmeros fatores, tais como mortalidade, flutuações no número de descendentes em cada geração, migração, entre outros inúmeros aspectos que influem na dinâmica das populações.

Outro exemplo consagrado de modelagem de processos de crescimento populacional foi desenvolvido em 1798 por Thomas Malthus (1766-1834), clérigo e economista, que propôs a seguinte fórmula para a evolução temporal de uma população sem limitações de recursos [Goel 1974]:

$$
\frac{d N(t)}{d t}=r N(t)
$$

com

$N(t)$, número de indivíduos na população em um determinado instante t.

$r$, taxa de replicação, constante e positiva.

A solução desta equação é conhecida como Lei de Malthus:

$$
N(t)=N(0) e^{r t}
$$

Segundo este modelo, o número de indivíduos desta população tende a crescer exponencialmente. Este comportamento não é observado em nenhum sistema populacional natural, já que existem diversos fatores que acabam limitando o crescimento de uma população, como por exemplo recursos e metabolismo.

A análise do modelo malthuseano foi um dos fatores que influenciaram Darwin na formulação da teoria das espécies, em 1859, uma vez que era óbvio para ele que nenhuma população poderia crescer ilimitadamente [Darwin 2002]. 
Darwin também fez uso de suas observações e pesquisas em criação e desenvolvimento de raças de pombos, doninhas, coelhos e cachorros, o que o levou a formular a teoria segundo a qual apenas "variações favoráveis"dentro da população tenderiam a ser preservadas, enquanto outras seriam eliminadas por "seleção natural", como propôs neste texto memorável:

"In October 1838, that is, fifteen months after I had begun my systematic inquiry, I happened to read for amusement Malthus on Population, and being well prepared to appreciate the struggle for existence which everywhere goes on from long-continued observation of the habits of animals and plants, it at once struck me that under these circumstances favourable variations would tend to be preserved, and unfavourable ones to be destroyed. The results of this would be the formation of a new species. Here, then I had at last got a theory by which to work" [Darwin 2000].

O primeiro modelo matemático de dinâmica de populações compatível com a idéia de uma limitação no crescimento de uma população foi proposto em 1846 pelo matemático Pierre François Verhulst (1804 -1849 ). Segundo ele, o processo de evolução do tamanho da população deve obedecer à seguinte dinâmica:

$$
\frac{d N(t)}{d t}=r N(t)\left(1-\frac{N(t)}{K}\right)
$$

Onde:

$N(t)$, número de indivíduos da população em um instante de tempo t.

$r$, taxa de replicação constante positiva.

$K$, tamanho máximo da população.

Esta equação é conhecida como a equação logística, cuja solução, dada por

$$
N(t)=\frac{N(0) K e^{r t}}{K+N(0)\left(e^{r t}-1\right)}
$$

é compatível com o limite assintótico independente da condição inicial $N(0)$ : 


$$
N_{\infty}=K
$$

Esta equação já foi utilizada para ajustar a curva de crescimento de populações humanas de diversos países [Goel 1974], e fazer previsões. Para isso, é necessário conhecer o tamanho destas populações em 3 instantes diferentes, uma vez que há 3 parâmetros $(N(0), K, r)$ para ajustar.

A Figura (2.1) ilustra o comportamento do tamanho de uma população segundo este modelo (eq. (2.5)), partindo da condição inicial $N(0)=0.01, r=2$ e $k=1$.

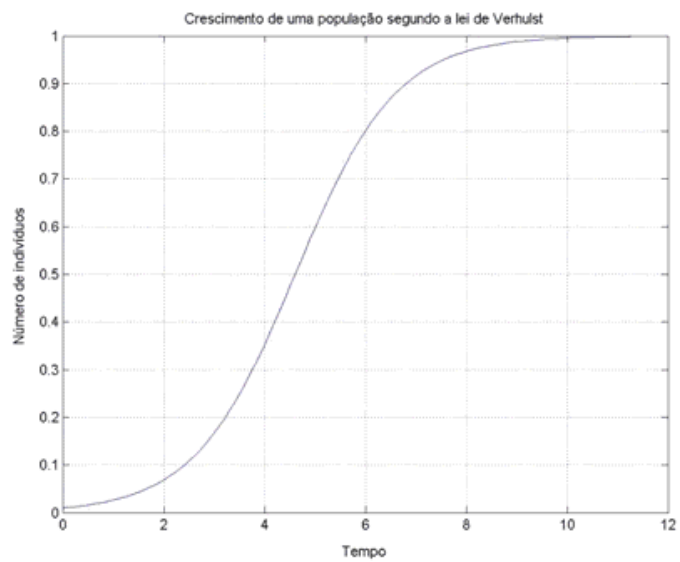

FigurA 2.1. Crescimento de uma população segundo a lei de Verhulst.

É interessante notar que para $t \sim 0$ a solução da equação de Verhulst (equação (2.5))

$$
t \sim 0 \rightarrow N(t)=\frac{N(0) K e^{r t}}{K+N(0)\left(e^{r t}-1\right)} \sim N(0) e^{r t}
$$

é a mesma que a de malthus (equação (2.3)).

Existem outras equações para descrever o comportamento de uma população "isolada"(sem migração), cujas soluções são limitadas assintoticamente e que, em alguns casos, ajustam melhor os dados experimentais, tais como a equação de Gompertz:

$$
\frac{d N(t)}{d t}=-r N(t) \ln \left(\frac{N(t)}{K}\right)
$$


Ou mesmo a generalização:

$$
\frac{d N(t)}{d t}=r N(t) \frac{\left(1-\left(\frac{N(t)}{K}\right)^{\alpha}\right)}{\alpha}
$$

que interpola as equações de Verhulst $(\alpha=1)$ e Gompertz $(\alpha=0)$.

A solução da equação (2.8) pode ser escrita da forma:

$$
f(t)=f(0)\left[f(0)+e^{-r t}\left(1-(f(0))^{\alpha}\right)\right]^{-\frac{1}{\alpha}}
$$

com

$$
f(t)=\frac{N(t)}{K}
$$

Em todos estes modelos determinísticos, cuja solução tende a um limite assintótico constante, uma população de tamanho inicial $N(0)$, com $0<N(0)<K$ irá aumentar, ou, se $N(0)>K$, irá diminuir, até alcançar o valor $K$.

Em uma situação mais realista, há outros mecanismos que influem no crescimento da população, tais como quantidade de recursos, taxas de mortalidade e de nascimento, migração, etc, que mudam de maneira não determinística.

Uma das maiores simplificações introduzidas na formulação dos modelos discutidos até o momento reside no fato da população modelada ser considerada homogênea, ou seja, constituída de indivíduos idênticos, o que impossibilitaria a formação de novas espécies, por exemplo.

Um dos primeiros modelos que leva em conta mais de uma população descreve a evolução de duas "espécies", ou seja, duas populações de indivíduos qualitativamente diferentes (sendo ainda cada uma formada por indivíduos idênticos).

O modelo foi proposto por pelo químico Alfred Lotka e pelo matemático Vito Volterra em 1925, e é considerado o modelo mais simples para análise da interação entre duas espécies. A dinâmica é dada pelo sistema de equações [Lotka 1925, Lotka 1956, Figueiredo 1997]: 


$$
\left\{\begin{array}{c}
\frac{d X(t)}{d t}=X(a-b Y) \\
\frac{d Y(t)}{d t}=Y(-c+d X)
\end{array}\right.
$$

Onde:

$X(t)$, número de presas no instante $t$,

$Y(t)$, número de predadores no instante $t$,

$a$, taxa de replicação das presas,

$b$, susceptibilidade das presas em relação aos predadores,

$c$, taxa de mortalidade dos predadores,

$d$, habilidade predatória dos predadores em relação às presas.

Nesta interação, chamada de predador-presa, uma espécie (predadores) aumenta o tamanho de sua população através da predação da outra (presas), que por sua vez diminui seu tamanho.

Este modelo foi exaustivamente estudado desde então, seja através de aproximações lineares, seja através do estudo do espaço de fases, ou mesmo numericamente.

A solução do sistema leva a um comportamento oscilatório para o número de indivíduos das duas populações, como mostra a Figura (2.2).

Diversas modificações foram propostas, com o intuito de se generalizar o modelo para situações mais realistas, com mais espécies, diferentes tipos de interação, tais como interações entre predadores.

Como exemplo ilustrativo, podemos citar um um modelo relativamente recente, que pretende resumir a evolução da infecção do vírus HIV no homem.

Seguindo a forma do modelo Lotka-Volterra, este modelo deve, neste contexto, conter os elementos básicos presentes no processo.

No caso, pode-se identificar nesta interação, além do vírus, as células do sistema imunológico, que combatem e são infectadas pelo vírus. Elas são chamadas células $T$ e, no processo de 
infecção, aparecem em três estados diferentes: aquelas que não estão infectadas (células $T$ sadias), aquelas que estão infectadas, porém ainda não produzindo vírus, são chamadas de células latentes, e também na forma ativa, quando estas produzem uma grande quantidade de vírus, e são eliminadas conseqüentemente.

Os parâmetros do modelo são as freqüências com que uma célula sadia torna-se latente, quando no encontro com um vírus, a freqüência com que uma célula latente tornar-se ativa, e assim por diante, como descrito no seguinte sistema de equações [Yeargers 1996]:

$$
\left\{\begin{array}{l}
\frac{d T(t)}{d t}=s+r T\left(1-\frac{T+T_{l}+T a}{T_{\max }}\right)-\mu T-K_{1} V T \\
\frac{d T_{l}(t)}{d t}=K_{1} V T-\mu T_{l}-K_{2} T_{l} \\
\frac{d T_{a}(t)}{d t}=K_{2} T_{L}-\beta T_{a} \\
\frac{d V(t)}{d t}=N \beta T_{a}-K_{1} V T-\alpha V
\end{array}\right.
$$

Onde:

$T(t)$, número de células $T$ não infectadas no instante $t$,

$T_{l}(t)$, número de células $T$ infectadas latentes no instante $t$, $T_{a}(t)$, número de células $T$ infectadas ativas no instante $t$, $V(t)$, número de virús no instante $t$ no instante $t$, $T_{\max }$, número máximo de células $T$, $s$, produção de novas células $T$ pelo organismo, $r$, taxa de reprodução das células $T$ e $T_{a}$, $\mu$, taxa de mortalidade natural das células $T$, $K_{1}$, taxa de transição das células $T$ para células $T_{l}$, devido à ação dos vírus, $K_{2}$, taxa de transição das células $T_{l}$ para células $T_{a}$, devido à ação dos vírus, $\beta$, taxa de mortalidade das células $T_{a}$ devido à infecção pelo vírus, $\alpha$, taxa de mortalidade do vírus em função das defesas do organismo. 
Embora neste modelo o número de populações seja maior, e contenha muito mais parâmetros, ele possui a mesma lógica do modelo Lotka-Volterra, e o tipo de análise acaba sendo muito parecido, ainda que neste caso o uso de simulação numérica seja necessário. Neste exemplo, há 4 tipos de espécies, o que leva a um sistema de quatro equações ordinárias acopladas, não-lineares.

Em geral, nestes modelos de interação predador-presa estuda-se as interações entre espécies uniformes (ou seja, populações homogêneas, constituídas por indivíduos idênticos), e se introduz explicitamente a evolução do "ambiente". No caso do modelo de infecção do vírus HIV, por exemplo, o ambiente é representado pelos diferentes tipos de células T. O interesse está nas soluções para o comportamento individual das 3 diferentes populações de células e da população de vírus.

Em nosso trabalho, iremos levar em conta o fato de que as populações (de vírus, no caso) são constituídas por diferentes indivíduos, formando uma "quasi-espécie". Ou seja, levaremos em conta o fato da população ser heterogênea, formada por diferentes indivíduos com diferentes genótipos e fenótipos. Grupos de indivíduos com mesmo fenótipo caracterizará uma sub-população (ou componente) da população considerada. Consideramos que estas sub-populações interagem umas com as outras. 


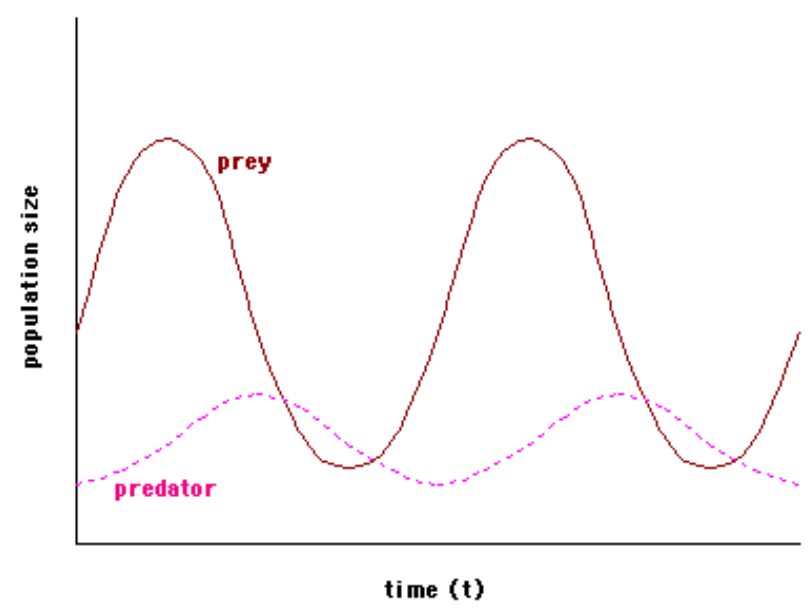

FiguRA 2.2. Interação predador-presa 


\subsection{Sobre os conceitos biológicos utilizados ao longo do trabalho}

\subsubsection{Espécie.}

Um dos conceitos mais utilizados em biologia, e ao mesmo tempo um dos mais problemáticos de se definir é o conceito de espécie.

Uma das definições mais aceitas foi elaborada no século XX pelo biólogo Ernst Mayr [Mayr 1963]. Segundo o autor, a definição biológica de espécie é a de um conjunto de todos os indivíduos que, em condições naturais, são fisiologicamente capazes de, real ou potencialmente, num dado lugar e momento, se reproduzirem e produzirem descendência fértil, encontrando-se isolados reprodutivamente de outros conjuntos semelhantes.

Esta definição, apesar de amplamente aceita e difundida, não esgota a questão de como caracterizar todos os tipos de seres que existem.

Por exemplo, como acomodar este conceito para seres que não se reproduzem sexuadamente?

E será que o conceito de espécie deve se aplicar a indivíduos cujo tamanho do genoma é pequeno, como no caso dos vírus, que possuem genomas da ordem de $10^{4}$ bases?

No caso de animais com genomas relativamente grandes (com mais de $10^{6}$ bases) e com baixas taxas de mutação, diferenças pontuais nos genomas não são tão significantes quanto para seres com genomas menores e com altas taxas de mutação, como no caso dos vírus. Neste caso, os genomas da ordem de $10^{4}$ bases, e com uma taxa de mutação da ordem de $10^{-4}$ bases por replicação, o que leva a aproximadamente 1 mutação por replicação.

Este fato faz com que uma população de vírus apresente uma diversidade genética tão ampla que a definição de espécie, tal como formulada por Mayr, por exemplo, talvez não seja a mais adequada.

Assim é o conceito de quasi-espécie, que abordaremos de forma mais detalhada a seguir, que permite incorporar uma população heterogênea, formada por, potencialmente, uma infinidade de diferentes genótipos, ou fenótipos. 


\subsubsection{Quasi-Espécie.}

Este termo foi cunhado por Manfred Eigen [Eigen 1992, Eigen 1996] para caracterizar a grande diversidade genotípica de uma população de vírus.

Em analogia a um sistema de osciladores acoplados, uma quasi-espécie é definida matematicamente por Eigen [Eigen 1996, Saakian 2004], de maneira análoga aos modos normais de vibração do sistema.

Porém, segundo Eigen, o conceito é utilizado normalmente por virologistas de maneira mais simplificada, de modo que significa apenas que há uma "aglomeração"de mutantes ao redor do tipo selvagem (do inglês wild type), sem se importar com algum tipo de estrutura para esta distribuição.

Em geral, os resultados dos processos de seqüênciamento genômico de uma espécie de vírus indicam uma seqüência de pares de bases que corresponde apenas à ocupação dominante (média) de cada posição, já que existe uma grande diversidade genética dentro de uma população de vírus, devido à alta taxa de mutação.

Esta característica de uma população de vírus foi estudada e quantificada, posteriormente, em diversos trabalhos experimentais [Parvin 1986, Novella, I. et al. 1995c, Schneider 2001, Solé 1999, Chao 1990, Duarte 1992, Holland 1982, Domingo 1997, Martell 1992].

Normalmente, em procedimentos laboratoriais, o que se tem é uma população de vírus heterogênea, mesmo que esta tenha sido fundada apenas por um único clone.

Segundo Eigen, o conceito de quasi-espécies adiciona um novo fator nas discussões evolucionistas. O alvo da seleção não é apenas o indivíduo mais adaptado da população, e sim toda ela, levando em conta todos indivíduos mutantes.

Para os virologistas, quando se fala em quasi-espécie, refere-se a uma população heterogênea, formada por diferentes indivíduos, porém sem a preocupação de se definir algum tipo de distribuição especial para esta heterogeneidade, tal como é definido no modelo de Eigen. 
Ao longo do nosso trabalho iremos empregar o conceito de quasi-espécie tal como ele é utilizando por virologistas, cuja imagem é de uma nuvem de mutantes que cercam o indivíduo selvagem.

\subsubsection{Fitness.}

Este é um dos conceitos centrais em muitas áreas da biologia, como a teoria da evolução, a dinâmica de populações e a ecologia.

Na literatura, existem diversas definições para o fitness. Este conceito se aplica às diversas maneiras de se caracterizar a população, ou seja, pode-se falar em fitness de um determinado genótipo (composição genética de um indivíduo ou grupo de genes); fitness de um fenótipo (manifestação visível ou detectável de um genótipo); fitness de um alelo (cada uma das formas que um gene pode apresentar e que determina características diferentes); fitness de um indivíduo; ou fitness de uma população. Porém todos concordam com a idéia geral de que o fitness mede o quanto este indivíduo ou espécie está, de alguma maneira, apto em um determinado instante, em um determinado ambiente, para sobreviver e gerar descendência. Ao longo de nosso trabalho utilizaremos este conceito em inglês, porém ele pode ser traduzido como aptidão, por exemplo.

Esta "ambientação"é avaliada, por exemplo, pela capacidade que um indivíduo com um determinado genótipo tem de se replicar, e normalmente é medida através da proporção relativa de um determinado genótipo (ou fenótipo) em uma população, nas várias gerações consideradas.

Neste trabalho, consideramos que a medida do fitness de uma espécie ou quasi-espécie viral guarda relação direta com a taxa replicação média da população.

Podemos falar em fitness absoluto ou relativo. Fitness absoluto é geralmente definido como a razão entre o número de indivíduos presentes em uma população antes e depois de uma geração ou de determinado intervalo de tempo:

$$
F(t)=\frac{N(t)}{N(0)}
$$


Onde:

$N(t)$, é o número de indivíduos de uma determinada população, em um determinado instante $t$,

$N(0)$, é o número de indivíduos de uma determinada população, no início do processo de replicação,

O fitness relativo geralmente é proporcional à razão entre o fitness absoluto de duas populações $P_{e}$ e $P_{w}$ que convivem em determinado ambiente [Novella 1995a]:

$$
F_{r e l}=\frac{N_{e}(t) / N_{e}(0)}{N_{w}(t) / N_{w}(0)}
$$

Onde:

$N_{e, w}(t)$, é o número de indivíduos de uma determinada população $\left(P_{e}\right.$ ou $\left.P_{w}\right)$, em um determinado instante $t$,

$N_{e, w}(0)$, é o número de indivíduos de uma determinada população $\left(P_{e}\right.$ ou $\left.P_{w}\right)$, no início do processo de replicação,

Experimentalmente, o processo de quantificação populacional não é simples. Resumese em conhecer o número absoluto de indivíduos de um determinado genótipo ou fenótipo existente em uma determinada geração. A determinação da quantidade relativa é mais simples.

Normalmente, o objetivo é medir o quanto uma determinada população $P_{e}$ que evolui em determinado ambiente está adaptada, em relação à população padrão $P_{w}$, que não evolui, geralmente chamada de população selvagem (wild type).

Para esta comparação, os vírus devem ser colocados para competir num mesmo ambiente, e suas concentrações relativas medidas, ao longo do tempo.

Se for considerado que as populações, quando não limitadas pelo ambiente, replicam-se segundo a lei de Malthus, e assumindo que as taxas de replicação médias destas populações não 
variam no tempo, pode-se definir fitness relativo malthuseano da seguinte maneira [Novella 1995a]:

$$
F_{r e l}(t)=e^{\left(r_{e}-r_{w}\right) t}
$$

Onde $r_{e, w}$ é a taxa de replicação constante das populações $P_{e}$ e $P_{w}$, respectivamente.

Os estudos experimentais contemplados em nosso trabalho [Novella 1995a,b e c Novella 1999, Duarte 1993] tem por objetivo medidas da grandeza acima, para diversos instantes de tempo.

\subsubsection{Espaço dos fenótipos.}

Em nosso trabalho o fenótipo de uma determinada sub-população presente na quisiespécie é indentificado como o logarítimo do fitness desta.

No caso de podermos associar um valor de fenótipo para cada componente da população (ou sub-população) em um determinado instante de tempo, a caracterização de uma população de vírus pode ser feita adotando-se como indicador a distribuição das concentrações $C(x, t)$ de indivíduos com fenótipo $x$, em um determinado instante $t$.

Esta caracterização baseia-se em características (fenotípicas) que podem ser observadas experimentalmente, de maneira relativamente simples, principalmente se comparado por exemplo ao trabalho impraticável caracterizar a população através do seqüênciamento de todos os indivíduos presentes na determinada população em determinado instante.

Isto simplifica drasticamente a caracterização de uma quasi-espécie, dado que muitos genótipos diferentes podem levar ao mesmo fenótipo, e, portanto, ao mesmo fenótipo, o que é chamado de plasticidade fenotípica.

Experimentalmente, o que se mede é ainda mais simplificado: o fenótipo médio da população, definido como

$$
<x>=\int x C(x, t) d x
$$


Ao longo de nosso trabalho faremos sempre referência a uma caracterização da população com base nessa descrição. 


\subsection{O trabalho experimental contemplado}

Quando uma população de vírus é submetida a um processo evolutivo é esperado que sua constituição, tanto genotípica quanto fenotípica, mude.

Nos trabalhos contemplados, encontramos experimentos que visam medir a variação da taxa de replicação de uma população de vírus, quando estes são submetidos a arranjos experimentais específicos, de forma a permitir quantificar a evolução de uma população de vírus in vitro, através da medição da variação temporal de sua taxa de replicação.

Nestes experimentos, o objeto de estudo é a taxa de replicação da população de vírus, e não o número de indivíduos da população, como é o caso dos modelos apresentados no início do capítulo.

Os experimentos contemplados no presente trabalho são devidos a Holland (1991), Lazaro (2002), Novella (1995a,b e c e 1999), Duarte (1993) e Clarke (1993).

A taxa de replicação média, $r(t)$, da população que evolui é, segundo os autores, um indicador relevante, que pode, portanto, servir para caracterizar uma quasi-espécie viral.

O primeiro artigo [Novella 1995a] cujos dados são analisados aqui de maneira fenomenológica descreve o procedimento experimental e a maneira como os dados foram tomados e analisados. A seguir faremos uma breve introdução a este procedimento.

Primeiramente, uma população de vírus é fundada à partir de um clone (indivíduo isolado), através de um processo chamado Bottlenecking, ou atenuação.

Este processo de atenuação é utilizado há anos para produção de vacinas [Enders 1960, Sabin 1973, Theiler 1937], visando diminuir o fitness da população, bem como a virulência dos vírus, de maneira que estes possam ser inoculados em seus hospedeiros naturais, promovendo a imunidade, sem causar uma infecção.

Neste processo, os vírus "fundadores"da população atenuada são colocados para se replicar em um meio pouco denso, com condições ótimas para replicação (grande concentração de células disponíveis). Geralmente tem-se uma multiplicidade de infecção de 0.1 (ou seja, 1 vírus para cada 10 células), o que significa que virtualmente não há coinfecção (onde mais de 
um vírus infecta uma mesma célula), e portanto há pouca competição, dado que os vírus não competem por recursos. Assim, normalmente é dito que a população está sob baixa pressão de seleção.

A seqüência lógica que leva à fundação de uma população com baixo fitness é a seguinte: a baixa pressão de seleção, somada ao fato de que os vírus possuem alta taxa de mutação deletéria ou letal, faz com que a população, que aumenta de tamanho, acumule grande quantidade de vírus com baixo fitness.

Este processo de acumulo de mutações deletérias na população por perda estocástica de componentes com fitness maior é chamado também de Catraca de Muller [Novella 1999, Muller 1964].

A população fundada por este processo encontra-se portanto inicialmente enfraquecida, ou seja, com baixa taxa de replicação, ou, equivalentemente, baixo fitness.

Em um segundo estágio do experimento, chamado de "passagens evolutivas"(large passages) em alusão à grande quantidade de vírus submetidos neste momento, esta população enfraquecida é reunida em um ambiente denso, com uma quantidade de células que leva à uma multiplicidade de infecção maior que 1. Isto aumenta drasticamente a pressão de seleção, uma vez que muitos vírus infectam a mesma célula, e portanto passam a competir por recursos.

É neste momento do experimento que se passa a considerar a evolução da população. Ao longo do processo, a população evolui e aumenta em número diariamente. No final de cada dia, é retirada uma alíquota de tamanho fixo da população, que é então levada a um novo "ambiente", idêntico aquele em que o processo começou, caracterizando uma passagem evolutiva.

Com isso, os autores esperam simular a evolução de uma população em um ambiente onde os recursos, são mantidos constantes. Ou seja, o número de células disponíveis, a diluição e todos outros parâmetros que caracterizam os recursos, tais como temperatura, são mantidos constantes a cada passagem evolutiva, a fim de se garantir que a evolução ocorra em um ambiente que não varia com o tempo. 
Neste novo ambiente, o fato dos recursos serem escassos faz com que ocorra uma competição muito maior entre os indivíduos, se comparado com um ambiente com baixa multiplicidade de infecção (menor que 1), o que leva a uma maior pressão de seleção: apenas indivíduos com fitness relativamente alto sobreviverão.

Isto faz com que o processo de seleção natural acabe excluindo os indivíduos menos aptos, cuja permanência era antes possível no processo de bottlenecking, o que transforma a população, caracterizando um processo evolutivo.

A evolução da população é quantificada pela variação de seu fitness a cada passagem evolutiva, que é medido em um terceiro processo, chamado de "passagens de competição" (competitive passages). Este processo se dá através competição direta (replicação em um mesmo ambiente) entre a população que evolui e a do tipo selvagem. A população selvagem é mantida refrigerada durante as passagens evolutivas, e portanto não evolui no tempo.

Para este processo de medida, no final de cada passagem evolutiva alíquotas de mesmo tamanho das duas populações que serão comparadas são misturadas em um mesmo meio, de forma que estas passam a replicar, competindo por recursos. Desta maneira, compara-se a variação temporal de suas concentrações relativas a intervalos de tempo fixos (24 horas), o que é proporcional à seus fitness, como foi definido anteriormente na equação (2.14).

Os valores das concentrações relativas de vírus medidas ao longo das passagens competitivas formam uma curva, chamada de "vetor de fitness", como ilustrado na Figura (2.4).

Nestas passagens competitivas, espera-se que as populações de vírus não evoluam, pois o objetivo é medir a taxa de replicação instantânea $r$, respectiva aquela passagem do processo evolutivo, da qual a alíquota foi retirada.

Isto é uma hipótese, que não é inteiramente verdadeira, dado que os vírus não param de mutar e competir, e, portanto, mesmo durante estas medidas de fitness, há evolução.

Para minimizar a interferência destas variações que se dão no momento das medidas de fitness, nestas passagens novamente estabelece-se uma situação em que a multiplicidade de infecção é de aproximadamente 0.1 (1 vírus para cada 10 células), o que minimiza os efeitos de seleção que modificam a população e seu fitness. 
A figura (2.3) mostra uma ilustração esquemática do experimento.

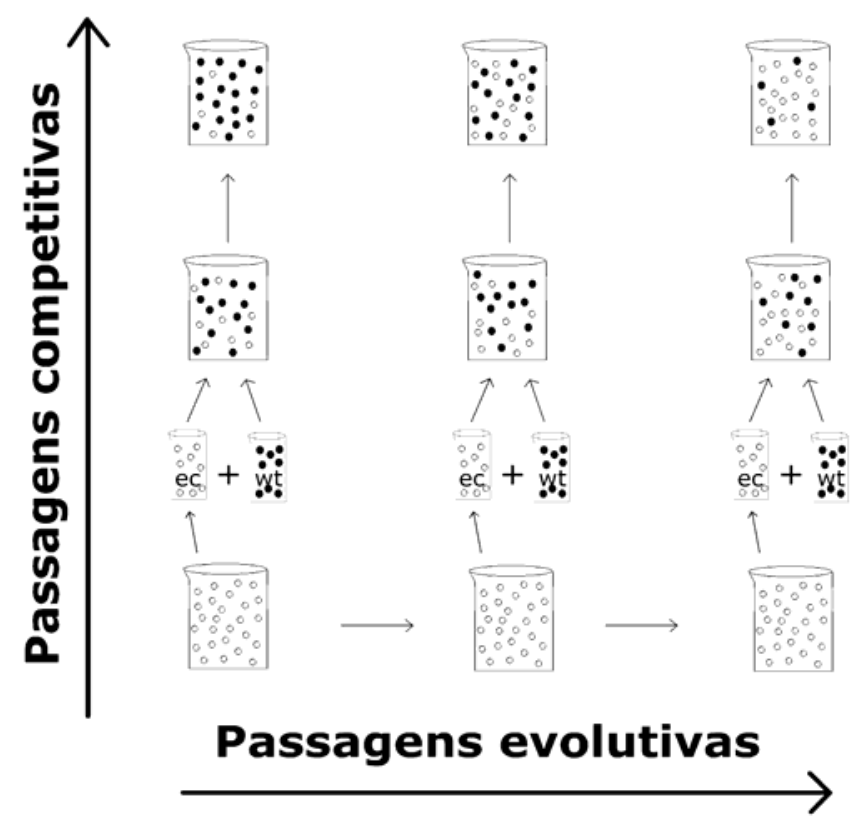

Figura 2.3. Esquema do arranjo experimental. No eixo horizontal estão esquematizadas as passagens evolutivas e no eixo vertical, as passagens competitivas.

A Figura (2.4) ilustra os resultados obtidos no experiemento [Novella 1995a], onde cada curva representa a competição direta entre as populações que estão sendo comparadas na passagem competitiva.

A partir destes dados, os autores ajustam a uma reta, que é chamada de "vetor de fitness"(fitness vectors), e constroem um gráfico com os coeficientes angulares de cada um destes, através das passagens evolutivas, vide Figura (2.5). Utilizando a hipótese de que as populações se replicam de maneira malthuseana, a inclinação de cada um destes vetores de fitness é, segundo os autores, a taxa de replicação relativa entre as populações na passagem competitiva em questão.

O que se observa, ao longo das passagens evolutivas, é um aumento da taxa de replicação, que, segundo os autores, se dá em duas etapas de crescimento. A primeira, mais rápida, se estende até que as taxas de replicação médias das populações que estão sendo comparadas 


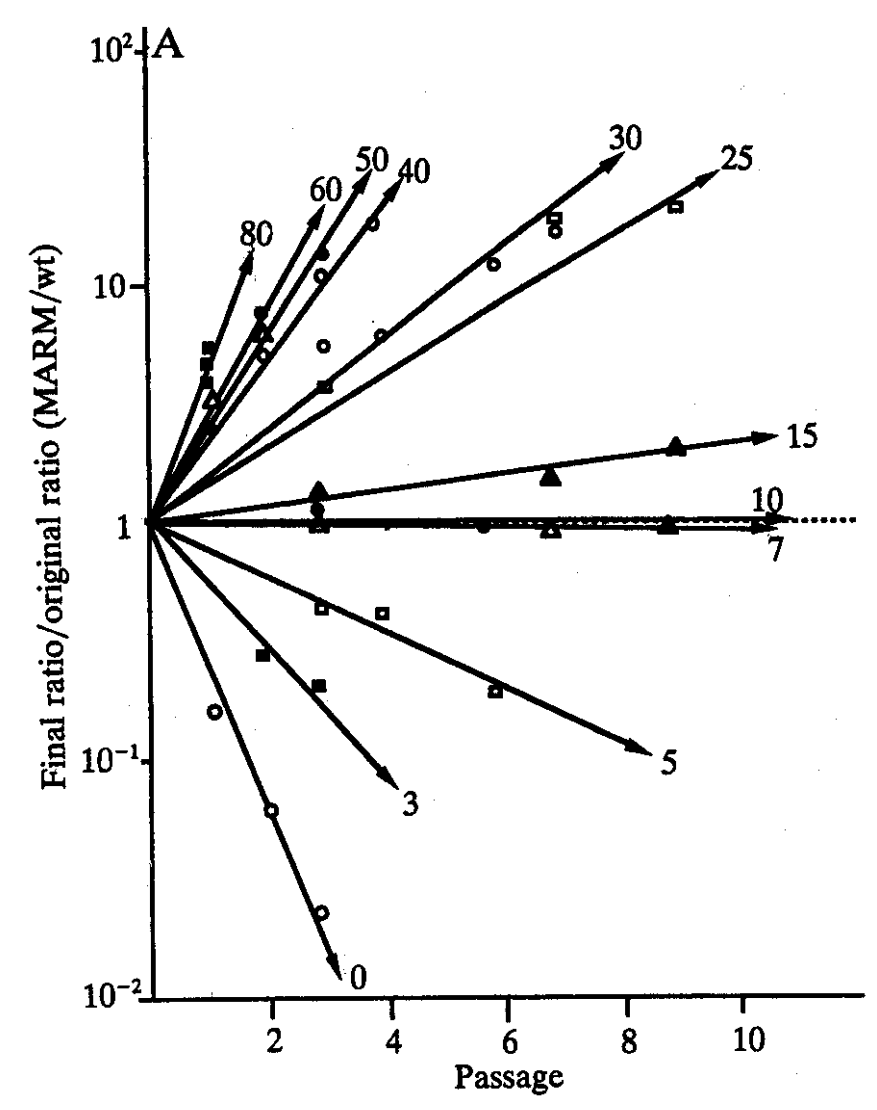

Figura 2.4. "Vetores de fitness". Cada curva representada é referente a uma determinada passagem evolutiva $n$ (indicado na ponta de cada vetor), e é construída a partir da variação da razão $C_{e} / C_{w}$ entre a população $e$ (que evolui), e a população padrão $w$ ao longo da passagem competitiva. A concentração inicial das populações é sempre a mesma.

(a população que evolui e a selvagem) se igualem, seguida por uma outra etapa em que o crescimento da taxa de replicação se dá de forma relativamente moderada, como mostra a Figura (2.5):

No trabalho de Novella (1995a), estes dados experimentais (Figura (2.5)) são ajustados pela seguinte curva:

$$
r(t)=A+B t+C e^{-D t}
$$




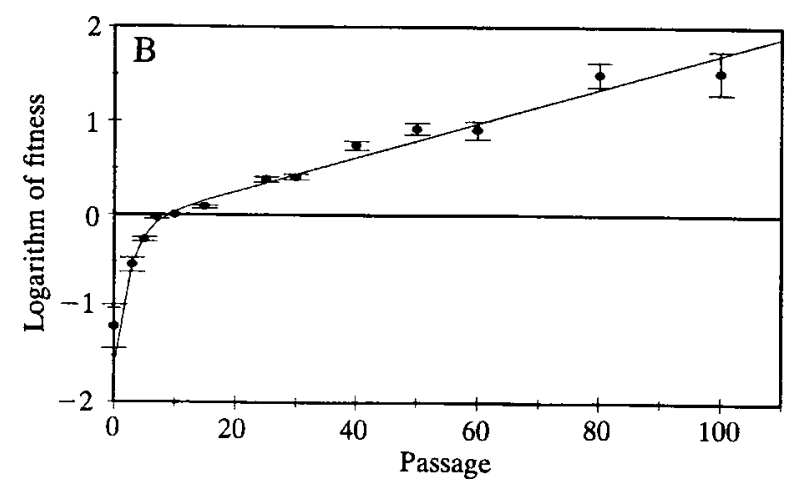

Figura 2.5. Passagens evolutivas. Dados experimentais para a evolução da taxa de replicação da população de vírus.

Onde $A, B, C$ e $D$ são parâmetros para serem ajustados à partir dos resultados experimentais, e $r(t)$ a taxa de replicação relativa entre as populações comparadas no instante $t$.

Como foi apontado por Aafif (1998), o ajuste proposto em (2.16) prevê que a taxa de replicação média da população de vírus aumenta indefinidamente, o que equivale a um processo malthuseano cuja taxa de replicação cresce linearmente com o tempo. Isto, porém, não respeitaria os limites metabólicos impostos pela natureza, como é limitante, por exemplo, o fato de uma célula passível de ser infectada ter tamanho finito e possibilitar apenas um número finito de replicações de vírus por vez.

Em um trabalho mais recente, Novella (1999) retoma o experimento e mostra os resultados obtidos em um número muito maior de passagens evolutivas: estão envolvidas mais de de 200 passagens, em comparação com as 100 do estudo anterior.

Neste importante estudo pretendeu-se, assim, investigar se há um limite finito para o comportamento assintótico da taxa de replicação da população de vírus, o que foi de fato verificado.

Neste artigo também são discutidas as dificuldades de se fazer medidas para valores altos de taxa de replicação, assim como sobre as possíveis causas das grandes flutuações dos dados observados nestes regimes. 
Nosso objetivo no presente trabalho resume-se na proposta de um modelo que descreva o comportamento temporal de $r(t)$, como mostrado na Figura (2.5), e que preveja a existência de um limite assintótico constante.

O modelo deve ser concebido de maneira a introduzir um número mínimo de parâmetros livres. Uma análise fenomenológica deve permitir também obter uma maior compreensão sobre a interação da população de vírus com o ambiente e recursos disponíveis, ou seja, sobre sua "adaptabilidade". 


\subsection{Interpretação dos procedimentos experimentais e da relação dos resultados com o processo de crescimento Malthuseano}

Os dados resultantes dos experimentos com populações de vírus considerados aqui [Novella 1995a, Novella 1999], mostram que uma população sujeita a um processo evolutivo, inicialmente apresentando baixo fitness, evolui, de maneira que sua taxa de replicação média aumenta, até alcançar um limite assintótico constante.

Este limite assintótico corresponde ao processo malthuseano com taxa de replicação constante.

Isto não está em desacordo com o que mencionamos anteriormente no presente capítulo, sobre a impossibilidade de uma população crescer segundo esta lei.

No caso, trata-se de um arranjo experimental que estabelece uma situação comum em procedimentos laboratoriais, que consiste em estabelecer condições de controle tais que tanto a população em estudo, quanto as condições ambientais são mantidas constantes (o que inclui a multiplicidade de infecção).

Porém, esta configuração é bem atípica se comparada com situações encontradas fora dos laboratórios (na natureza, portanto). Da mesma forma, em situações não laboratoriais não se repete a precisão com que esta configuração pode ser mantida e controlada [Bell 1997].

Estas condições possibilitam a evolução do fitness da população em um ambiente controlado, onde os recursos não são ilimitados, mas também não se esgotam, ou seja, onde os recursos são mantidos constantes. O que muda, portanto, é apenas a qualidade dos vírus presentes na população, ou seja, a distribuição da concentração $C(x, t)$ de indivíduos com determinado fenótipo $x$ na população no instante $t$.

O processo experimental de medição do fitness e a posterior atribuição da taxa de replicação, a cada passagem evolutiva $n$ da população de vírus, se dá através da competição direta entre a população que está evoluindo e a tipo selvagem replicando no mesmo ambiente, como foi explicado anteriormente. 
Neste caso, as populações tendem a variar seus tamanhos, suas concentrações relativas, bem como suas taxas de replicação.

Usualmente, fitness é definido em termos da razão entre a quantidade $N_{n}(\tau)$ de vírus presente no instante $n \tau$ após ter replicado por um intervalo de tempo $\tau$, e a quantidade inicial $N_{n}(0)$. Por convêniencia, o tempo é medido em unidades de $\tau$, para $n=1,2,3, \ldots$.

Desta maneira, considerando que a população cresce de maneira exponencial, e com taxa de replicação dependente do tempo, podemos escrever:

$$
F_{n}(\tau)=\frac{N_{n}(\tau)}{N_{n}(0)}=\exp \left(\int_{n \tau}^{(n+1) \tau} r_{e}(t) d t\right)=\exp \left[r_{e}\left(t_{n}\right) \tau\right]
$$

Onde

$F_{n}(\tau)$, razão entre a quantidade $N_{n}(\tau)$ de vírus presente no instante $(n+1) \tau$ após ter replicado por um intervalo de tempo $\tau$, e a quantidade inicial $N_{n}(0)$ presente no instante $n \tau$,

$r_{e}(t)$, taxa de replicação média da população, considerada como função do tempo.

$r_{e}\left(t_{n}\right)$, valor representativo da integral da função $r_{e}(t)$ no intervalo de tempo considerado, segundo o teorema do valor médio do calculo [Guidorrizi 1987].

Para que se efetue o processo de medida do fitness relativo, através da definição (2.14), e posterior atribuição da taxa de replicação relativa $r\left(t_{n}\right)=r_{e}\left(t_{n}\right)-r_{w}$ entre as populações $P_{e}$ e $P_{w}$, uma alíquota $\tilde{N}_{n}(0)$ da população $P_{e}$ é misturada com uma alíquota de mesmo tamanho $\tilde{N}_{w}(0)$ da população $P_{w}$, e estas passam então a competir ao longo de $j$ passagens competitivas, ao final das quais é medida a razão $\tilde{N}_{n}(j \tau) / \tilde{N}_{w}(j \tau)$.

As taxas de replicação $r_{e}\left(t_{n}\right)$ e $r_{w}(t)$ devem ser consideradas como médias sobre a distribuição das duas espécies (as que evoluem e as do tipo selvagem, respectivamente) lembrando que as populações são heterogêneas.

Como se está interessado em obter o fitness relativo em um determinado instante $n \tau$ do processo evolutivo, é necessário que a taxa de replicação não varie durante o processo de medida. Ou seja, esta medida requer a hipótese de que nenhuma das populações "evolua"ao 
longo das $j$ passagens competitivas. Isto pode ser considerado uma aproximação razoável, dado que nesta situação os vírus competem em um ambiente com baixa multiplicidade de infecção [Novella 1999].

Portanto, para cada passagem evolutiva $n$, são obtidos $j$ pontos (valores de fitness reativo) (normalmente de 1 a 3 pontos) através das $j$ passagens competitivas.

O conjunto destes pontos, para cada $n$, é ajustado a uma reta na escala logarítmica. Cada reta é chamada de "vetor de fitness"respectiva à passagem $n$, como mostra a Figura (2.4) [Novella 1995a,b, Novella 1999, Duarte 1993, Clarke 1993, Holland 1991].

Desta maneira,

$$
\tilde{F}_{n}(j \tau)=\frac{\tilde{N}_{n}(j \tau)}{\tilde{N}_{w}(j \tau)}=\exp \left(r\left(t_{n}\right) j \tau\right)
$$

Onde

$\tilde{F}_{n}(j \tau)$, Fitness relativo na passagem competitiva $j$, da passagem evolutiva $n$.

$\tilde{N}_{n, w}(j \tau)$, tamanho da população $P_{e}$ e $P_{w}$ na passagem competitiva $j$, da passagem evolutiva $n$.

A taxa de replicação relativa $r\left(t_{n}\right)$ para cada $n$ é obtida como o coeficiente angular de cada um destes "vetores de fitness". No limite em que o número de passagens $j$ é muito grande e o tempo entre passagens é pequeno, temos o limite contínuo deste processo, onde $j \tau \rightarrow t$

$$
\frac{d}{d t} \ln [\tilde{F}(t)]=r(t)
$$

Onde

Os resultados dos experimentos analisados desta forma foram apresentados em diversos trabalhos [Novella 1995a, Novella 1999].

O nosso trabalho resume-se na proposta de um modelo para descrever a evolução temporal da taxa de replicação $r(t)$, na situação em que o tamanho da população e os recursos são mantidos constantes. 


\subsection{Análise das primeiras propostas de descrições teóricas do experimento.}

Os modelos teóricos que foram propostos para descrever o processo evolutivo que leva à variação da taxa de replicação média da população de vírus, sujeita ao procedimento experimental descrito, pertencem a uma classe de modelos chamada de modelos de seleçãomutação.

Estes modelos visam descrever um processo de conservação para uma determinada população que difunde em um espaço de fenótipos, ou genótipos, dependendo do contexto.

A equação geral para este tipo de processo é dada por [Saldaña 2003]

$$
\frac{\partial C(r, t)}{\partial t}=\left(f(r)-\int_{a}^{b} f(y) C(y, t) d y\right) C(r, t)+\mu \frac{\partial^{2} C(r, t)}{\partial r^{2}}, \quad a<r<b
$$

Onde:

$C(r, t)$ é a concentração de indivíduos com determinado fitness $r$ no instante $t$, tal que $\int C(r, t) d r=1$.

$f(r)$ é a taxa de replicação, que mede a produção de vírus com fitness $r$.

$\int_{a}^{b} f(y) C(r, t) d r$ é a taxa média de produção de vírus, em um determinado instante $t$.

$\mu \frac{\partial^{2} C(r, t)}{\partial r^{2}}$ representa a mutação de fitness sofrida por parte da população, ou seja, a taxa com que indivíduos com determinado fitness $r$ se transformam em indivíduos com fitness $r^{\prime}$. É representado por um termo que descreve a difusão neste espaço.

O primeiro modelo teórico para descrever a dinâmica da evolução da taxa de replicação, como observado nos experimentos de Isabel Novella, foi proposto em 1996 por Lev. S. Tsimring e Herbert Levine [Tsimring 1996].

Neste trabalho [Tsimring 1996], assim como também em [Aafif 1998], os autores propõem uma maneira de descrever a evolução da taxa de replicação da população de vírus como um processo dinâmico no espaço contínuo de fitness. No caso, fitness é definido como taxa de replicação, ou seja, $f(r)=r$ no contexto dos modelos de seleção-mutação. 
Nesta abordagem, faz-se a hipótese de que é possível caracterizar a população apenas com a informação da fração $C(r, t)$ de indivíduos com determinada taxa de replicação $r$ que estão presentes na população, em um determinado instante $t$. A evolução desta distribuição, ao longo do tempo, é o processo que é modelado nestes trabalhos.

Uma equação para a evolução no espaço/tempo da função de distribuição dos fitness presentes na população em cada instante de tempo $t$ foi proposta e resolvida numericamente por Tsimring. Em seguida, uma expressão analítica para a média dos fitness foi obtida por Amal Aafif e Juan Lin [Aafif 1998], como veremos a seguir.

Para tanto, parte-se inicialmente de uma caracterização da população através de um espaço discreto da taxa de replicação $k$, onde cada indivíduo é caracterizado por uma seqüência de zeros e uns, cada uma das quais um mapa do genoma de cada indivíduo.

Em cada nova geração, os vírus replicam e mutam, o que significa que durante as gerações novas seqüências são criadas, substituindo as antigas, no caso, mutando apenas uma base (0 ou 1) por geração.

A taxa de replicação $k$ é definida pela soma dos valores de cada sítio, ou seja, o número de uns que a seqüência contém, não importando a maneira com que estes estão distribuídos, e é identificado como a taxa de replicação da população. Neste sentido, a passagem do "espaço dos genótipos"(microscópica) para o espaço dos "fenótipos"(macroscópica) é efetuada através de uma aproximação de campo médio.

Esta escolha simplifica bastante a descrição da dinâmica, dado que diferentes configurações dos genomas devem levar ao mesmo valor de taxa de replicação.

No primeiro trabalho [Tsimring 1996] o processo evolutivo da população de vírus é descrito pela seguinte equação mestra:

$$
\frac{d C(k, t+1)}{d t}=\frac{k}{N} C(k, t)+\lambda\left[\frac{k+1}{N} C(k+1, t)+\frac{N-k+1}{N} C(k-1, t)-C(k, t)\right]
$$

onde:

$$
k=1,2,3 \ldots, \text { número de uns de uma determinada seqüência, definide a }
$$
taxa de replicação neste espaço discreto. 
$C(k, t)$, concentração de seqüências com taxa de replicação $k$ no instante $t$, $N$, tamanho do genoma, considerado constante, $\lambda$, taxa de mutação.

Trata-se de um sistema de $N$ equações diferenciais ordinárias, de primeira ordem, acopladas, e que descrevem a variação temporal das quantidades relativas de indivíduos caracterizados pelos respectivos valores de diferentes taxas de replicação $k$ presentes na quasi-espécie.

Nisso reside a maior diferença entre este modelo e os modelos do tipo predador-presa (Lotka-Volterra), pois no presente caso, o número de "espécies"pode ser considerado infinito (trata-se de uma quasi-espécie). Esta aproximação para o número de espécies, justifica de certa forma o limite contínuo.

Perde-se, no entanto, informações sobre comportamentos individuais, o que é o objetivo dos modelos predador-presa.

A equação mestra (2.21) possui o seguinte limite contínuo, com $k \rightarrow r$, no espaço de taxa de replicação contínuo:

$$
\frac{\partial C(r, t)}{\partial t}=(r-<r>) C(r, t)+D \frac{\partial^{2} C(r, t)}{\partial r^{2}}+\frac{\partial\left(\nu_{d r i f t} C(r, t)\right)}{\partial r}
$$

Onde:

$D$, constante de difusão,

$r$, taxa de replicação no limite contínuo,

$<r>=\frac{\int r C(r, t) d r}{\int C(r, t) d r}$, taxa de replicação média da população,

$\nu_{d r i f t}$, termo oriundo da predominância de mutações deletérias sobre benéficas.

Esta equação corresponde a um modelo seleção-mutação onde $w(r)=r$, exceto pela presença do termo $\frac{\partial\left(\nu_{d r i f t} C(r, t)\right)}{\partial r}$. 
A equação diferencial (2.22), excluindo-se o termo $(r-<r>) C(r, t)$, pode ser comparada a uma equação de Foker-Planck.

A equação de Fokker-Planck

$$
\frac{\partial P(r, t)}{\partial t}=D \frac{\partial^{2} P(r, t)}{\partial r^{2}}+\frac{\partial(F(r) P(r, t))}{\partial r}
$$

é uma equação diferencial parcial de segunda ordem, para a evolução da probabilidade de se encontrar uma partícula que difunde em um meio com constante de difusão $D$, sujeita a uma força $F(r)$ (neste caso considerada constante), em uma determinada posição (ou, com determinado valor "espacial" $r$, que no caso é o taxa de replicação), em um determinado instante $t$.

Já no segundo trabalho teórico [Aafif 1998], os autores assumem a seguinte relação de recorrência que deve ser satisfeita pela distribuição da população com taxa de replicação $k$ (no espaço de taxa de replicação discreto) presentes na amostra em um instante $t$.

$C(k, t+\tau)=(k-<k>) \tau C(k, t)+\left(\frac{1}{2}-\frac{k-\Delta}{N \Delta}\right) C(k-\Delta, t)+\left(\frac{1}{2}+\frac{k+\Delta}{N \Delta}\right) C(k+\Delta, t)$

onde

$C(k, t)$, concentração da população com taxa de replicação $k$ no instante de tempo $t$,

$\Delta$, unidade de taxa de replicação,

$\tau$, intervalo de tempo,

Tomando-se $\tau \rightarrow 0, \Delta \rightarrow 0$ e $N \rightarrow \infty$, de tal forma que $\frac{\Delta^{2}}{\tau} \rightarrow D$ e $\frac{2}{N \Delta} \rightarrow \mu$, a equação (2.24) admite limite contínuo, $\operatorname{com} k \rightarrow r:$

$$
\frac{\partial C(r, t)}{\partial t}=(r-<r>) C(r, t)+\frac{D}{2} \frac{\partial^{2} C(r, t)}{\partial r^{2}}+\mu \frac{\partial(r C(r, t))}{\partial r}
$$


Com:

$D$, taxa de mutação,

$\mu$, "coeficiente de drift".

A grande diferença entre as equações contínuas nos dois modelos reside no termo que os autores chamam de "drift velocity" $(F(r))$, que é o termo que deriva de um potencial, ainda segundo analogia com a equação de Fokker-Planck (2.23).

No primeiro caso (eq. 2.22), $F(r)=\nu_{\text {drift }}$ é considerado constante; no segundo (eq. 2.25) $\nu_{\text {drift }}=r$, termo que representa, segundo analogia com um processo Foker-Planck, um processo difusivo com um "termo de drift"derivado de um potencial harmônico $\left(U=\frac{r^{2}}{2}\right)$, chamado processo de Ornstein-Ulenbeck.

Esta diferença nos dois trabalhos irá se refletir principalmente no comportamento assintótico da solução das equações.

No trabalho de [Aafif 1998] as probabilidades de transição $p$ e $q$ entre as sub-populações, tal como descrito pelas equação discreta que leva ao limite contínuo, depende exclusivamente da taxa de replicação $k$ destas sub-populações:

$$
\begin{aligned}
& p=\left(\frac{1}{2}-\frac{k-\Delta}{N \Delta}\right) \\
& q=\left(\frac{1}{2}+\frac{k+\Delta}{N \Delta}\right)
\end{aligned}
$$

Esta é a maior diferença entre este trabalho e o nosso, como veremos no próximo capítulo. Além disso, as duas equações apresentadas $((2.22)$ e (2.25)) são equações de conservação global, ou seja, conservam a distribuição integrada. Como veremos adiante, esta é outra diferença entre os trabalhos, dado que nossa equação é uma equação de conservação local.

\subsubsection{Soluções das equações (2.22) e (2.25):}

As soluções das equações contínuas $(2.22)$ e $(2.25)$ para $C(r, t)$ são obtidas de maneira diferente nos dois trabalhos. 
O primeiro trabalho modifica a equação (2.22), de maneira a possibilitar um tratamento numérico: nesta solução, o parâmetro "drift velocity"é negligenciado, ou seja, o termo viscoso (derivada de primeira ordem espacial) é abandonado.

Além disso, adiciona-se à equação uma nova função $\theta\left(C(r, t)-C_{c}\right)$ definida como:

$$
\theta\left(C(r, t)-C_{c}\right)=\left\{\begin{array}{l}
0, C(r, t)<C_{c} \\
1, C(r, t)>C_{c}
\end{array}\right.
$$

Esta função aparece multiplicando o termo $(r-<r>) C(r, t)$ da equação $(2.22)$. $C_{c}$ é um limite imposto pela capacidade reprodutiva da população. O objetivo com isto é evitar divergência em $<r>$ para baixas concentrações de vírus de determinadas sub-populações.

Desta forma, este termo é introduzido por Tsimring na equação (2.22) um termo "cutoff", que, embora tenha um apelo biológico, não aparece naturalmente a partir da versão discreta.

O argumento biológico para justificar esta função é que o parâmetro $C_{c}$ representa uma concentração mínima de uma determinada sub-população, a partir da qual esta possui uma densidade significativa, a fim de não ser eliminada em determinada passagem evolutiva, independentemente de seu taxa de replicação.

Com esta modificação, a equação (2.22) torna-se:

$$
\frac{\partial C(r, t)}{\partial t}=\theta\left(C(r, t)-C_{c}\right)(r-<r>) C(r, t)+D \frac{\partial^{2} C(r, t)}{\partial r^{2}}
$$

A solução numérica para esta equação resulta em um comportamento para a evolução da taxa de replicação média da população que reproduz apenas qualitativamente os resultados experimentais, visto que a taxa de replicação relativa apresenta valores positivos em todo processo, diferente do que mostram os dados experimentais, Figura (2.5).

Mas, segundo os autores, o mais importante nos resultados é que eles indicam que o valor médio de $r$ para determinadas condições iniciais consiste em com dois estágios de crescimento linear diferentes, tal como foi observado pelos autores do trabalho experimental. 
Porém, os autores do segundo trabalho [Aafif 1998] afirmam que existe uma inconsistência neste resultado, que reside no fato do crescimento no segundo estágio ser linear, com derivada não nula, positiva, mesmo para tempos longos (limite assintótico). Isto levaria a uma situação que equivale a um processo malthuseano com taxa de replicação que cresce linearmente com o tempo.

Segundo os autores do segundo trabalho teórico [Aafif 1998], este não seria um comportamento assintótico biológicamente possível devido aos limites metabólicos, tamanho do béquer, quantidade de células passíveis de infecção, replicação por célula, etc. O correto seria um limite assintótico com um valor constante para taxa de replicação.

É interessante notar que na época os resultados experimentais não eram conclusivos para a existência de um limite assintótico finito [Novella 1995a], que só foi verificado experimentalmente em 1999 [Novella 1999] e portanto os argumentos quanto a existência deste limite eram puramente teóricos.

No segundo trabalho teórico [Aafif 1998] os autores encontram o seguinte resultado para o limite assintótico (constante) da taxa de replicação:

$$
<r>_{\infty}=\frac{D}{2 \mu^{2}}
$$

Este limite finito é obtido pelo fato da equação (2.25) se tratar fisicamente de um processo difusivo, com uma "velocidade de drift"derivada de um potencial harmônico $\left(U=\frac{r^{2}}{2}\right)$, que "localiza"a partícula, impedindo a divergência da média espacial (no caso, da taxa de replicação).

Os autores também ressaltam que, embora possam argumentar logicamente em favor deste limite assintótico constante, os dados experimentais na época não eram suficientes para demonstrar qual o comportamento assintótico do experimento, e que, assim sendo, experimentalmente mais dados seriam necessários para resolver esta questão.

Porém nos resultados obtidos neste segundo trabalho [Aafif 1998], segundo os próprios autores, não foi contemplado o comportamento que consiste em duas regiões de crescimento 
com comportamentos diferentes da taxa de replicação da população, uma vez que subestima o crescimento inicial da taxa de replicação.

No trabalho de Tsimring (1996), a taxa de replicação é obtida de maneira numérica, através da média espacial de uma função diferente daquela obtida como solução da equação diferencial proposta, e que foi interpretada biológicamente. Além disso, esta solução numérica permite apenas uma comparação qualitativa com o resultado experimental. Segundo Tsimring, a solução composta de duas etapas de crescimento é obtida apenas para uma distribuição inicial aleatória.

Para uma distribuição inicial com forma de pulso (uma gaussiana por exemplo) a solução numérica para a taxa de replicação da população não apresenta "dois estágios"de crescimento. Este comportamento também observado experimentalmente [Novella 1995a] em outras réplicas do experimento.

Como mencionamos, uma característica importante presente nestes dois modelos teóricos é que o processo de evolução markoviano descrito pelas taxas de transição leva em sua formulação a própria taxa de replicação da população (ou seja, de cada sub-população), através da hipótese de que estas se replicam de maneira malthuseana.

Em nosso trabalho, propomos que $\langle x\rangle(t)$ seja identificado de fato com o fenótipo médio da população, tal como este é definido pelos autores dos experimentos (definição (2.14)), e que a taxa seja obtida através da derivada temporal desta função,

$$
r(t)=\frac{d}{d t}(<x>(t))=\frac{d}{d t} \int x C(x, t) d x
$$

No próximo capítulo, introduzimos o modelo que proposemos para explicar os mesmos dados experimentais, motivados pelas razões que serão explicitadas a seguir. 



\section{CAPíTULO 3}

\section{Desenvolvimento Teórico}

\subsection{Modelo não-linear para a evolução do fenótipo de uma quasi-espécie de virus}

O modelo que propomos em nosso trabalho reside no âmbito conceitual dos processos markovianos.

Neste contexto, o estado de um sistema em um determinado instante pode ser definido inequivocamente a partir do conhecimento do estado do mesmo em um instante anterior.

O objetivo é modelar o processo de evolução in vitro de uma população de vírus, tal como é observado nos experimentos de Novella [Novella 1995a, Novella 1999] discutidos anteriormente, respeitando o caráter de conservação populacional inerente ao experimento [Novella 1995a ].

A população de vírus é uma quasi-espécie, o que significa que ela é constituída de subpopulações com diferentes características, que designaremos por diferentes fenótipos $x$. Os possíveis valores de $x$ formam o chamado de espaço dos fenótipos.

Descrevemos a população de vírus através de uma função distribuição $C(x, t)$ das concentrações de indivíduos com diferentes fenótipos $x$ presentes na população em um determinado instante $t$.

As grandezas de interesse são calculadas como médias sobre esta distribuição dos fenótipos da população, que é conservada em número, mas cujas características evoluem no tempo.

Pretendemos relacionar a taxa de replicação média $r(t)$ da população com a variação temporal da média dos fenótipos da população, ou seja:

$$
r(t)=\frac{d}{d t}<x>(t)=\frac{d}{d t} \int x C(x, t) d x
$$


Onde:

$r(t)$, taxa de replicação média da população, num determinado instante $t$.

$<x>(t)$, média do fenótipos da população, num determinado instante $t$.

$C(x, t)$, função distribuição das concentrações dos diferentes fenótipos $x$ da população em um determinado instante $t$.

Para obter uma equação que descreva a evolução no espaço e tempo de $C(x, t)$, partimos de um processo discreto que descreve um passeio aleatório unidimensional no espaço dos fenótipos, para depois tomar o limite contínuo, onde a diferença entre dois valores de fenótipos $x$ consecutivos pode ser considerada infinitesimal.

O passeio aleatório se dá por meio de probabilidades de transição $p$ e $q$, que quantificam como a população ocupa os diversos sítios do espaço dos fenótipos, com o tempo.

Este passeio é caracterizado por ser unidimensional, conter $N$ partículas (identificados como os indivíduos da população), onde cada sítio, que representa um determinado fenótipo (caracterizado por $\lambda k$ neste espaço discreto, com $k=1,2,3, \ldots$ e $\lambda$ é a unidade de fenótipo), pode ser ocupado por um número arbitrário de partículas, e cujo número de sítios é infinito (espaço aberto), como representado na Figura (3.1).

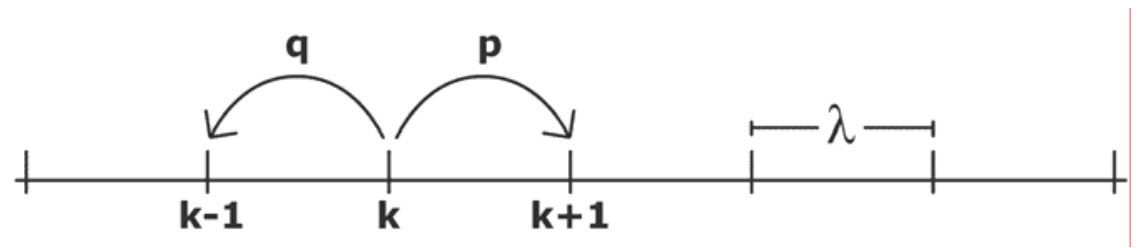

Figura 3.1. Espaço dos fitness, constituído por diferentes sítios $k$, espaçados por uma distância $\lambda$.

Estas probabilidades de transição "macroscópicas" $p$ e $q$ refletem a dinâmica interna dos processos evolutivos "microscópicos" de competição: seleção e mutação, determinados principalmente pelo arranjo experimental. 
Atendo-se ao fato de que a característica medida no sistema é uma média dos diferentes fenótipos $x$ dos indivíduos presentes na quasi-espécie, em cada instante de tempo, procuramos uma descrição que leve em conta a dinâmica destas diferentes sub-populações, que reflita o comportamento evolutivo médio de toda população, tal como é observado experimentalmente.

Devemos enfatizar que há uma grande diferença entre nosso modelo evolutivo e os dois outros trabalhos teóricos apresentados anteriormente [Tsimring 1996, Aafif 1998].

Em nosso modelo não é feita a hipótese a priori de que cada espécie presente na quasiespécie se replica de modo a obedecer a lei de malthus. Os dois modelos citados são formulados em termos desta hipótese, desde que a atribuição das probabilidades de transição são proporcionais ao valor da taxa $r$ em cada ponto $k$ do espaço considerado.

No modelo que apresentamos, as probabilidades de transição neste espaço $p$ e $q$ são proporcionais à população relativa $C(x, t)$ presente no instante e ponto considerado. Nos dois modelos citados, $p$ e $q$ são proporcionais ao valor de $r$ local

Para o processo markoviano, podemos escrever [Montrol 1979, Tomé 2001]:

$$
\begin{aligned}
C_{(i+1) \tau}(k \lambda)= & C_{i \tau}(k \lambda)-\left[p_{i \tau}(k \lambda)+q_{i \tau}(k \lambda)\right] C_{i \tau}(k \lambda) \\
& +p_{i \tau}((k-1) \lambda) C_{i \tau}((k-1) \lambda)+q_{i \tau}((k+1) \lambda) C_{i \tau}((k+1) \lambda)
\end{aligned}
$$

Onde:

$\lambda$, unidade de fenótipo,

$\tau$, unidade de tempo, identificado como intervalo de tempo entre duas passagens consecutivas,

$k$, contador de unidades de fenótipo, $k=0,1,2, \ldots$

$i$, contador de unidades de tempo, $i=0,1,2, \ldots$

$C_{i \tau}(k \lambda)=\frac{N_{i \tau}(k \lambda)}{N}$, onde $N_{i \tau}(k \lambda)$ é o número de indivíduos com fenótipo $k \lambda$ presentes na quasi-espécie na i-ésima passagem (instante $i \tau$ ), e $N=\sum_{k} N_{i \tau}(k \lambda)$. 
$p_{i \tau}(k \lambda)$, probabilidade da sub-população com fenótipo $k \lambda$ no instante $i \tau$ aumentar seu fenótipo de uma unidade, ou "probabilidade de transição"para a direita neste espaço.

$q_{i \tau}(k \lambda)$, probabilidade da sub-população com fenótipo $k \lambda$ no instante $i \tau$ diminuir seu fenótipo de uma unidade, ou "probabilidade de transição"para a esquerda neste espaço.

Trata-se de um sistema de virtualmente infinitas equações acopladas, para as transições entre os diferentes fitness $x$ presentes na quasi-espécie.

A equação (3.2) descreve a evolução das concentrações das sub-população com fenótipo $\lambda k$ presentes na população. Esta evolução ocorre durantes as passagens evolutivas, como discutido no primeiro capítulo.

No presente modelo, as transições $p_{i \tau}(k \lambda)$ e $q_{i \tau}(k \lambda)$, por construção, referem-se a aumentar ou diminuir uma unidade de fenótipo, respectivamente, o número de indivíduos de uma determinada sub-população com fenótipo $k \lambda$, em uma determinada passagem evolutiva (ou seja, quando na escolha da alíquota),

As transições quantificadas por $p_{i \tau}(k \lambda)$ e $q_{i \tau}(k \lambda)$ só ocorrem entre sítios vizinhos. Para a população de vírus, isto significa que estamos admitindo que em cada passagem evolutiva, a substituição de indivíduos ocorre por meio da variação de uma unidade de fenótipo por indivíduo. O limite do espaço de fenótipo contínuo significa que a diferença entre duas unidades de fenótipo consecutivas se torna infinitesimal.

Nosso modelo consiste em escolher $p_{i \tau}(k \lambda)$ e $q_{i \tau}(k \lambda)$ da forma:

$$
\begin{aligned}
& p_{i \tau}(k \lambda)=P-\alpha C_{i \tau}(k \lambda) \\
& q_{i \tau}(k \lambda)=(1-P)+\alpha C_{i \tau}(k \lambda)
\end{aligned}
$$


O parâmetro $\alpha$ foi introduzido para abordar a questão da evolução do fenótipo em conexão com a dinâmica do hospedeiro (células), e está relacionado com um limite para a concentração de uma determinada sub-população com fenótipo $x$. Mais específicamente, este parâmetro avalia como se dá o aparecimento de componentes com fenótipo mais elevado, uma vez que estes, mesmo possuindo maior taxa de replicação, precisam estar presentes em um determinado instante com uma certa concentração relativa significativa para fazer parte da dinâmica da população no instante posterior.

O parâmetro $P$ é uma taxa de mutação a priori, que está relacionado com o balanço mutação-seleção determinado pelo arranjo experimental.

Como as taxas $p_{i \tau}(k \lambda)$ e $q_{i \tau}(k \lambda)$ são positivas, $\alpha$ e $P$ devem satisfazer as seguintes desigualdades:

$$
\left\{\begin{array}{l}
0<P<1 \\
\alpha<P
\end{array}\right.
$$

Sendo $C_{i \tau}(k \lambda)$ a concentração de indivíduos com fenótipo $k \lambda$ presentes na alíquota na i-ésima passagem (instante $i \tau$ ), em relação à população total de vírus $N$, mantida fixa no experimento,

$$
\sum_{k} C_{i \tau}(k \lambda)=1
$$

A interpretação biológica destes parâmetros é discutida adiante.

As escolhas de $p_{i \tau}(k \lambda)$ e $q_{i \tau}(k \lambda)$ foram inspiradas em um modelo proposto por Montroll [Montroll 1979] para descrever o experimento de separação de gases que levou à descoberta do argônio, como concebido por Lord Rayleigh em 1896.

Com esta escolha, a relação de recorrência (3.2) torna-se: 
$C_{(i+1) \tau}(k \lambda)=\left[P-\alpha C_{i \tau}((k-1) \lambda)\right] C_{i \tau}((k-1) \lambda)+\left[(1-P)+\alpha C_{i \tau}((k+1) \lambda)\right] C_{i \tau}((k+1) \lambda)$

\subsubsection{Conservação.}

A idéia de escrever a evolução da quasi-espécie mantendo constante o número de indivíduos está de acordo com o experimento, em que as medidas são efetuadas considerando-se alíquotas fixas, ou seja, contendo o mesmo número de indivíduos.

A demonstração do caráter conservativo da equação pode ser obtida através da soma em $k$, como demonstrado a seguir:

$$
\sum_{k=-\infty}^{k=+\infty} C_{(i+1) \tau}(k \lambda)=\sum_{k=-\infty}^{k=+\infty} C_{i \tau}((k-1) \lambda)\left[P-\alpha C_{i \tau}((k-1) \lambda)\right]
$$

$$
\begin{aligned}
& +\sum_{k=-\infty}^{k=+\infty} C_{i \tau}((k+1) \lambda)\left[(1-P)+\alpha C_{i \tau}((k+1) \lambda)\right] \\
= & \sum_{k \prime=k-1=-\infty}^{k \prime=k-1=+\infty} C_{i \tau}\left(k^{\prime} \lambda\right)\left[P-\alpha C_{i \tau}\left(k^{\prime} \lambda\right)\right] \\
& +\sum_{k \prime \prime=k+1=-\infty}^{k \prime \prime=k+1=+\infty} C_{i \tau}\left(k^{\prime \prime} \lambda\right)\left[(1-P)+\alpha C_{i \tau}\left(k^{\prime \prime} \lambda\right)\right] \\
= & \sum_{k}\left[C_{i \tau}(k \lambda)+\left(C_{i \tau}(k \lambda)-C_{i \tau}(k \lambda)\right) P+\left(C_{i \tau}^{2}(k \lambda)-C_{i \tau}^{2}(k \lambda)\right) \alpha\right] \\
= & \sum_{k=-\infty}^{k=+\infty} C_{i \tau}(k \lambda)=1
\end{aligned}
$$

Em que foi utilizada a hipótese de que o espaço dos fenótipos $x$ é aberto. 


\subsubsection{Limite do contínuo.}

Para grandes distâncias e tempos, o limite contínuo do processo descrito pela equação (3.2), é obtido tomando-se $\lambda \rightarrow 0$ e $\tau \rightarrow 0$, com

$$
\frac{\lambda}{\tau} \rightarrow \Gamma
$$

(constante), ou seja, quando a unidade de fenótipo $\lambda$ tende a zero (o que torna contínuo o espaço dos fenótipos) e o intervalo entre as passagens $\tau$ também tende a zero.

Como resultado, obtemos (vide Apêndice A):

$$
\frac{\partial C(x, t)}{\partial t}=\Gamma \frac{\partial}{\partial x} C(x, t)[(1-2 P)+2 \alpha C(x, t)]
$$

Onde $C(x, t)$ é o limite contínuo para a distribuição $C_{i \tau}(k \lambda)$.

Trata-se de uma equação diferencial parcial quasi-linear de conservação para a evolução da função distribuição das concentrações $C(x, t)$ das sub-populações caracterizadas pelo fenótipos $x$ presentes na alíquota no instante $t$.

Esta equação pode ser resolvida analiticamente pelo método das características (vide Apêndice B), para determinadas condições iniciais. As soluções serão apresentadas no próximo capítulo.

Para condições iniciais mais gerais, utilizamos métodos numéricos, como descreveremos adiante.

\subsubsection{Sobre os parâmetros do modelo.}

A equação (3.10) proposta acima possui três parâmetros: $\alpha, P$ e $\Gamma$. Os parâmetros $\alpha$ e $P$ referem-se à dinâmica do sistema, e $\Gamma$ é um fator de escala.

No presente modelo a dinâmica das transições entre os fenótipos $x$ da população é determinada pelas probabilidades de transição $p_{i \tau}(k \lambda)$ e $q_{i \tau}(k \lambda)$, vide (3.3).

Podemos reescrever as taxas de transição de maneira a evidenciar o caráter logístico de sua formulação (para $P \neq 0$ e $P \neq 1$ ): 


$$
\begin{aligned}
& p_{i \tau}(k \lambda)=P\left(1-\frac{\alpha}{P} C_{i \tau}(k \lambda)\right) \equiv P\left(1-\frac{1}{K_{1}} C_{i \tau}(k \lambda)\right) \\
& q_{i \tau}(k \lambda)=(1-P)\left(1+\frac{\alpha}{1-P} C_{i \tau}(k \lambda)\right) \equiv(1-P)\left(1+\frac{1}{K_{2}} C_{i \tau}(k \lambda)\right)
\end{aligned}
$$

Assim, $p_{i \tau}(k \lambda)$ pode ser entendido como um termo logístico, com $\frac{1}{K_{1}}$ como sendo "fator limitante"desta probabilidade de transição de uma determinada sub-população com fenótipo $k \lambda$ aumentar seu fenótipo em uma unidade. Ou seja, se $C_{i \tau}(k \lambda)=K_{1}$, então $p_{i \tau}(k \lambda)=0$.

Já $q_{i \tau}(k \lambda)$, probabilidade de que uma determinada sub-população com fenótipo $k \lambda$ diminua seu fenótipo em uma unidade, nunca se anula, dado que todos seus termos são positivos.

Desta maneira, o modelo descreve a dinâmica da evolução da população de vírus através de $p_{i \tau}(k \lambda)$ e $q_{i \tau}(k \lambda)$, que ditam como se dá a substituição de indivíduos cada vez que uma alíquota fixa é selecionada aleatoriamente da população que evolui.

A seleção, em particular, é incorporada no modelo de duas formas. Primeiro, no próprio termo logístico, que impede o crescimento arbitrário da concentração relativa de uma determinada sub-população com fenótipo $k \lambda$. Segundo, no caráter conservativo da dinâmica, que exprime a seleção de um número fixo de indivíduos no experimento.

As implicações biológicas implícitas nestes parâmetros são discutidas no Capitulo Discussão.

\subsubsection{Dimensões.}

A concentração $C(x, t)$ é adimensional, assim como as taxas de transição $p_{i \tau}(k \lambda)$ e $q_{i \tau}(k \lambda)$. Já o parâmetro $\Gamma$ é inversamente proporcional ao tempo, dado que vêm do limite $\frac{\lambda}{\tau} \rightarrow \Gamma$. 


\subsection{Soluções da equação}

\subsubsection{Soluções da equação (3.10) utilizando o método das caracteristicas.}

A solução analítica da equação contínua (eq. (3.10)) será obtida pelo método das características (Apêndice B).

Lembramos que a função distribuição de fenótipos $x$ da população $C(x, t)$ satisfaz:

$$
\frac{\partial C}{\partial t}-\Gamma \frac{\partial}{\partial x} C[(1-2 P)+2 \alpha C]=0
$$

Definindo:

$$
a \equiv \Gamma(2 P-1)
$$

$$
b \equiv 4 \alpha \Gamma
$$

obtemos

$$
\frac{\partial C}{\partial t}+\frac{\partial}{\partial x}\left[C\left(a-\frac{b}{2} C\right)\right]=0
$$

$\mathrm{Ou}$

$$
\frac{\partial C}{\partial t}+(a-b C) \frac{\partial C}{\partial x}=0
$$

ou ainda

$$
\frac{\partial C}{\partial t}=-\frac{\partial}{\partial x} F(C)
$$

onde 


$$
F(C)=C\left[a-\frac{b}{2} C\right]
$$

Os parâmetros $a$ e $b$ possuem dimensão de inverso de tempo.

Comparando (3.12) com a derivada total da função $C(x, t)$, considerando $x$ função de $t$ :

$$
\frac{d}{d t} C(x(t), t)=\frac{\partial C}{\partial t}+\frac{d x}{d t} \frac{\partial C}{\partial x}
$$

Para uma condição inicial $C(x, 0)=f(x) \equiv C_{0}$, identificamos:

$$
\left\{\begin{array}{l}
\frac{d}{d t} C(x(t), t)=0 \\
\frac{d x}{d t}=a-b C
\end{array}\right.
$$

As curvas características são dadas por:

$$
x(t)=x_{0}+\left[a-b C_{0}\right] t
$$

Obtem-se a seguir as soluções da equação para duas condições inicias diferentes. 
3.2.1.1. Condição inicial "pulso retangular".

Primeiramente vamos analisar a solução da equação para a seguinte condição inicial (ver Figura 3.2) :

$$
C(x, 0)= \begin{cases}0, & x \leq \Delta \\ n, & \Delta \leq x \leq \Delta+m \\ 0, & x>\Delta+m\end{cases}
$$

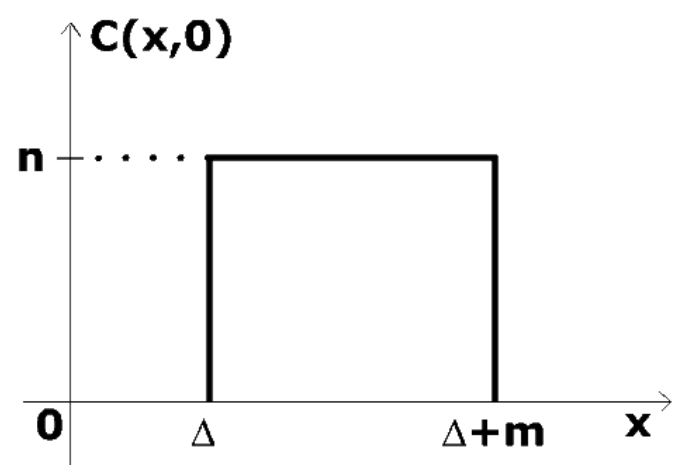

Figura 3.2. Perfil da distribuição inicial de fitness da população, segundo a condição inicial (3.22).

A escolha de $\Delta, m$, e $n$ como parâmetros para caracterizar o perfil inicial possibilita um controle tanto na média quanto na dispersão (largura) da distribuição inicial da população, cuja normalização é garantida pelo vínculo:

$$
m n=1
$$

Para esta escolha de condição inicial, as curvas características são dadas por: 


$$
x(t)=\left\{\begin{array}{l}
x_{0}+a t, \quad x_{0} \leq \Delta \\
x_{0}+[a-b n] t, \quad \Delta<x_{0} \leq \Delta+m \\
x_{0}+a t, \quad x_{0}>\Delta+m
\end{array}\right.
$$

ou, invertendo,

$$
x_{0}(x, t)=\left\{\begin{array}{l}
x-a t, \quad x \leq \Delta+a t \\
x-[a-b n] t, \quad \Delta+[a-b n] t \leq x \leq \Delta+m+[a-b n] t \\
x-a t, \quad x \geq \Delta+m+a t
\end{array}\right.
$$

A Figura (3.3) mostra a família de curvas características para a escolha $a>0, b>0$ e $(a-b n)>0\left(\forall x_{0} / \Delta<x_{0}<\Delta+m\right)$. Esta escolha não influi nos resultados finais, como veremos à seguir.

Em $t=0$, vemos que há um choque em $x_{0}=\Delta$, onde que as características referentes às regiões $x<\Delta$ e $\Delta<x<\Delta+m$ se interceptam, e uma zona de rarefação em $x_{0}=\Delta+m$ (ver Figura 3.3).

As características que emanam de $x_{0}=\Delta+m$ são dadas por:

$$
x=m+[a-b C] t+\Delta
$$

Logo, nesta região de rarefação, a solução que corresponde à solução entrópica [Evans 1999, Haberman 1998] (ver Apêndice B) é:

$$
C(x, t)=\frac{\Delta+m-x+a t}{b t}
$$




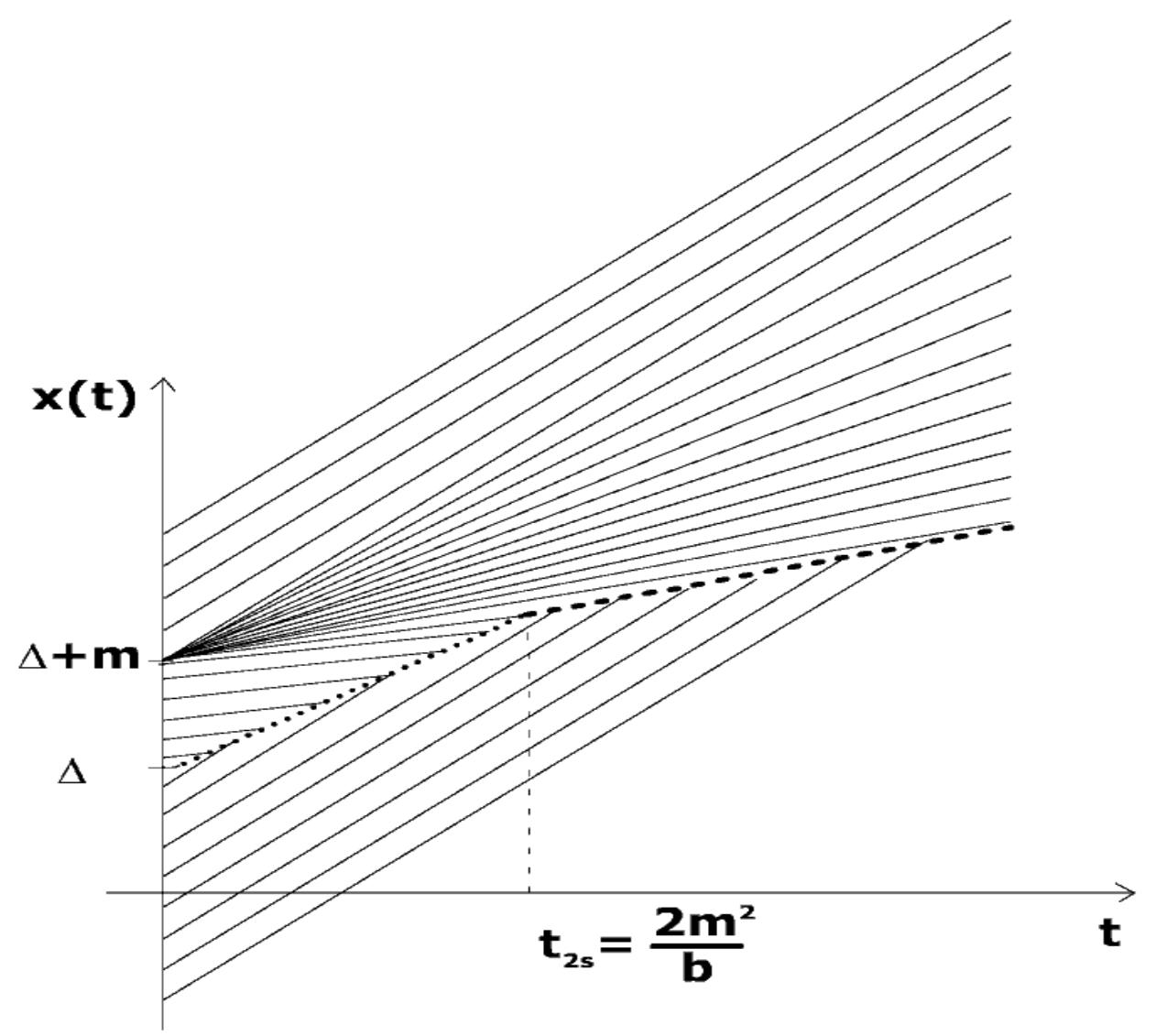

Figura 3.3. Curvas características da equação (3.16) para a condição inicial (3.22) para $(a-b n)>0, a>0$ e $b>0$. No instante $t=0$, temos uma região de rarefação composta pelas curvas que emanam de $x_{r}=\Delta+m$, e uma frente de choque com início em $x_{1 s}=\Delta$. No instante $t_{2 s}=\frac{2 m^{2}}{b}$ temos um segundo choque em $x_{2 s}=m\left(\frac{2 a m}{b}-1\right)+\Delta$.

A onda de choque, que começa em $t=0$ e $x_{1 s}(0)=\Delta$, como pode ser observado na Figura (3.3), move-se com velocidade $\frac{d x_{1 s}(t)}{d t}$ determinada pela condição de Rankine [Evans 1999, Haberman 1998] (ver Apêndice B): 


$$
\begin{aligned}
\frac{d x_{1 s}(t)}{d t} & =\frac{F\left(C_{l}\right)-F\left(C_{r}\right)}{C_{l}-C_{r}}=\frac{a(n)-\frac{b}{2}(n)^{2}-a(0)-\frac{b}{2}(0)}{n-0}=a-\frac{b n}{2} \\
& \therefore \quad x_{1 s}(t)=\Delta+\left[a-\frac{b n}{2}\right] t
\end{aligned}
$$

Onde $F(C)$ é a função definida em (3.18), $C_{l}=n$ e $C_{r}=0$ são os valores que $C(x, t)$ assume nas regiões delimitadas pela onde de choque, definidas pelas curvas características que emanam de $\Delta<x_{0} \leq \Delta+m$ e $x_{0} \leq \Delta$, respectivamente, vide figura (3.3).

A curva $x_{1 s}(t)$ está representada na Figura (3.3) pela linha pontilhada.

Há um segundo choque, que ocorre quando a primeira característica da região de rarefação (região definida pelas características que emanam de $x_{0}=\Delta+m$ ) encontra a solução $x_{1 s}$ do primeiro choque (linha pontilhada na Figura 3.3).

Este encontro ocorre no instante $t_{2 s}$ tal que

$$
\Delta+\left[a-\frac{b n}{2}\right] t_{2 s}=\Delta+m+[a-b n] t_{2 s}
$$

Daí

$$
t_{2 s}=\frac{2 m}{b n}=\frac{2 m^{2}}{b}
$$

Portanto, $t_{2 s}$, o instante em que ocorre o segundo choque, e onde há uma mudança na solução, é proporcional ao quadrado da dispersão $m$ inicial da distribuição, e inversamente proporcional ao parâmetro $b(=4 \Gamma \alpha)$. As implicações biológicas desta dependência são discutidas no capítulo Discussão.

Este choque se dará em

$$
x_{1 s}\left(t_{2 s}\right)=x_{1 s}\left(\frac{2 m^{2}}{b}\right)=\frac{2 a m}{b n}-m+\Delta=m\left(\frac{2 a m}{b}-1\right)+\Delta
$$


A segunda onda de choque que inicia em $x_{1 s}\left(t_{2 s}\right)$ move-se com velocidade $\frac{d x_{2 s}(t)}{d t}$, determinada pela condição de Rankine, que nesse caso se escreve:

$$
\begin{gathered}
\frac{d x_{2 s}(t)}{d t}=\frac{F\left(C_{l}\right)-F\left(C_{r}\right)}{C_{l}-C_{r}} \\
=\frac{a\left(\frac{\Delta+m-x_{2 s}(t)+a t}{b t}\right)-\frac{b}{2}\left(\frac{\Delta+m-x_{2 s}(t)+a t}{b t}\right)^{2}-a(0)-\frac{b}{2}(0)}{\frac{\Delta+m-x_{2 s}(t)+a t}{b t}-0} \\
=a-\frac{\Delta+m}{2 t}+\frac{x_{2 s}(t)}{2 t}-\frac{a}{2}
\end{gathered}
$$

$\mathrm{Ou}$

$$
\frac{d x_{2 s}(t)}{d t}=\frac{x_{2 s}(t)-m-\Delta}{2 t}+\frac{a}{2}
$$

de onde obtemos

$$
x_{2 s}(t)=a t-\sqrt{2 b t}+\Delta+m
$$

Onde $F(C)$ é a função definida em (3.18), $C_{l}=\frac{\Delta+m-x_{2 s}(t)+a t}{b t}$ e $C_{r}=0$ são os valores que $C(x, t)$ assume nas regiões delimitadas pela onde de choque: a região de rarefeção (definida pelas curvas que emanam de $x_{0}=\Delta+m$ ), onde $c(x, t)$ é dado por (3.27) e a região definida pelas curvas características que emanam de $x_{0} \leq \Delta$, vide figura (3.3).

A curva (3.33) está representada na Figura (3.3) pela linha tracejada.

Os detalhes da solução da equação (3.32) para $x_{2 s}(t)$ encontram-se no Apêndice C

Podemos então escrever a solução para $C(x, t)=C\left(x_{0}(x, t), t\right)$ voltando às condições iniciais, através das características. 
A solução é portanto composta pelas diferentes soluções respectivas aos dois intervalos: antes e após o segundo choque.

Para $0 \leqslant t<t_{2 s}$ :

$$
C(x, t)=\left\{\begin{array}{l}
0 \leq \Delta+\left[a-\frac{b n}{2}\right] t \\
n, \quad \Delta+\left[a-\frac{b n}{2}\right] t<x \leq \Delta+m+[a-b n] t \\
\frac{\Delta+m-x+a t}{b t}, \quad \Delta+m+[a-b n] t<x+m+a t \\
0, \quad x>\Delta+m+a t
\end{array}\right.
$$

Para $t \geqslant t_{2 s}$ :

$$
C(x, t)=\left\{\begin{array}{l}
0, \quad x \quad a t-\sqrt{2 b t}+\Delta+m \\
\frac{\Delta+m-x+a t}{b t}, \quad a t-\sqrt{2 b t}+\Delta+m<x \leq \Delta+m+a t \\
0, \quad x>\Delta+m+a t
\end{array}\right.
$$

O perfil da solução acima para $C(x, t)$ pode ser representado como na Figura (3.4): 


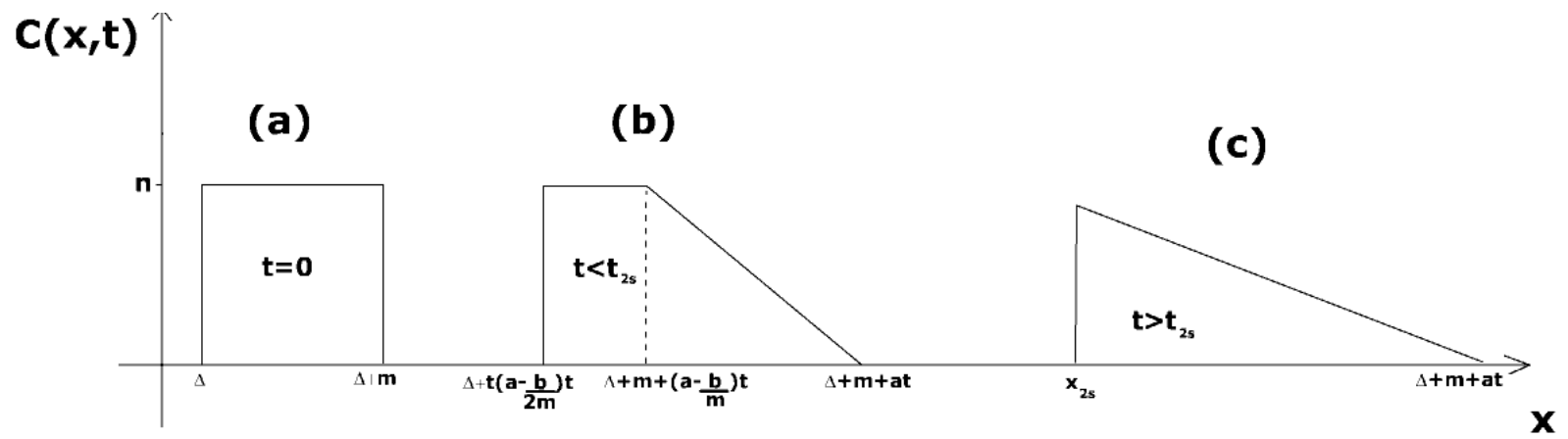

Figura 3.4. Perfil da evolução temporal de $C(x, t)$ mostrado em diferentes instantes de tempo. (a) instante inicial $t=0$; (b) instante anterior ao segundo choque $\left(0<t<t_{s}\right)$; a região de rarefação da distribuição tem início em $x(t)=\Delta+m+\left(a-\frac{b}{m}\right) t ;($ c) instante posterior ao segundo choque.

\section{Conservação.}

A equação é de conservação, logo devemos ter:

$$
\frac{\partial}{\partial t} \int C(x, t) d x=0
$$

Se integrarmos a nossa solução em $x$, devemos ter um resultado independente do tempo. Isto deve valer para antes e depois do segundo choque.

Para $t>t_{2 s}$ :

$$
\begin{aligned}
N_{1} & =\int_{-\infty}^{+\infty} C(x, t) d x=\int_{\Delta+\left[a-\frac{b n}{2}\right] t}^{\Delta+m+[a-b n] t}[n] d x+\int_{\Delta+m+[a-b n] t}^{\Delta+m+a t}\left[\frac{\Delta+m-x+a t}{b t}\right] d x \\
& =m n=1, \forall t
\end{aligned}
$$

Para $t>t_{2 s}$ : 


$$
\begin{aligned}
N_{2} & =\int_{-\infty}^{+\infty} C(x, t) d x=\int_{x_{2 s}}^{\Delta+m+a t}\left[\frac{\Delta+m-x+a t}{b t}\right] d x \\
& =\frac{2 n m b t}{2 b t}=m n=1, \quad \forall t
\end{aligned}
$$

Isto mostra que as soluções permanecem normalizadas no tempo, como esperado. 


\subsubsection{Condição inicial "pulso triangular".}

Em seguida, resolvemos a equação (3.16) pelo método das características para uma segunda condição inicial:

$$
C(x, 0)=\left\{\begin{aligned}
0, & x \leq 0 \\
\frac{n x}{m}, & 0<x \leq m \\
0, & x>m
\end{aligned}\right.
$$

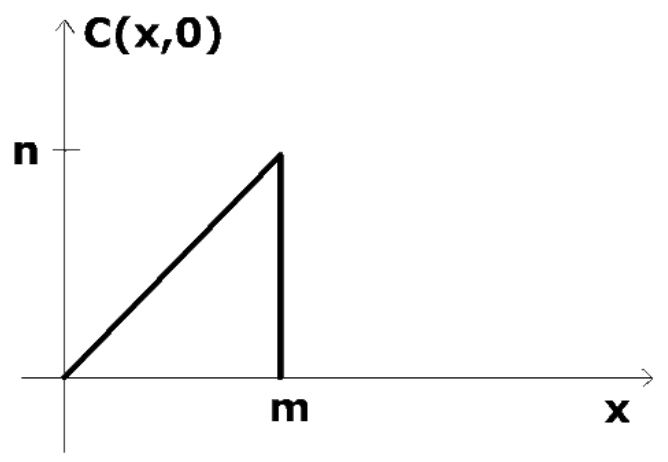

Figura 3.5. Perfil da distribuição inicial (3.39).

A escolha de $m$ e $n$ como parâmetros da condição inicial possibilita um controle da dispersão inicial da distribuição $C(x, t)$.

Vimos no exemplo anterior que a média inicial não influi na evolução do fenótipo da população.

Neste exemplo de condição inicial optamos por não inserir o parâmetro $\Delta$, pois ele levaria a uma equação transcendental para o instante do segundo choque, o que impossibilitaria uma solução analítica fechada.

O seguinte vínculo garante a normalização da distribuição:

$$
m n=2
$$


Com isto, e de acordo com a equação (3.21) as curvas características são dadas por:

$$
x(t)=\left\{\begin{array}{l}
x_{0}+a t, \quad x_{0} \leq 0 \\
x_{0}+\left[a-\frac{b n}{m} x_{0}\right] t, \quad 0 \leq x_{0} \leq m \\
x_{0}+a t, \quad x_{0}>m
\end{array}\right.
$$

A Figura (3.6) mostra a família de curvas características $x(t)$ para a escolha $a>0, b>0$ e $\left(a-\frac{b n}{m} x_{0}\right)>0\left(\forall x_{0} / 0<x_{0}<m\right)$. Esta escolha não influi nos resultados finais, como veremos a seguir.

Invertendo as equações acima, obtemos:

$$
x_{0}(x, t)=\left\{\begin{array}{l}
x-a t, \quad x \leq a t \\
\frac{x-a t}{1-\frac{n b}{m} t}, \quad \text { at } \\
x-a t, \quad x>m+a t
\end{array}\right.
$$

Em $t=0$, vemos pela Figura (3.6) que há uma zona de rarefação em $x_{r}=m$, e um choque no instante $t_{s}=\frac{m^{2}}{2 b}$.

As características que emanam de $x_{r}=m$ são dadas por [Evans 1999, Haberman 1998]:

$$
x=m+[a-b C] t
$$

Logo, nesta região,

$$
C(x, t)=\frac{m-x+a t}{b t}
$$




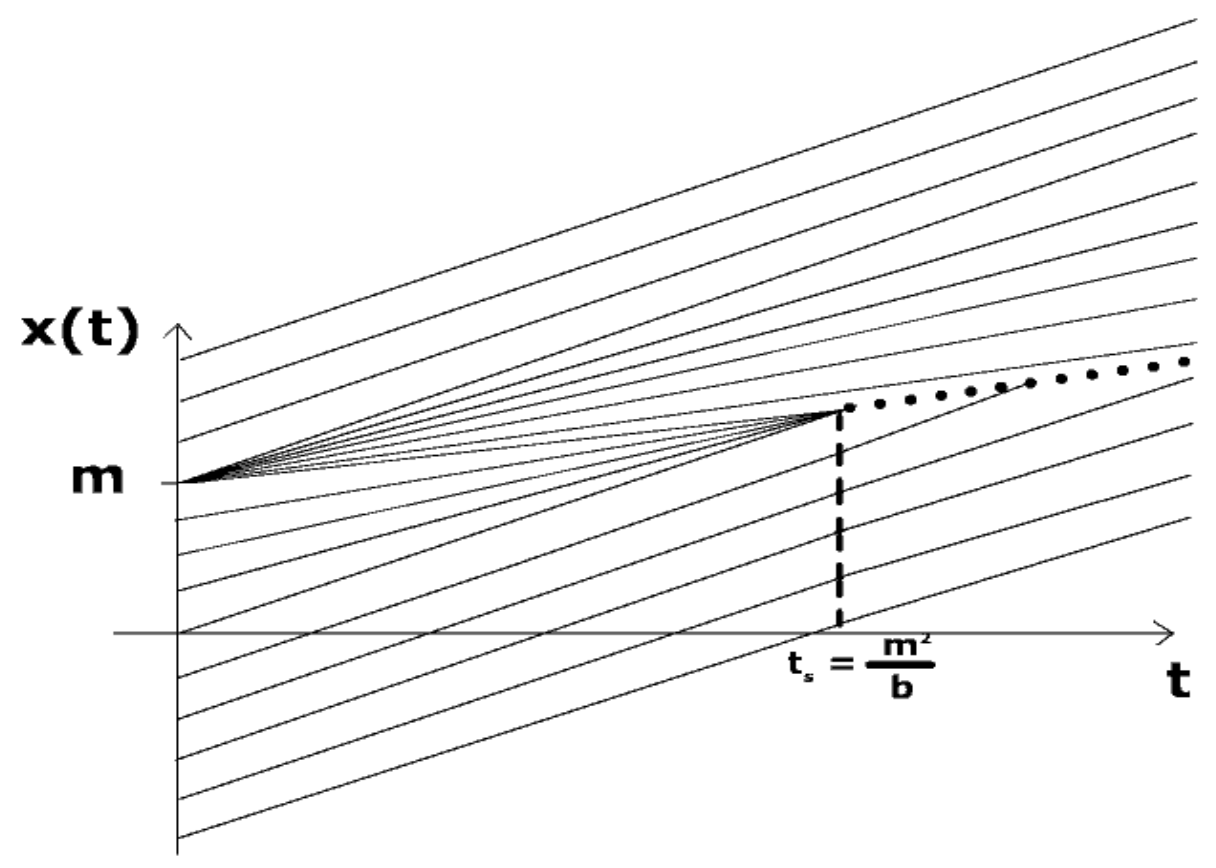

Figura 3.6. Curvas características da equação (3.16) para a condição inicial (3.39), com $(a-b n)>0, a>0$ e $b>0$. Uma região de rarefação, composta pelas curvas que emanam de $x_{r}=m$, que tem início no instante instante $t=0$, e um choque no instante $t_{s}=\frac{m^{2}}{2 b}$ em $x_{s}=\frac{a m^{2}}{b}$.

Ocorre choque quando a região de rarefação encontra a região das características que emanam de $0<x_{0}<m$, como indica a Figura (3.6), ou seja:

$$
0+a t_{s}=m+\left[a-\frac{b n}{m}(m)\right] t_{s}
$$

Daí,

$$
t_{s}=\frac{m}{b n}=\frac{m^{2}}{2 b}
$$

Como observado na Figura (3.6), $t_{s}$, o instante em que ocorre o segundo choque, e onde há uma mudança na solução, é proporcional ao quadrado da dispersão $m$ inicial da distribuição, e inversamente proporcional ao parâmetro $b(=4 \Gamma \alpha)$, como no caso do pulso retangular.

As implicações biológicas desta dependência são discutidas no capítulo Discussão. 
Este choque se dará em

$$
x_{s}\left(\frac{m}{b n}\right)=0+a\left(\frac{m}{b n}\right)=\frac{a m^{2}}{b}
$$

A onda de choque, se move de acordo com a curva que emana de $x_{s}=\frac{a m^{2}}{b}$. A velocidade de propagação do choque é dado pela condição de Rankine [Evans 1999, Haberman 1998] (ver Apêndice B).

$$
\begin{aligned}
& \frac{d x_{s}(t)}{d t}=\frac{F\left(C_{l}\right)-F\left(C_{r}\right)}{C_{l}-C_{r}} \\
& =\frac{a\left(\frac{a t-x_{s}(t)+m}{b t}\right)-\frac{b}{2}\left(\frac{a t-x_{s}(t)+m}{b t}\right)^{2}-0}{\frac{a t-x_{s}(t)+m}{b t}-0}=a-\frac{b}{2}\left(\frac{a t-x_{s}(t)+m}{b t}\right)
\end{aligned}
$$

$$
\therefore x_{s}(t)=a t-\sqrt{b t}+m
$$

Onde $F(C)$ é a função definida em (3.18), $C_{l}=\frac{a t-x_{s}(t)+m}{b t}$ e $C_{r}=0$ são os valores que $C(x, t)$ assume nas regiões de rarefação (definida pelas curvas que emanam de $x_{0}=m$ ), e das curvas características que emanam de $x_{0} \leq 0$, respectivamente.

A curva $x_{s}(t)$ está representada na Figura (3.6) pela linha pontilhada.

A solução da equação (3.48) para $x_{s}(t)$ é analoga à apresentada para a equação (3.33), com a condição inicial (3.47) [Apêndice C]. Trata-se de um polinômio de mesmo grau em $t$ que aparece na função $x_{2 s}(t)$, o segundo choque das características referentes à condição inicial (3.22). 
Podemos então escrever a solução para $C(x, t)=C\left(x_{0}(x, t), 0\right)$, voltando nas condições iniciais, através das características.

A solução é composta pelas soluções nos dois intervalos: antes e depois do choque.

Para $t<t_{s}$ :

$$
C(x, t)=\left\{\begin{array}{l}
0, \quad x \leq a t \\
{\left[\frac{x-a t}{\left.1-\frac{n b t}{m}\right]} \frac{n}{m}, \quad a t<x \leq m+[a-b n] t\right.} \\
\frac{m-x+a t}{b t}, \quad m+[a-b n] t<x+a t \\
0, \quad x>m+a t
\end{array}\right.
$$

Para $t>t_{s}$ :

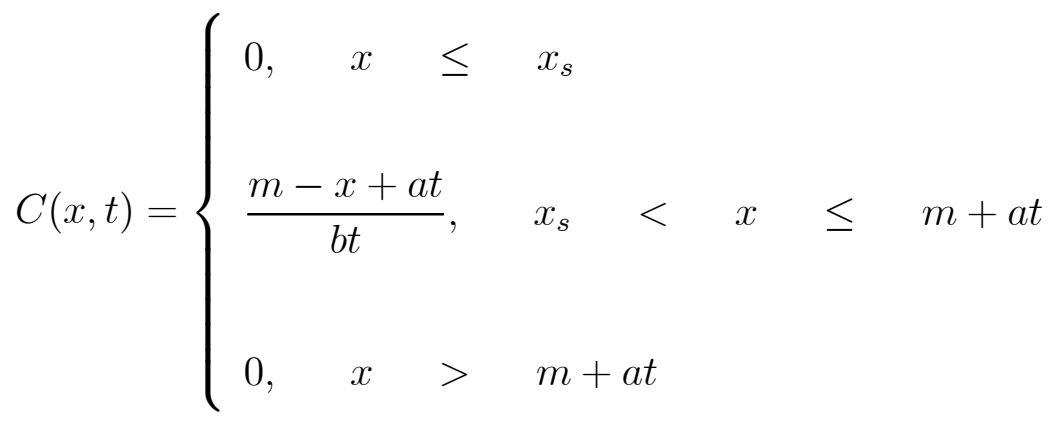

O perfil da solução acima para $C(x, t)$ pode ser representado como na Figura (3.7), para diferentes instantes de tempo. 


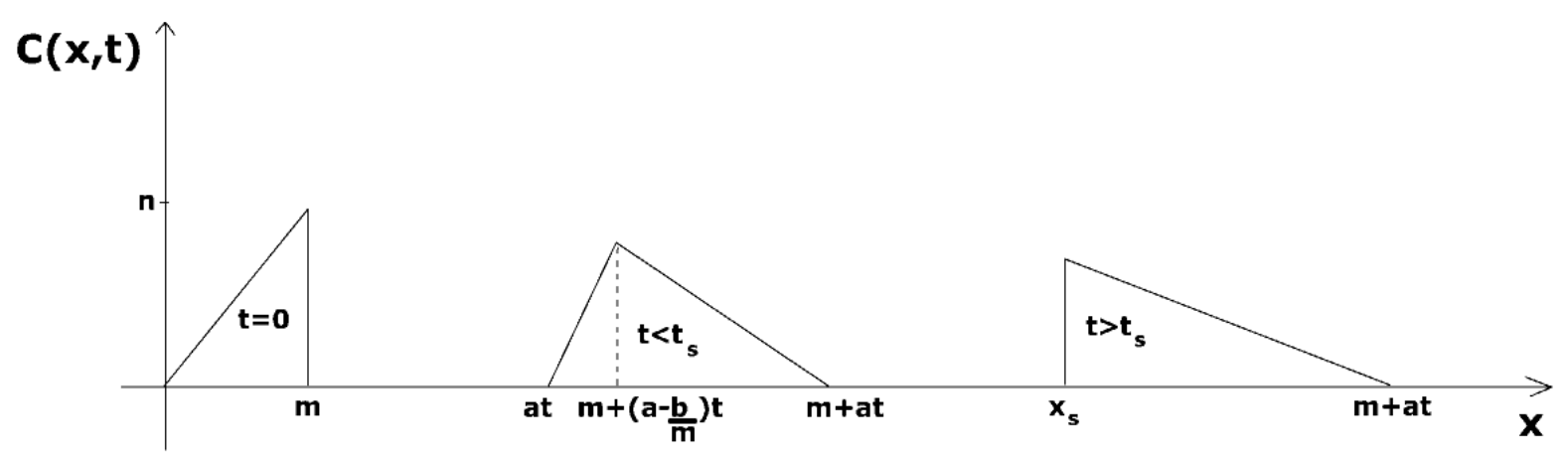

Figura 3.7. Perfil da evolução temporal de $C(x, t)$ mostrado em diferentes instantes de tempo. (a) instante inicial $t=0$; (b) instante anterior ao segundo choque $0<t<t_{s}$; a região de rarefação da distribuição tem início em $x(t)=$ $m+\left(a-\frac{b}{m}\right) t ;(\mathrm{c})$ instante posterior ao segundo choque.

Conservação.

A equação é de conservação, logo devemos ter:

$$
\frac{\partial}{\partial t} \int C(x, t) d x=0
$$

Se integrarmos a nossa solução em $x$, devemos ter um resultado independente do tempo. Isto deve valer para antes e depois do choque.

Para $t<t_{s}$ :

$$
\text { (3.53) } \begin{aligned}
N_{1} & =\int_{-\infty}^{+\infty} C(x, t) d x=\int_{a t}^{m+[a-b n] t}\left[\frac{x-a t}{1-\frac{n b t}{m}}\right] \frac{n}{m} d x+\int_{m+[a-b n] t}^{m+a t}\left[\frac{m-x+a t}{b t}\right] d x \\
& =\frac{m n}{2}=1, \quad \forall t
\end{aligned}
$$

Para $t>t_{s}$ : 


$$
\begin{aligned}
N_{2} & =\int_{-\infty}^{+\infty} C(x, t) d x=\int_{x_{s}}^{m+a t}\left[\frac{m-x+a t}{b t}\right] d x \\
& =\frac{m n}{2}=1, \quad \forall t
\end{aligned}
$$

O que mostra que as soluções permanecem normalizadas no tempo, como esperado.

O fato das soluções serem formadas literalmente por duas funções distintas para diferentes instantes de tempo remete ao experimento de maneira especial, visto que em diversos artigos foi comentado esta peculiaridade do comportamento da população de vírus, que se reflete em sua taxa de replicação [Tsimring 1996, Aafif 1998, Novella 1995a].

Este tipo de solução parece ser ímpar dentre os trabalhos teóricos [Tsimring 1996, Aafif 1998] que visam descrever o experimento [Novella 1995a]. 


\subsubsection{Médias do fenótipo $x$ da população e taxa de replicação.}

De acordo com a nossa proposta, a média do fenótipo da população é obtida através de

$$
<x>(t)=\int x C(x, t) d x
$$

onde para $C(x, t)$ utilizamos as soluções obtidas para cada uma das condições iniciais escolhidas.

A taxa de replicação média estará associada à derivada temporal:

$$
r(t)=\frac{d}{d t}<x>(t)
$$

3.2.2.1. Médias do fitness $x$ da população e taxa de replicação para a condição inicial pulso retangular (3.22).

Para $t<t_{2 s}$ :

fenótipo médio:

$$
\begin{aligned}
< & x_{1}>(t)=\int_{-\infty}^{+\infty} x C(x, t) d x \\
= & \int_{\Delta+\left[a-\frac{b n}{2}\right] t}^{\Delta+m+[a-b n] t} x[n] d x+\int_{\Delta+m+[a-b n] t}^{\Delta+m+a t} x\left[\frac{\Delta+m-x+a t}{b t}\right] d x \\
= & \Delta+\frac{m}{2}+a t+\frac{t^{2} b^{2}}{24 m^{3}}-\frac{t b}{2 m}
\end{aligned}
$$

Taxa de replicação:

$$
r_{1}(t)=\frac{\partial}{\partial t}<x_{1}>(t)=a-\frac{b}{2 m}+\frac{b^{2}}{12 m^{3}} t
$$


Para $t>t_{2 s}$ :

fenótipo médio:

$$
\begin{aligned}
& <x_{2}>(t)=\int_{-\infty}^{+\infty} x C(x, t) d x \\
& =\int_{x_{2 s}}^{\Delta+m+a t} x\left[\frac{\Delta+m-x+a t}{b t}\right] d x \\
& =a t-\frac{2 \sqrt{2 b t}}{3}+\Delta+m
\end{aligned}
$$

Taxa de replicação:

$$
r_{2}(t)=\frac{\partial}{\partial t}<x_{2}>(t)=a-\frac{\sqrt{2 b}}{3} \frac{1}{\sqrt{t}}
$$

Neste caso, a taxa de replicação possui inicialmente um comportamento linear no tempo (equação (3.58)), seguido por uma segunda parte, após o choque, em que a taxa aumenta, tendendo a uma constante igual a $a$, através de um polinômio em $t^{-\frac{1}{2}}$ (equação (3.60)) como indica a Figura (3.8). 


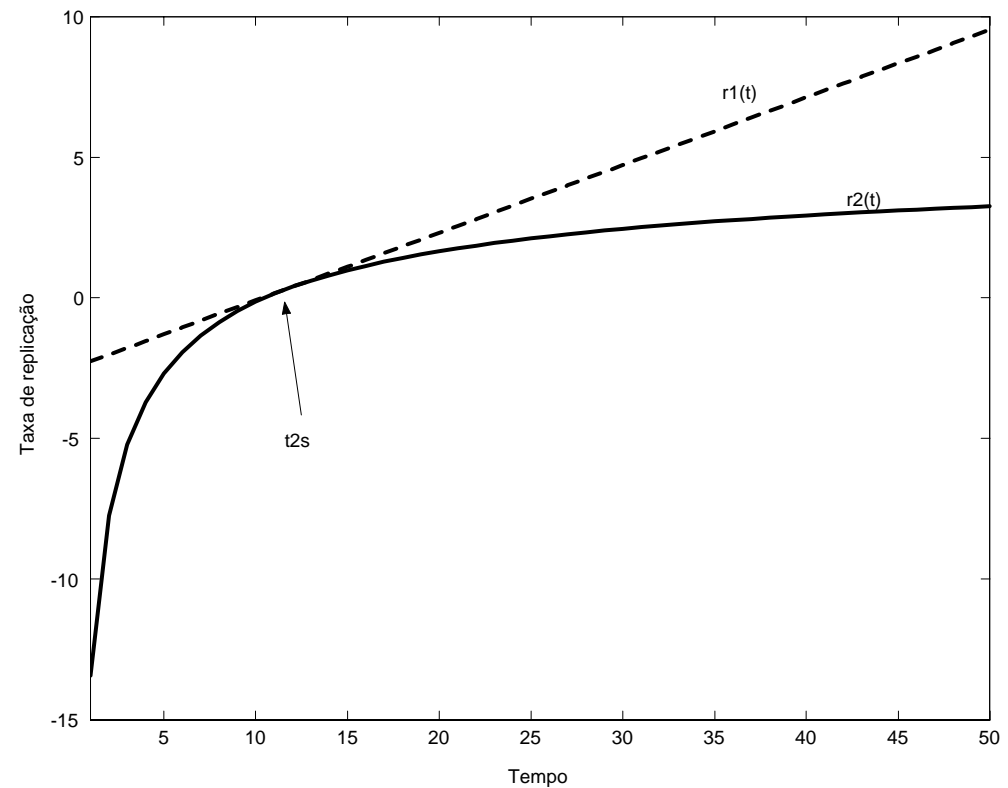

Figura 3.8. Comportamento das taxas de replicação $r_{1}(t)$ (curva tracejada) e $r_{2}(t)$ (curva contínua), referente à condição inicial (3.22) com $a=6, b=17$, $m=1$. 
3.2.2.2. Médias Temporais e derivadas (Fitness) para a condição inicial pulso triangular (3.39).

Para $t<t_{s}$ :

fenótipo médio:

$(3.61) x_{1}>(t)=\int_{-\infty}^{+\infty} x C(x, t) d x=\int_{a t}^{m+[a-b n] t} x \frac{n}{m}\left[\frac{x-a t}{1-\frac{n b t}{m}}\right] d x+\int_{m+[a-b n] t}^{m+a t} x\left[\frac{m-x+a t}{b t}\right] d x$ $=m+\left(a-\frac{b}{3 m}\right) t$

Taxa de replicação:

$$
r_{1}(t)=\frac{\partial}{\partial t}<x_{1}>(t)=a-\frac{b}{3 m}
$$

Para $t>t_{s}$ :

fenótipo médio:

$$
\begin{aligned}
& <x_{2}>(t)=\int_{-\infty}^{+\infty} x C(x, t) d x=\int_{x_{2 s}}^{\Delta+m+a t} x\left[\frac{m-x+a t}{b t}\right] d x \\
& =a t-\frac{2 \sqrt{2 b t}}{3}+m
\end{aligned}
$$

Taxa de replicação:

$$
r_{2}(t)=\frac{\partial}{\partial t}<x_{2}>(t)=a-\frac{\sqrt{2 b}}{3} \frac{1}{\sqrt{t}}
$$


Neste caso a taxa de replicação possui um comportamento inicialmente constante no tempo (equação (3.62)), seguido por uma segunda parte após o choque, em que a taxa aumenta, tendendo a uma constante $a$, através de um polinômio em $t^{-\frac{1}{2}}$.

Para as duas condições iniciais (3.22) e (3.39), encontramos soluções $C(x, t)$ que são constituídas de duas funções, definidas para intervalos de tempo distintos.

A grande diferença que ocorre entre estas é a dependência temporal obtida para a média e portanto para a taxa de replicação na primeira parte da solução $\left(r_{1}(t)\right)$. No caso da condição inicial (3.22) temos uma função linear no tempo, e no caso da condição inicial (3.39) temos uma função constante no tempo. 


\subsubsection{Solução numérica.}

A solução analítica, para outras escolhas de condições iniciais, levam a equações transcedentais quando na solução da equação (3.10) pelo método das características, o que nos leva a buscar soluções numéricas.

A equação (3.6) pode ser iterada numericamente para qualquer condição inicial $C(k, 0)$ pré-definida.

Para isso, foi criado um programa em linguagem C, capaz de gerar diversos tipos de condições iniciais discretas $C_{0}(k)$ para as concentrações de indivíduos com fenótipo $k$, que são armazenados em vetores.

A partir deste vetor inicial, o programa constrói uma matriz contendo todos vetores gerados subseqüentemente, ao longo de $i$ iterações, para diferentes valores dos parâmetros $\alpha$ e $P$, como indica a Figura (3.9), através da equação de evolução (3.6).

As condições de contorno são absorventes, o que significa que não há conservação quando a distribuição $C_{i}(k)$ atinge os limites da matriz, o que portanto deve ser evitado.

Não é possível a escolha de condições periódicas de contorno pois estamos interessados na média da distribuição, e este tipo de condição leva a resultados incompatíveis, dado que as substituições de indivíduos entre as sub-populações se dá apenas entre vizinhos próximos.

A questão da conservação da população é ilustrada na Figura (3.10), em que o número $N$ de indivíduos é ilustrado junto com a evolução da distribuição $C_{i}(k)$, que no caso não é conservada pois "encosta"nos limites da matriz.

Em seguida, o programa cria um vetor que contém as médias mediak $(i)$ da distribuição $C_{i}(k)$ em cada iteração $i$, e depois a derivada desta curva, definida por:

$$
r(i)=\frac{[\operatorname{mediak}(i+1)-\operatorname{mediak}[i-1])]}{2}
$$

Onde:

$r(i)$, derivada da media espacial de $C_{i}(k)$ em uma determinada iteração $i$, 


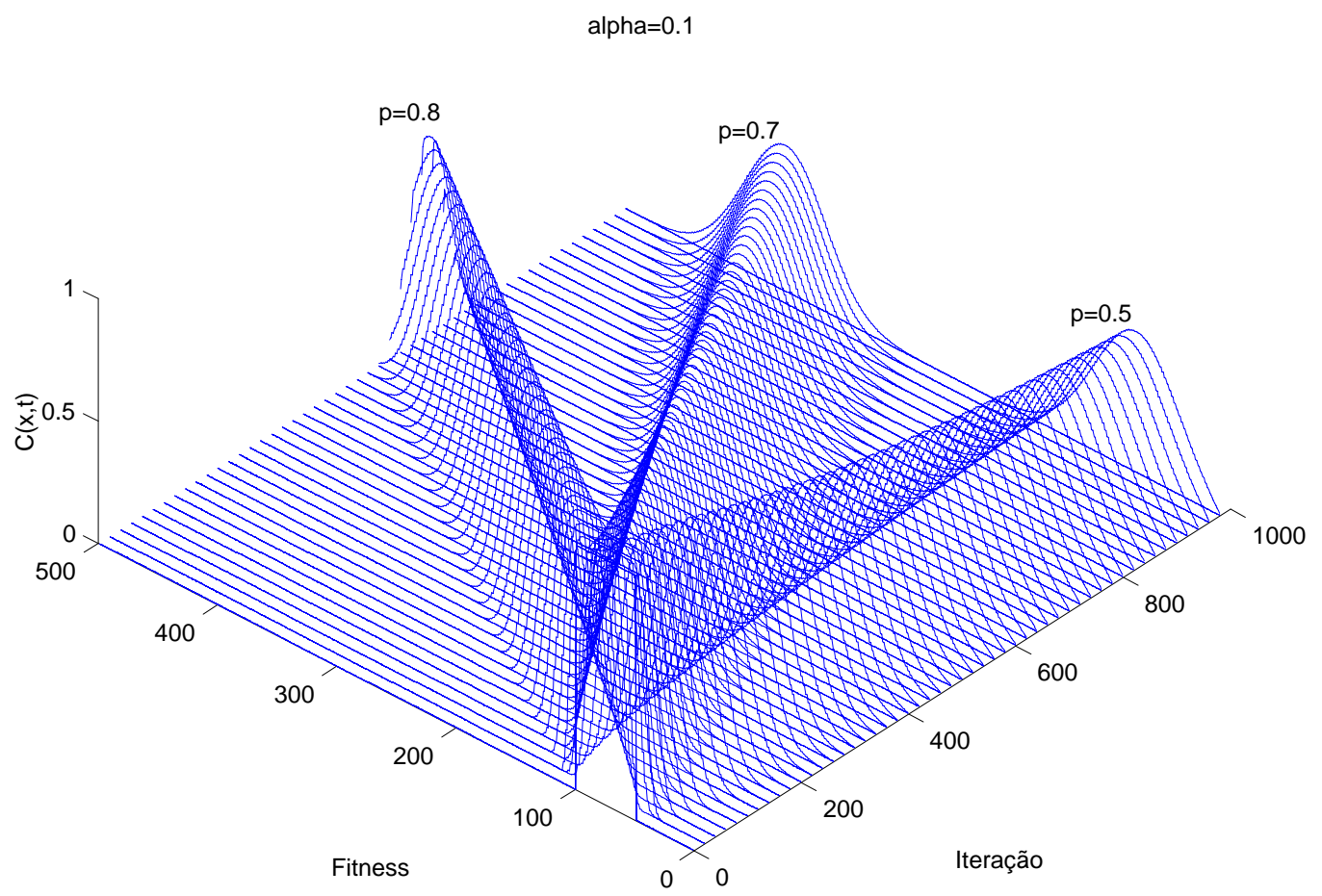

Figura 3.9. Comportamento de três distribuições $C_{0}(k)$ para diferentes valores do parâmetro $P$, através das iterações do programa, para uma mesma condição inicial pulso retangular indicado.

mediak(i), valor médio de fenótipo $k$ referente à uma determinada iteração $i$.

$$
\operatorname{mediak}(i)=\frac{\sum_{k} k C_{i}(k)}{\sum_{k} C_{i}(k)}
$$

As Figuras (3.11) e (3.12) mostram alguns exemplos de médias mediak(i) e da taxa de replicação $r(i)$, tal como obtido numericamente, para a condição inicial ilustrada na figura $(3.9)$.

A dependência das médias dos fenótipos $k$ e das taxas de replicação $r(i)$ em relação à condição inicial e aos parâmetros $P$ e $\alpha$, obtidas por este método serão discutidas no próximo capítulo. 


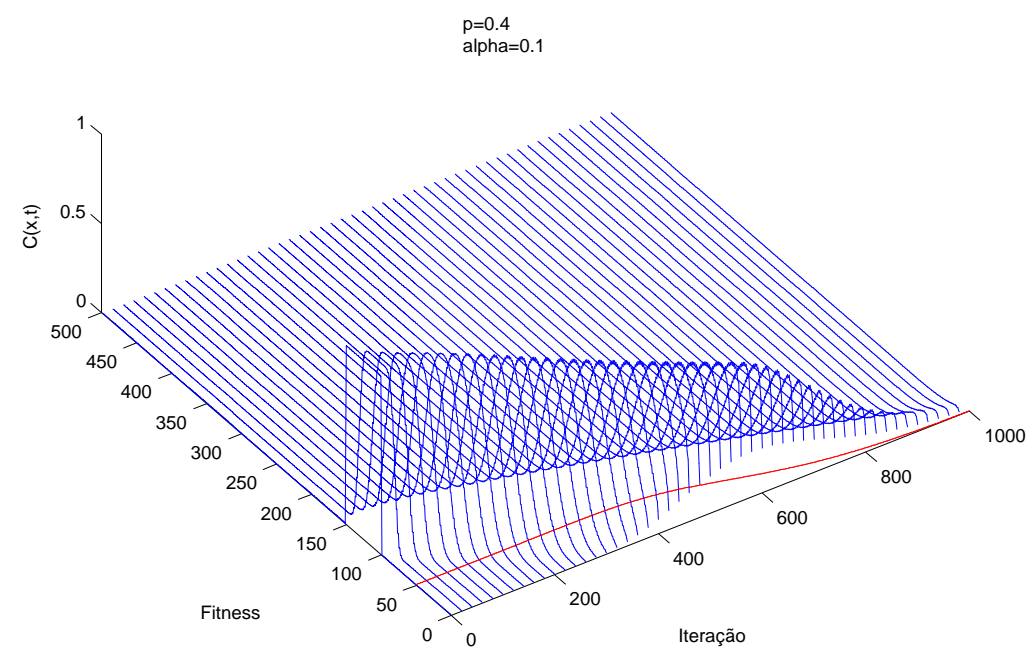

Figura 3.10. A conservação da população só se dá quando a distribuição $C_{i}(k)$ não atinge os limites da matriz, uma vez que utilizamos condições de contorno absorventes. A linha vermelha indica o número de indivíduos, que começa a decrescer a partir da iteração 400, quando a distribuição $C_{i}(k)$ "encosta"os limítes da matriz. 


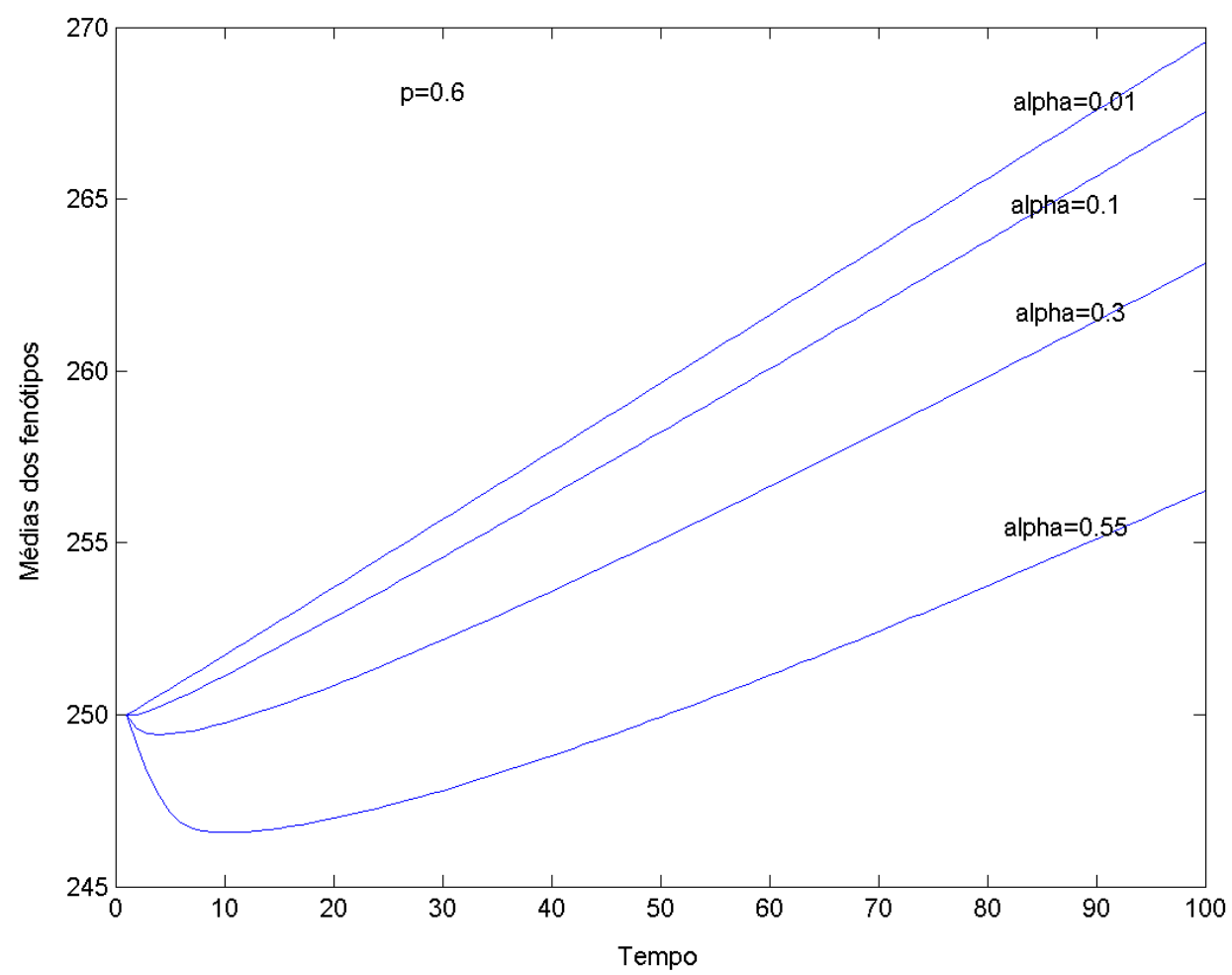

FigurA 3.11. Médias dos fenótipos $k$ obtidas numericamente para a equação ( 3.6), para uma condição inicial delta de kronecker $C_{0}(k)=\delta_{k, 250}$. 


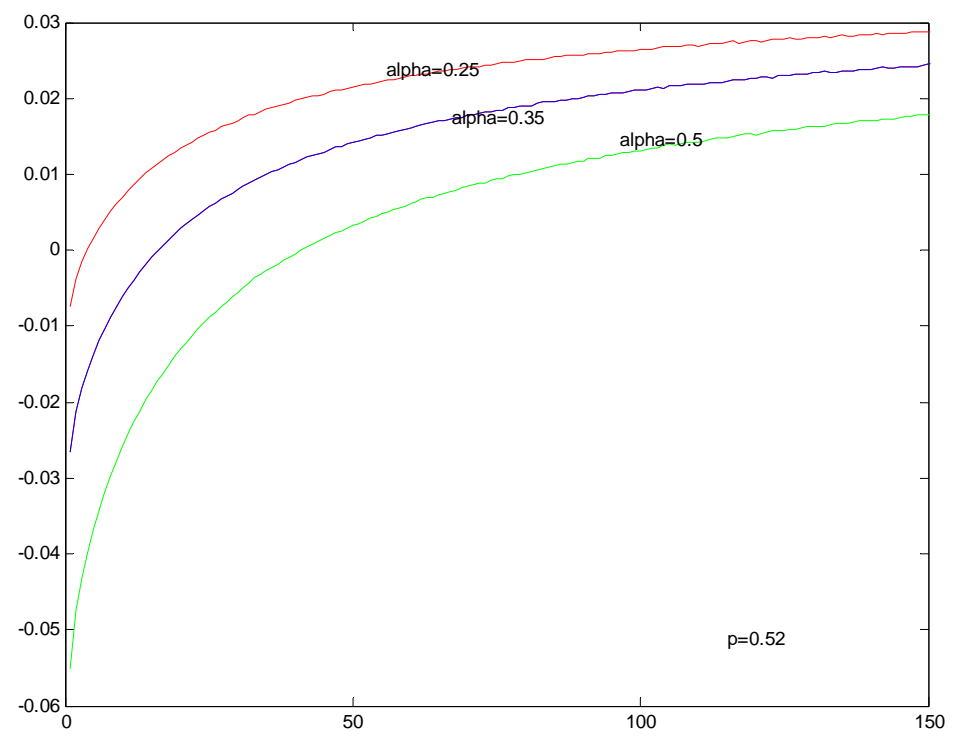

Figura 3.12. Taxas de replicação obtidas numericamente para a equação ( 3.6), para uma condição inicial delta de kronecker $C_{0}(k)=\delta_{k, 250}$. 



\section{CAPíTULO 4}

\section{Discussão dos resultados}

No capítulo 3 introduzimos nosso modelo para o processo evolutivo ao qual populações de vírus foram submetidas no experimento descrito no capítulo 2.

Derivamos expressões analíticas e obtivemos resultados numéricos para a evolução da distribuição $C(x, t)$ de indivíduos com fenótipo $x$, presentes na população no instante $t$, além da média,

$$
<x>(t)=\int x C(x, t) d x
$$

bem como sua derivada temporal,

$$
r(t)=\frac{d}{d t}<x>(t)
$$

identificada por nós como a taxa de replicação da população de vírus.

Neste capítulo mostramos alguns gráficos que ilustram o comportamento do fenótipo médio $\langle x\rangle(t)$ e da taxa de replicação $r(t)$ da população de vírus, equações (4.1) e (4.2), respectivamente, para a condição inicial (3.22), através da variação dos parâmetros $\alpha, P$ (ou, equivalentemente, $a=\Gamma(2 P-1)$ e $b=4 \Gamma \alpha$, nos resultados analíticos $)$ e $m$, assim como uma discussão sobre o significado biológico destes parâmetros.

Mostraremos também os resultados da iteração numérica da equação (3.6) para diferentes condições iniciais, bem como o ajuste de nossos resultados analíticos pelos dados experimentais. 


\subsection{Soluções Analíticas}

Lembramos que a solução $C(x, t)$ da equação (3.10), referente à condição inicial (3.22), apresenta comportamento temporal distinto em diferentes intervalos de tempo. O primeiro se manifesta antes da ocorrência do segundo choque das características e o segundo logo após o choque, como visto no capítulo 3.

Decorre disto funções distintas para as taxas de replicação $\left(r_{1}(t)\right.$ e $r_{2}(t)$, respectivamente), nestes dois regimes diferentes.

Em todos os resultados apresentados, levamos em consideração a normalização de $C(x, t)$ (vide $(3.22))$ :

$$
m n=1
$$

As funções $r_{1}(t)$ e $r_{2}(t)$, decorrentes da solução de (3.10) para a condição inicial (3.22), são dadas por:

$$
r_{1}(t)=\frac{\partial}{\partial t}<x_{1}>(t)=a-\frac{b}{2 m}+\frac{b^{2}}{12 m^{3}} t
$$

para $t<t_{2 s}=\frac{2 m^{2}}{b}, \mathrm{e}$

$$
r_{2}(t)=\frac{\partial}{\partial t}<x_{2}>(t)=a-\frac{\sqrt{2 b}}{3} \frac{1}{\sqrt{t}}
$$

para $t>t_{2 s}$.

Portanto, a taxa de replicação relativa passa por duas fases de evolução: a primeira linear no tempo, e a segunda que varia com $\frac{1}{\sqrt{t}}$.

Esta mudança de comportamento na taxa de replicação pode ser entendida como sendo devida ao choque que ocorre entre a frente de onda decorrente do primeiro choque e a família de curvas características que emana de $\Delta+m$ (região de rarefação, vide Figura (3.3). 


\subsubsection{A mudança de regime na solução $C(x, t)$.}

Vimos, na solução analítica de (3.10) para a condição inicial (3.22), que a mudança na solução de $C(x, t)$, devida ao segundo choque entre as curvas características, ocorre no instante

$$
t_{2 s}=\frac{2 m^{2}}{b}
$$

Portanto $t_{2 s}$ é proporcional ao quadrado da dispersão inicial da distribuição, e inversamente proporcional ao parâmetro $b(=4 \Gamma \alpha)$.

Isto sugere que a dispersão inicial da distribuição (uma medida da diversidade inicial da população) seja uma característica importante na variação do fenótipo médio e da taxa de replicação da população: quanto maior a dispersão inicial, mais tempo a população permanecerá no regime em que a taxa de replicação aumenta linearmente com o tempo (equação (4.3)), e portanto alcançará o limite assintótico da taxa de replicação $r(t)$ mais rapidamente (vide Figura (4.6)). 


\subsubsection{Gráficos.}

Para ilustrar o comportamento dos nossos resultados apresentamos a seguir gráficos para a média do fenótipo $\langle x>(t)$, e da taxa de replicação $r(t)$ referente à condição inicial (3.22).

Lembramos que devemos compor a solução final em termos das soluções em cada uma das regiões, pré e pós-choque, ou seja, para antes e depois de $t_{2 s}$, que são dadas por $r_{1}(t)$ (eq. (4.3)) e $r_{2}(t)$ (eq. (4.4), e que dependem de três parâmetros livres: $a, b$ e $m$.

\subsubsection{O parâmetro a.}

Primeiramente, mantendo $b$ e $m$ constantes, vemos, na Figura (4.1), a variação da média $<x>(t)$ do fenótipo da população para diferentes valores arbitrários do parâmetro $a$.

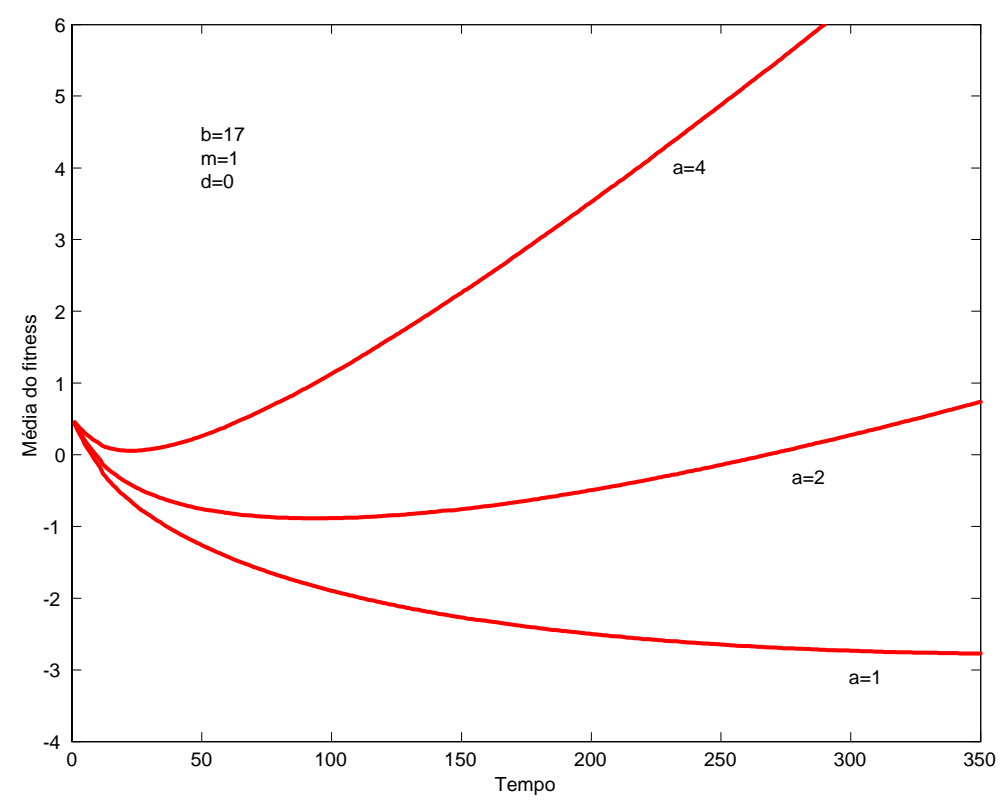

Figura 4.1. Diferentes comportamentos da média $\langle x\rangle(t)$ variando o parâmetro $a=\Gamma(2 P-1)$.

Ainda mantendo $b$ e $m$ constantes, vemos, na Figura (4.2), a variação da taxa de replicação para diferentes valores do parâmetro $a$.

No limite assintótico $(t \rightarrow \infty)$, a população possui taxa de replicação constante $r(\infty)=a$, o que corresponde a um processo de replicação malthuseano. Isto é devido ao comportamento $<x>(t) \sim a t$ neste regime. 


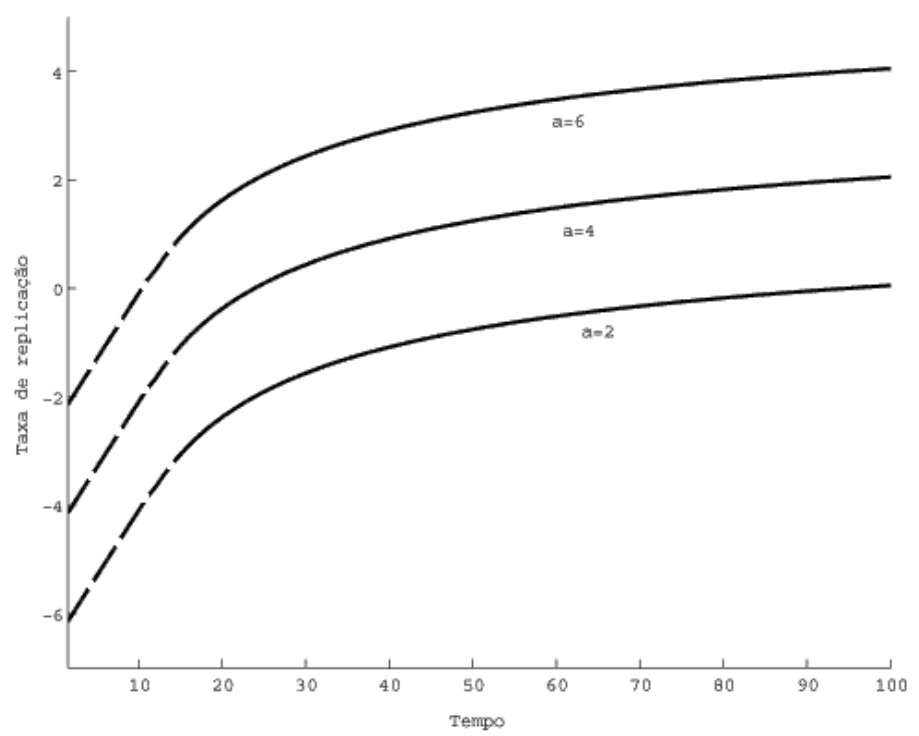

Figura 4.2. Diferentes comportamentos da taxa de replicação $r(t)$ variando o parâmetro $a=\Gamma(2 P-1)$, com $m=1$ e $b=17 . r_{1}(t)$ é representada pela curva tracejada e $r_{2}(t)$ é representada pela curva contínua.

O comportamento assintótico da taxa de replicação da população de vírus foi considerada alvo de discussão durante algum tempo tanto pelos experimentais (entre eles Isabel Novella (1995a e 1999), Santiago Elena e John Holland (1991)), quanto por teóricos (Tsimring 1996, Aafif 1998). Aparentemente, somente no trabalho de Aafif (1998) a existência de um limite assintótico para a taxa de replicação foi previsto e no trabalho de Novella (1999) foi confirmado experimentalmente.

A existência de diferentes valores para a taxa de replicação no limite assintótico, observada nas diferentes réplicas de populações produzidas no experimento de Novella (1999) (Figura (4.3)), são devidos, segundo Isabel Novella (2003), ao processo de bottlenecking (descrito no capítulo 2), que seleciona diferentes tipos de populações de vírus, também chamados de diferentes fenótipos.

Segundo Novella, devido às diferentes mutações que estas populações sofreram durante o processo de bottlenecking, os diferentes fenótipos selecionados muitas vezes não conseguem, através da variação de seus genótipos, fazer o "caminho inverso", ou seja, obter, através das passagens evolutivas, mutações que levem exatamente ao estado (taxa de replicação) que a 

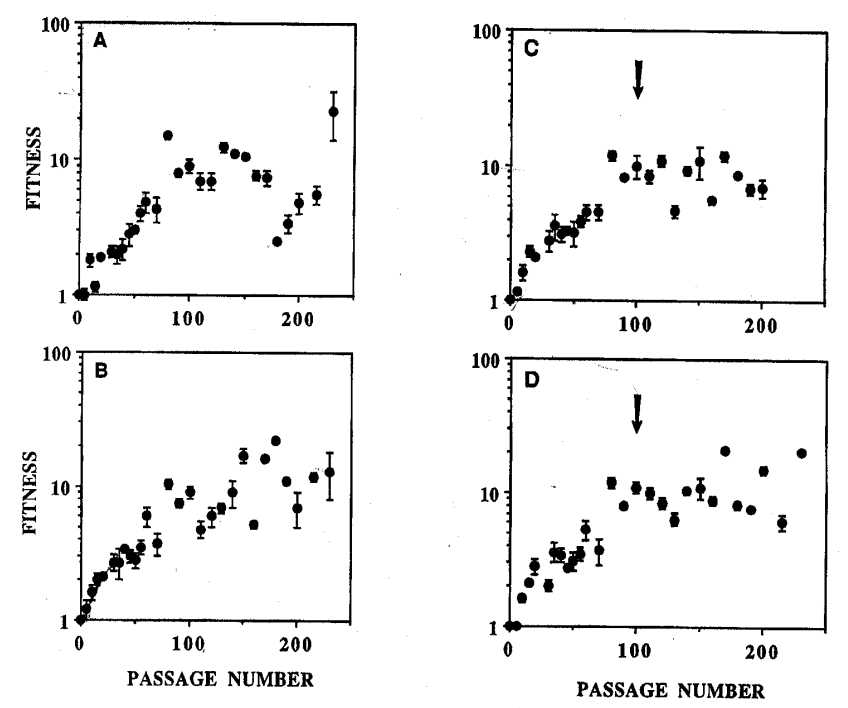

Figura 4.3. Diferentes réplicas do experimento, com diferentes limites assintóticos, presentes em Novella 1999.

população se encontrava antes de ter sofrido bottlenecking, mas percorre outro "caminho", que leva à diferentes limites para taxas de replicação.

É interessante notar que, segundo nossos resultados, neste limite assintótico, a população, descrita por seu fenótipo, continua se transformando, aumentando sua diversidade, como veremos adiante. Porém, a taxa de replicação média permanece constante. 


\subsubsection{O parâmetro b.}

Pela maneira com que o modelo foi concebido, o parâmetro $b(=4 \Gamma \alpha)$ atua apenas na limitação do crescimento relativo de uma sub-população com determinado fenótipo $x$, o que pode levar a uma interpretação deste como sendo relacionado com a virulência dos indivíduos, como discutiremos a seguir.

Mantendo $a$ e $m$ constantes, vemos, na Figura (4.4), a variação da taxa de replicação para diferentes valores do parâmetro $b$.

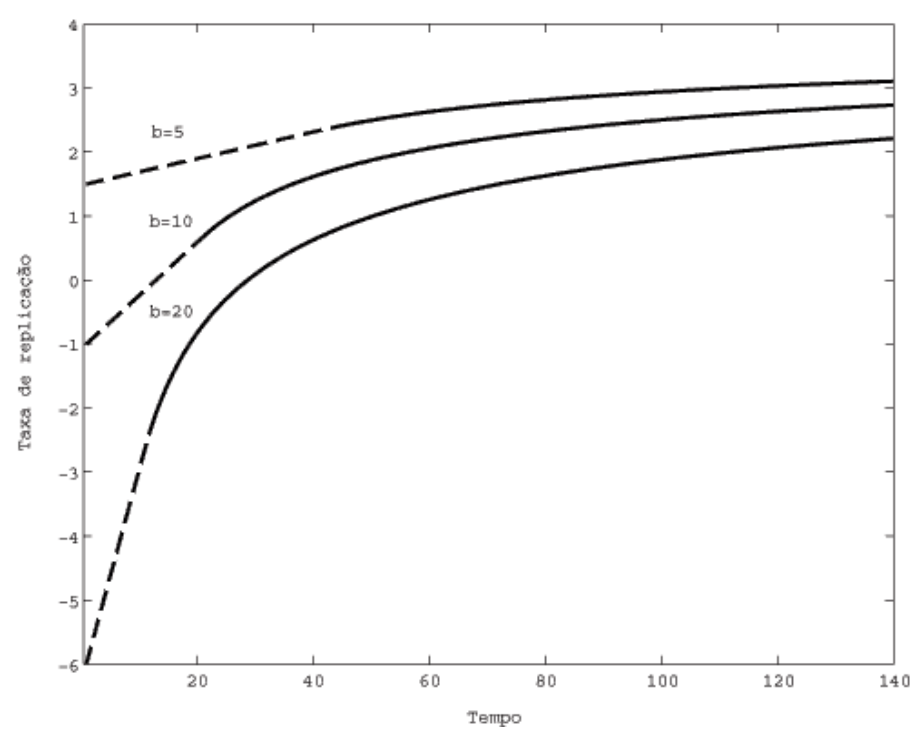

FigurA 4.4. Diferentes comportamentos da taxa de replicação $r(t)$ variando o parâmetro $b=4 \Gamma \alpha$, com $m=1$ e $a=4 . r_{1}(t)$ é representada pela curva tracejada e $r_{2}(t)$ é representada pela curva contínua.

Nesta situação, notamos que o parâmetro $b$ influi principalmente na velocidade com que a população alcança o limite assintótico, porém não no limite assintótico em sí, como pode ser observado na Figura (4.4) tomando $t \rightarrow \infty$.

Isto porque $t_{2 s}$ é inversamente proporcional à $b$, o que significa que quanto menor este parâmetro, mais tempo a população permanecerá numa fase evolutiva em que o ganho na taxa de replicação é mais acentuado (varia linearmente com o tempo), o que significa uma vantagem evolutiva, caso duas populações, uma mais e outra menos "virulenta", estejam competindo para se fixar em um mesmo ambiente: num mesmo instante, aquela que possui 
menor $b$ (ou, equivalentemente, menor $\alpha$ ) aumenta sua taxa de replicação mais rapiamente, embora o limite assintótico não dependa deste parâmetro.

Isto se deve ao fato de $b$, sendo responsável pela não-linearidade da equação (3.10), molda a forma da distribuição da população durante o processo evolutivo, como veremos a seguir na discussão sobre a dispersão de $x$.

A figura (4.5) resume duas réplicas de experimentos presentes em [novella 1995a], cujo comportamento é qualitativamente compatível com os resultados ilustrados na figura (4.4).

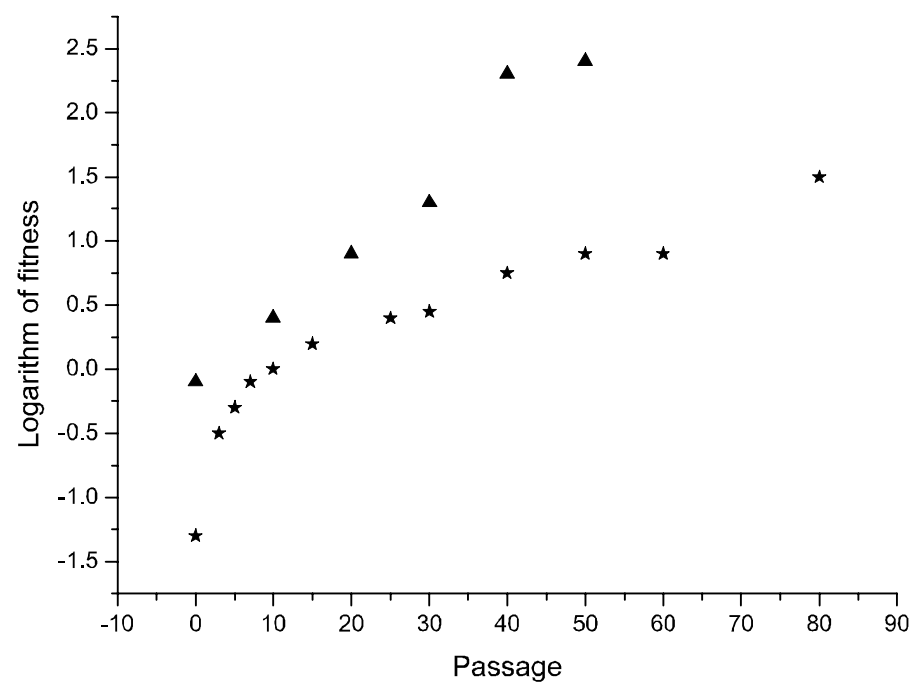

FigurA 4.5. Dados experimentais para a evolução da taxa de replicação publicados em [Novella 1995a]. MARM clones C( $\mathbf{\Delta})$ e MARM D $(\star)$. 


\section{Possível relação do parâmetro $\alpha$ com a virulência.}

Virulência é um conceito que não foge da regra dos conceitos em biologia: admite diversas definições. Em geral, cada autor delimita um sentido para o conceito, aquele que se adapta à discussão ou ao caminho do raciocínio que ele quer desenvolver [Bull 1994].

Normalmente, a virulência é definida como a capacidade que um determinado parasita tem de causar a morte, ou danos ao hospedeiro, quando numa infecção.

Em geral, os trabalhos que utilizam este conceito concordam com a idéia de que virulência é um fator que impede o aumento do fenótipo de um determinado indivíduo ou população. Além disso, a virulência de uma determinada população ou indivíduo é uma grandeza que depende da interação parasita-hospedeiro.

Em nosso modelo fazemos uma hipótese simplificada de que o parâmetro $\alpha$, que regula o termo logístico, é o mesmo para todas sub-populações com fenótipo $x$, uma vez que escolhemos $\alpha$ constante.

Em vista disto, podemos sugerir que o parâmetro $\alpha$ esteja relacionado com a virulência dos indivíduos da quasi-espécie, bastando para isso duas hipóteses "biológicas".

A primeira, é a de que o hospedeiro possui uma quantidade limitada de anti-corpos. A segunda, de que estes anti-corpos são específicos para cada diferente sub-população com fenótipo $x$.

Estas duas hipóteses sugerem um mecanismo de seleção de grupo, onde o aumento relativo de uma determinada sub-população é balanceado (sofre um trade-off) com o aumento da diversidade (dispersão) da população.

Isto porque se um hospedeiro possui uma quantidade limitada de anti-corpos, é possível que talvez ele não suporte um certo número de parasitas, se estes forem todos de mesma sub-população com determinado fenótipo $x$, porém poderá suportar o mesmo número de parasitas, se estes forem de diferentes sub-populações. Portanto, para a população de vírus, pode-se dizer que o aumento da diversidade seria uma estratégia evolutiva.

O aumento da diversidade da população e sua relação com o parâmetro $\alpha$ é observado em nossos resultados, como veremos adiante. 
Já a dependência de $t_{2 s}$ com o parâmetro $b$ está de acordo com sua interpretação sugerida aqui tendo relação com a virulência, ou seja, a relação de interação danosa parasitahospedeiro, como veremos adiante. 


\subsubsection{O parâmetro $m$.}

Mantendo $a$ e $b$ constantes, vemos, na Figura (4.6), a variação da taxa de replicação para diferentes valores do parâmetro $m$.

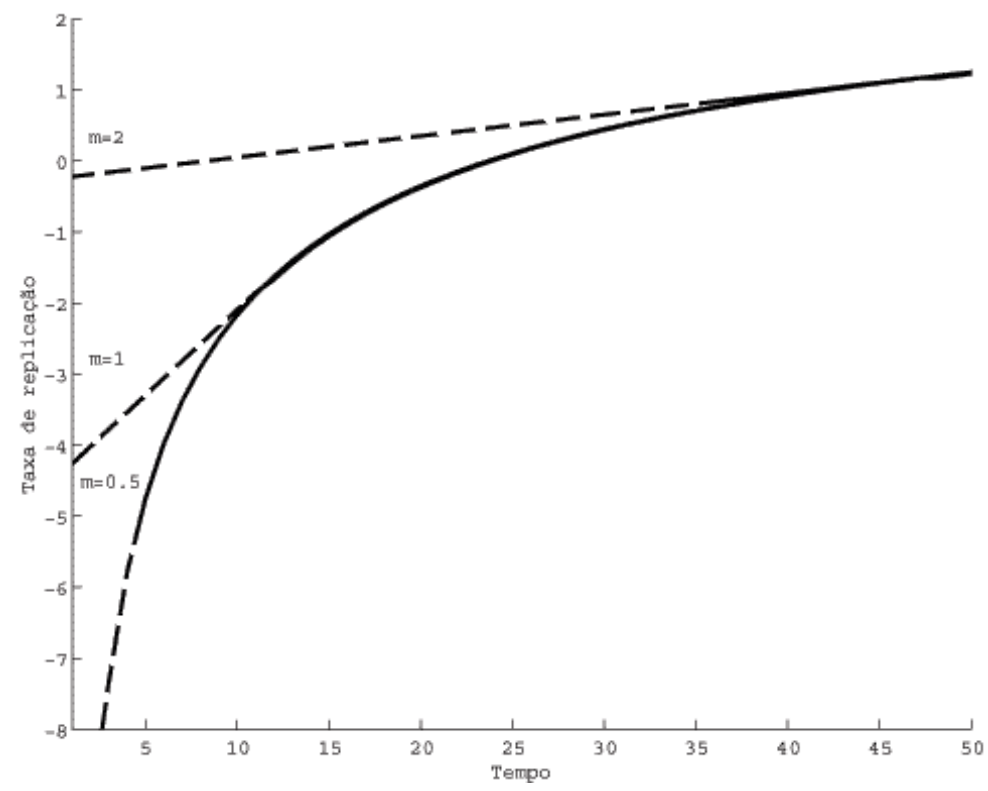

FigurA 4.6. Diferentes comportamentos da taxa de replicação $r(t)$ variando o parâmetro $m$, com $a=4$ e $b=17 . r_{1}(t)$ é representada pela curva tracejada e $r_{2}(t)$ é representada pela curva contínua.

O parâmetro $m$ é diretamente proporcional à dispersão inicial da distribuição $C(x, 0)$ da população de vírus. Este parâmetro pode ser interpretado como sendo a diversidade da população, descrita por suas sub-populações com fenótipo $x$.

Observamos, através da Figura (4.6), que uma maior dispersão $m$ na distribuição inicial $C(x, t)$ afeta o comportamento inicial da taxa de replicação $r_{1}(t)$ (quando $t<t_{2 s}$ ), bem como o instante $t_{2 s}$ em que ocorre o segundo choque.

O parâmetro $m$ não participa de $r_{2}(t)$ (eq. (4.4)), o que significa que, depois do segundo choque (ou, quando $t>t_{2 s}$ ), $m$ não influi mais na taxa de replicação. Neste instante, a distribuição $C(x, t)$ assume o perfil (triangular) em que irá permanecer, apenas aumentando sua variância, como veremos adiante, vide Figura (3.4). 
Em seu trabalho de 2003, Isabel Novella (Novella 2003) comenta que populações que foram sujeitas à bottlenecking (discutido no capítulo 2) adquirem diferentes graus de diversidades iniciais, que irão refletir em diferentes comportamentos da taxa de replicação.

Segundo Novella, uma maior diversidade inicial deve levar mais rapidamente a altas taxas de replicação pois existe maior probabilidade de que haja pelo menos alguma cepa (sub-população da quasi-espécie) que possua maior adaptabilidade, ou seja, que atinja mais rapidamente (através de relativamente poucas mutações) altas taxas de replicação. Vemos que nossos resultados teóricos corroboram estas hipóteses.

Existem poucos estudos que relacionam a diversidade inicial da população com seu comportamento evolutivo. Esta carência de trabalhos experimentais é devida, principalmente, ao fato de que é muito difícil medir apropriadamente a diversidade genética de uma quasiespécie [Herre 1993, Pickering 2000].

A seguir, discutimos sobre a diversidade (dispersão) da população, e sua relação com os parâmetros do modelo proposto. 


\subsubsection{Dispersão da distribuição dos fenótipos.}

A variância $\sigma_{x}^{2}(t)$ da distribuição do fenótipo $x$ da população, definida por

$$
\sigma_{x}^{2}(t)=<x^{2}>(t)-(<x>(t))^{2}=\int x^{2} C(x, t) d x-\left(\int x C(x, t) d x\right)^{2}
$$

contém a informação do comportamento temporal da diversidade (ou dispersão) de fenótipo $x$ da população.

No caso da condição inicial $(3.22), \sigma_{x}^{2}(t)$ pode ser calculado explicitamente:

$$
\sigma_{x}^{2}(t)=\frac{m^{2}}{12}+\frac{b^{2} t^{2}}{24 m^{2}}-\frac{b^{4} t^{4}}{576 m^{6}}
$$

para $t<t_{2 s}=\frac{2 m^{2}}{b}, \mathrm{e}$

$$
\sigma_{x}^{2}(t)=\frac{b t}{9}
$$

para $t>t_{2 s}$.

É interessante notar que a $\sigma_{x}^{2}(t)$ é obtida aqui como função do parâmetro $m$ e do parâmetro $b$, que está relacionado com a não-linearidade da equação (3.10).

As Figuras (4.7) e (4.8) ilustram o comportamento de $\sigma_{x}^{2}(t)$ para determinadas escolhas dos parâmetros $m$ e $b$.

A dependência da variância com o parâmetro $m$ só ocorre para $t<t_{2 s}$, ou seja, antes do segundo choque. Isto se deve principalmente ao fato de que a velocidade de propagação do perfil $C(x, t)$ é função do parâmetro $m$ apenas para $t<t_{2 s}$, como pode ser observado em $(3.35)$.

Para $t>t_{2 s}, \sigma_{x}^{2}(t)$ é função apenas do parâmetro $b$, responsável pela quasi-linearidade da equação (3.10). Esta não-linearidade leva à rarefação da solução da distribuição $C(x, t)$, como mostrado no capítulo 3, ou, equivalentemente. como podemos ver em (4.6) e (4.7), o aumento da dispersão.

Este aumento da variância $\sigma_{x}^{2}(t)$, e portanto na dispersão do fenótipo da população com $b$, sugere uma relação deste parâmetro com uma interação parasita-hospedeiro, o que poderia 


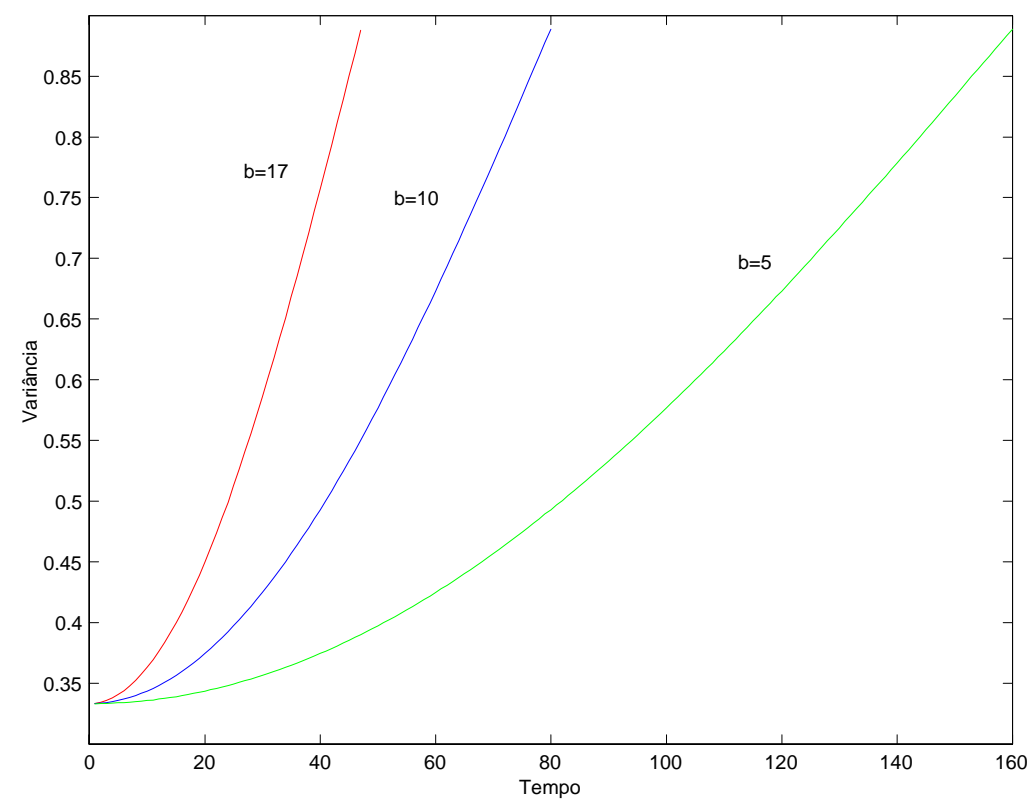

Figura 4.7. Dependência da variância de $x$ em função do parâmetro $b$, dada pela solução analítica referente à condição inicial ( 3.22).

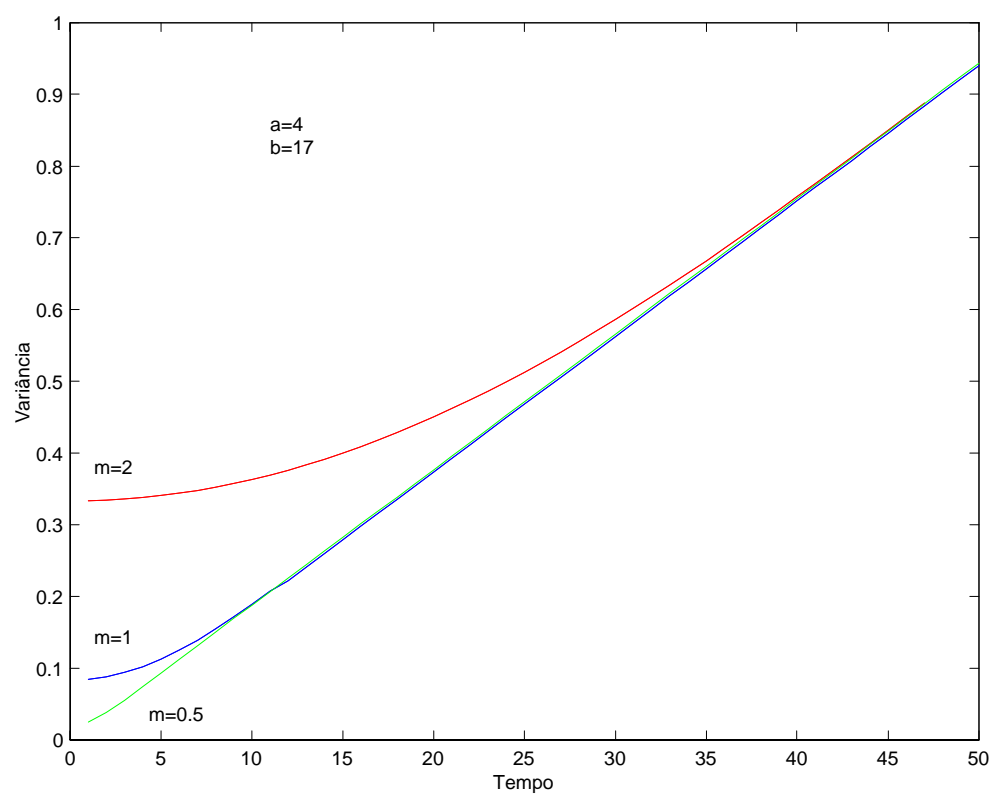

Figura 4.8. Dependência da variância de $x$ no parâmetro $m$, dada pela solução analítica referente à condição inicial (3.22).

definir a virulência dos vírus, como foi discutido anteriormente: quanto maior a virulência 
da população, mais deve ela se dispersar em seus componentes, de acordo com as 2 hipóteses "biológicas"propostas anteriormente.

É interessante notar que, para $b=0(\alpha=0)$ a equação (3.10) torna-se

$$
\frac{\partial}{\partial t} C(x, t)=a \frac{\partial}{\partial x} C(x, t)
$$

que, para a condição inicial (3.22), leva à solução:

$$
C(x, t)= \begin{cases}0, & x \leq \Delta+a t, \quad \forall t \\ n, & \Delta+a t<x \leq \Delta+m+a t, \quad \forall t \\ 0, & x>\Delta+m+a t, \quad \forall t\end{cases}
$$

cuja variância é constante no tempo:

$$
\sigma_{x}^{2}(t)=\int_{\Delta+a t}^{\Delta+m+a t} x^{2} n d x-\left(\int_{\Delta+a t}^{\Delta+m+a t} x n d x\right)^{2}=\frac{m^{2}}{12}, \quad \forall t
$$

como é demonstrado de maneira análoga no primeiro exemplo do Apêndice B. 


\subsubsection{Comportamento de $r(t)$ para tempos longos.}

No limite em que $t \rightarrow \infty$, a taxa de replicação torna-se independente do tempo:

$$
r(\infty)=a
$$

o que equivale a um processo malthuseano com taxa de replicação constante.

Este resultado é o mesmo que seria obtido para todos os tempos se partíssemos de uma equação de conservação linear (ou seja, a equação (3.10) com $\alpha=0$, e portanto $b=0$ ), cuja solução leva à um resultado para a média do fenótipo $x$ que varia linearmente com o tempo:

$$
<x>(t)=a t
$$

como visto no primeiro exemplo do apêndice B. 


\subsection{Soluções Numéricas}

A equação (3.6) foi iterada numericamente para diferentes condições iniciais pré-definidas.

Lembramos que, neste limite discreto do modelo, o fenótipo assume valores inteiros, que serão denominados aqui por $k(\lambda=1)$, assim como o tempo se refere às interações $i$, e

utilizaremos os parâmetros $P\left(=\frac{1}{2}\left(\frac{a}{\Gamma}+1\right)\right)$ e $\alpha\left(=\frac{b}{4 \Gamma}\right)$, que definem as taxas de transição entre as sub-populações com fenótipo $k$.

As simulações numéricas nos permitiram observar o comportamento da taxa de replicação $r(i)$ da população para diferentes condições iniciais.

\subsubsection{Condição inicial delta de kronecker.}

Uma primeira condição inicial que podemos explorar, que não é possível no caso analítico, é a distribuição delta de kronecker:

$$
\delta_{k, k^{\prime}}=\left\{\begin{array}{cc}
1, & k=k^{\prime} \\
0, & k \neq k^{\prime}
\end{array}\right.
$$

o que corresponde a uma situação em que $m \rightarrow 0$ na condição inicial (3.22), ou seja, uma população inicial extremamente homogênea.

A Figura (4.9) mostra a evolução de uma distribuição inicial delta para uma determinada escolha de parâmetros.

A Figura (4.10) ilustra a variação da média do fenótipo $\langle k>(i)$ para diferentes condições iniciais delta de kronecker $\delta_{k, 200}$ e $\delta_{k, 210}$ (distribuições com diferentes médias iniciais).

A Figura (4.11) ilustra o comportamento das respectivas taxas de replicação, que são idênticas. Isto é devido ao fato de que as taxas de transição $p$ e $q$ entre as sub-populações 


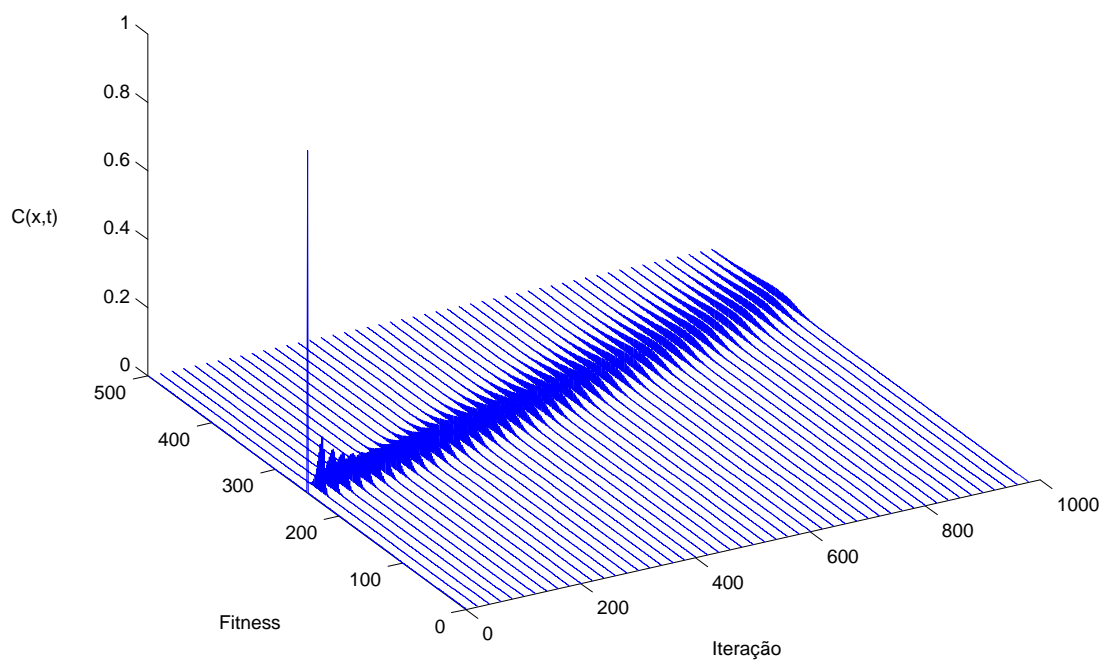

Figura 4.9. Evolução da distribuição $C(k, i)$ para uma condição inicial $C(k, 0)=\delta_{k, 250} \operatorname{com} P=0.6$ e $\alpha=0.4$

(sítios com determinado fenótipo $k$ ) não dependem explicitamente do fenótipo $k$ de cada sub-população em sí, mas apenas da concentração local $C(k, i)$.

Em outras palavras, trata-se de um espaço em que todos os sítios são igualmente prováveis, ou seja, um espaço plano.

Para uma condição $\delta_{k, 250}$, observamos na Figura (4.12) como varia a taxa de replicação no tempo para diferentes valores do parâmetro $\alpha$. Notamos que o resultado exibe o mesmo comportamento do pulso retangular nos resultados analíticos: Há uma primeira fase de variação linear com o tempo, seguida de uma fase em que o aumento da taxa de replicação passa a diminuir, levando a um valor constante no limite assintótico (não ilustrado no gráfico).

Para a mesma condição inicial $\delta_{k, 250}$, observamos, na Figura (4.13) como varia a taxa de replicação para diferentes valores do parâmetro $P$.

Nestes dois casos, notamos a mesma dependência de $r(i)$ com a variação dos parâmetros $\alpha$ e $P$, quando comparado com os resultados analíticos. 


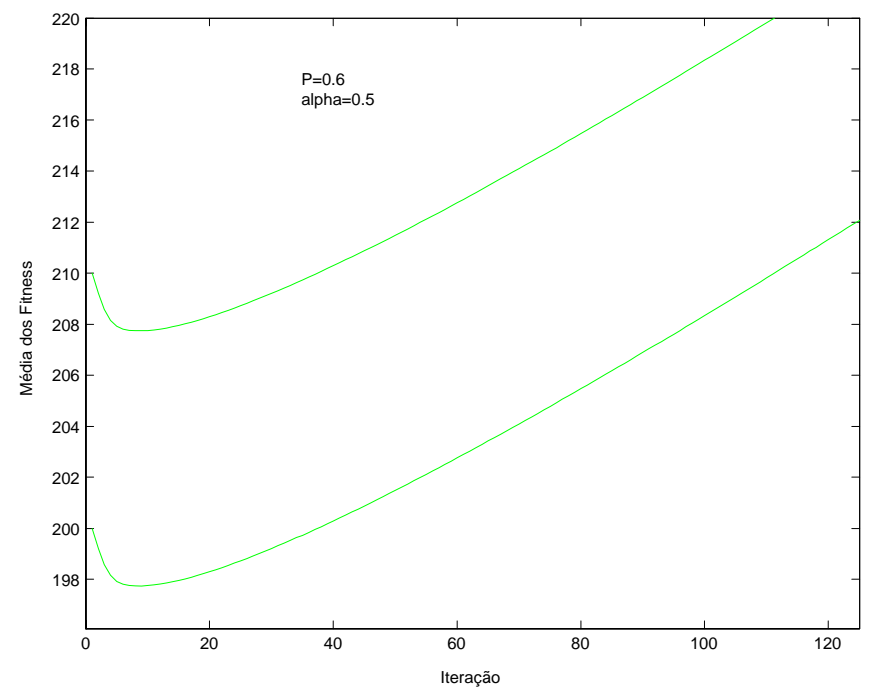

FigurA 4.10. Médias para duas condições iniciais deltas de kronecker $C(k, 0)=\delta_{k, 200}$ e $C(k, 0)=\delta_{k, 210}$.

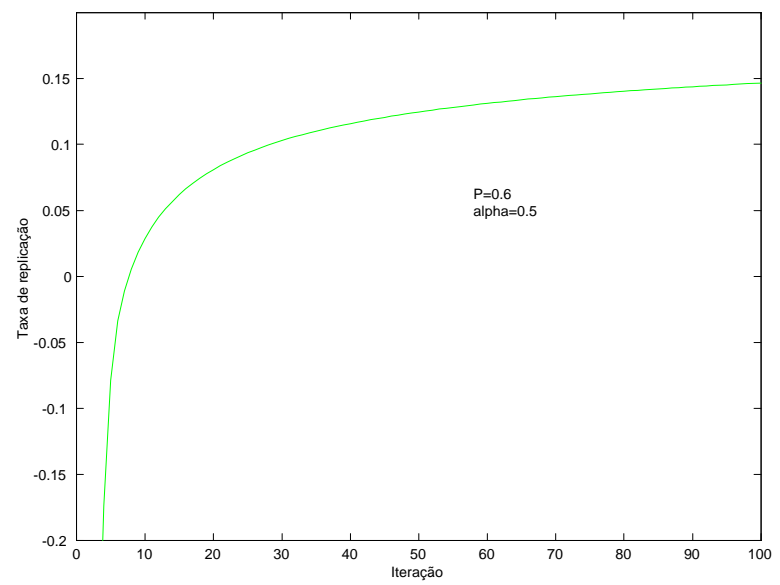

FiguRA 4.11. Taxas de replicação idênticas para diferentes condições iniciais delta de kronecker $C(k, 0)=\delta_{k, 200}$ e $C(k, 0)=\delta_{k, 210}$. 


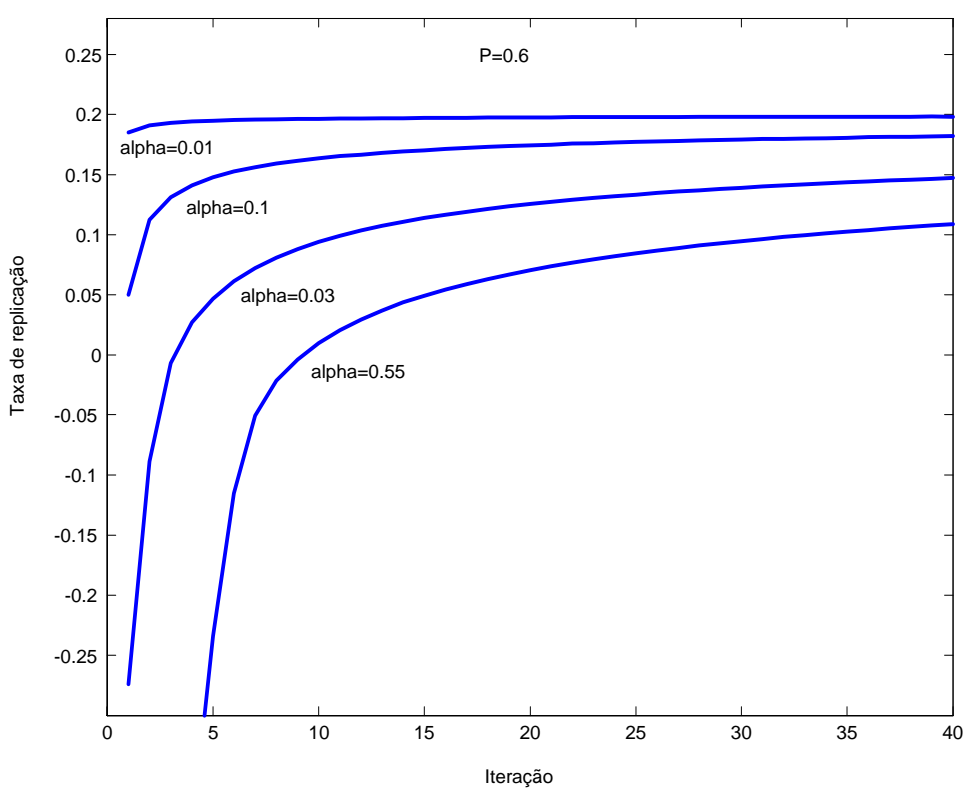

FigurA 4.12. Variação da taxa de replicação para diferentes valores do parâmetro $\alpha$, para condições iniciais deltas $C(k, 0)=\delta_{k, 250}$. Embora não ilustrado, o limite assintótico atingido nos 4 casos coincidem.

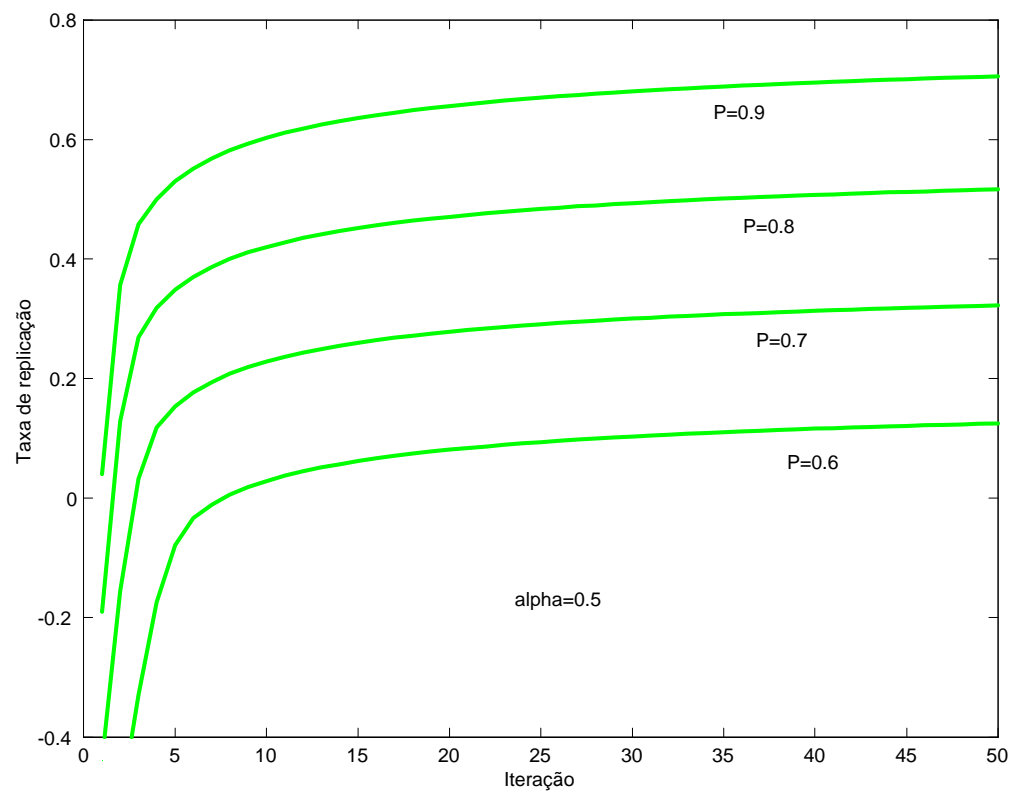

Figura 4.13. Variação da taxa de replicação para diferentes valores do parâmetro $P$, para a condição iniciail delta $C(k, 0)=\delta_{k, 250}$. 


\subsubsection{Condição inicial com perfil de um pulso retangular.}

Outra característica importante observada com a solução numérica foi a dependência da variação da taxa de replicação com a dispersão da distribuição inicial da população, que também se assemelha com os resultados analíticos.

A Figura (4.14) mostra três perfis iniciais de $C(k, i)$ com médias iniciais iguais porém diferentes dispersões.

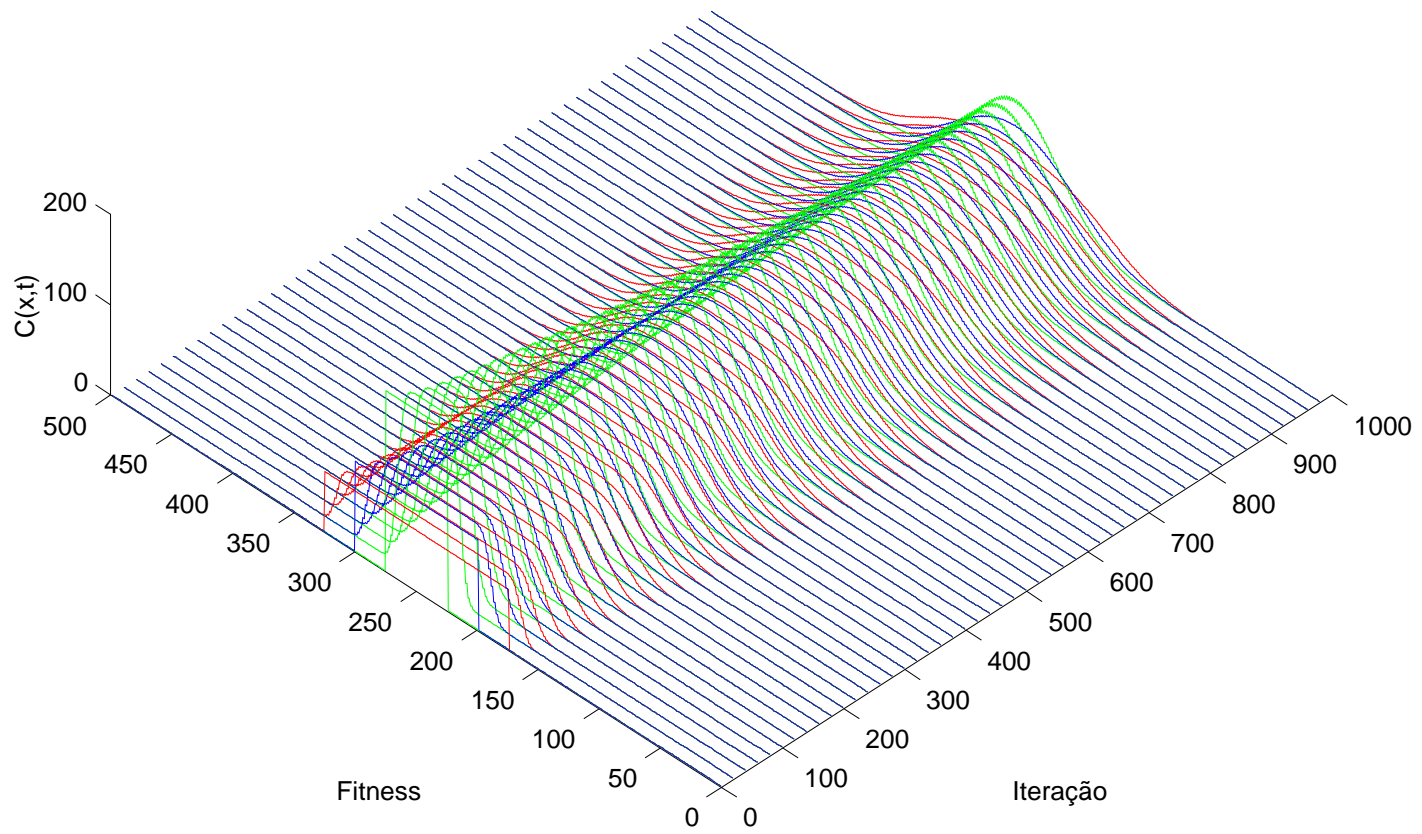

Figura 4.14. Distribuição $C(k, i)$ da população através das iterações temporais, para a mesma média inicial porém diferentes larguras iniciais (pulso retangular com $m=50, m=100$ e $m=150)$.

Para uma escolha de parâmetros $P$ e $\alpha$, vemos a variação da taxa de replicação para diferentes dispersões iniciais na Figura (4.15).

Para uma distribuição inicial com forma de pulso retangular de $10 \times 0.1$, vemos na Figura (4.16) a dependência da taxa de replicação da população com a variação do parâmetro $\alpha$, da mesma maneira como nos resultados analíticos. 


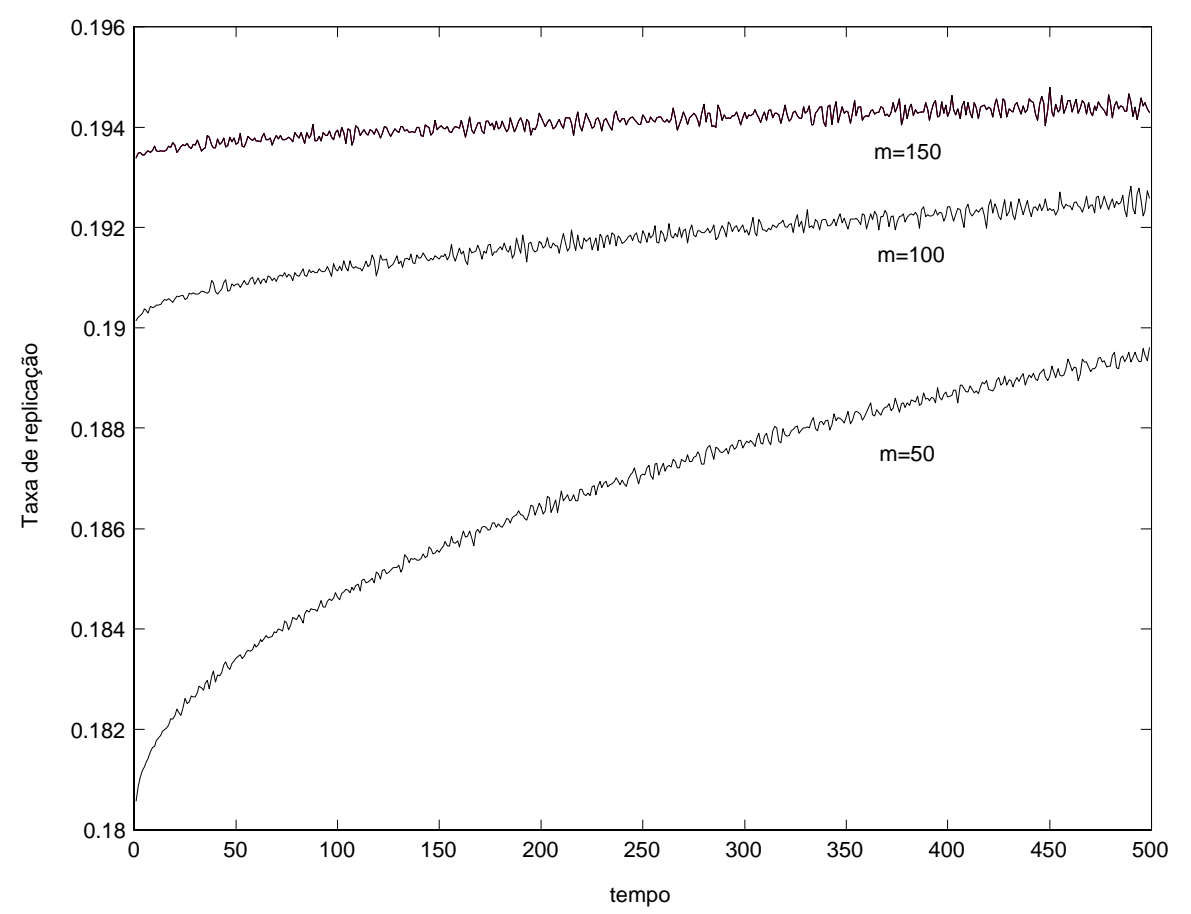

FiguRA 4.15. Taxas de replicação para condições iniciais ilustradas na Figura (4.14) com $P=0.6$ e $\alpha=0.5$. Embora não ilustrado, o limite assintótico atingido nos 3 casos coincidem (pulso retangular).

Para uma mesma distribuição inicial com forma de pulso, vemos na Figura (4.17) a dependência da taxa de replicação da população com a variação do parâmetro $P$, que está de acordo com os resultados analíticos.

A condição inicial gaussiana foi testada e a respectiva taxa de replicação não apresentou dois regimes para nenhuma escolha de parâmetros. Isto provavelmente se deve ao fato de que este comportamento ocorre em um instante de tempo menor do que o qual utilizamos nas iterações. Ou seja, logo na primeira iteração a distribuição já se conforma de maneira que leva ao limite assintótico, como observado nos outros casos discutidos anteriormente. 


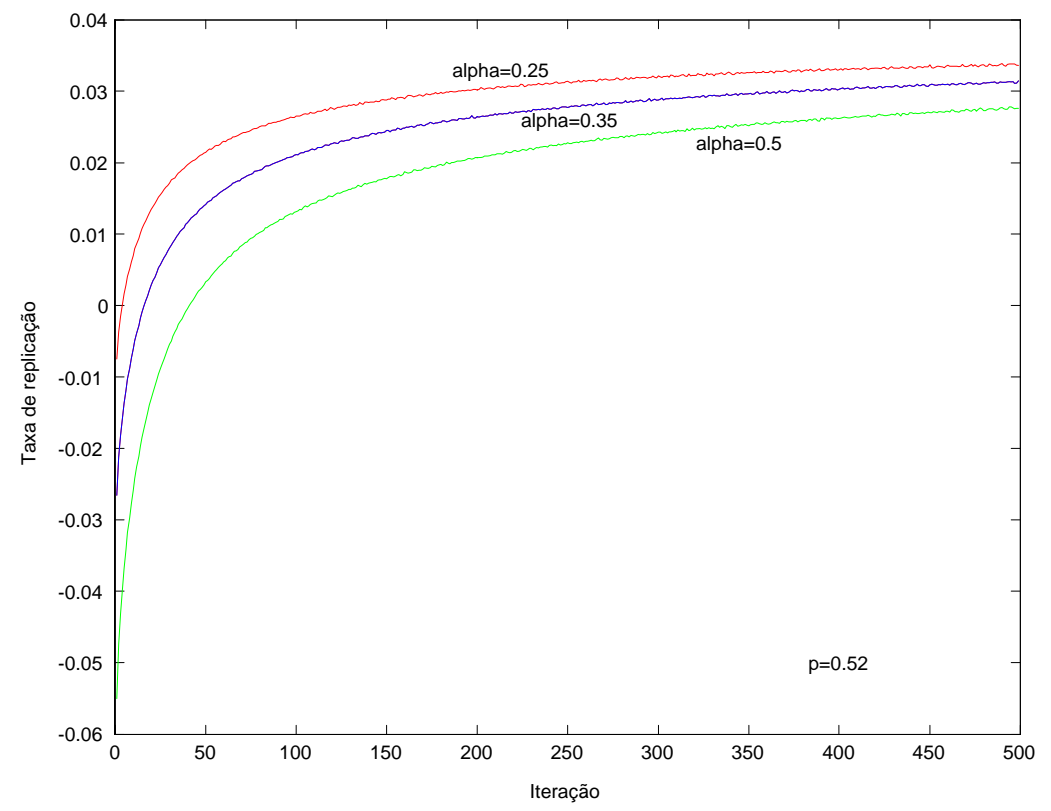

FigurA 4.16. Dependência da taxa de replicação com a variação do parâmetro $\alpha, \operatorname{com} P=0.52$ (pulso retangular).

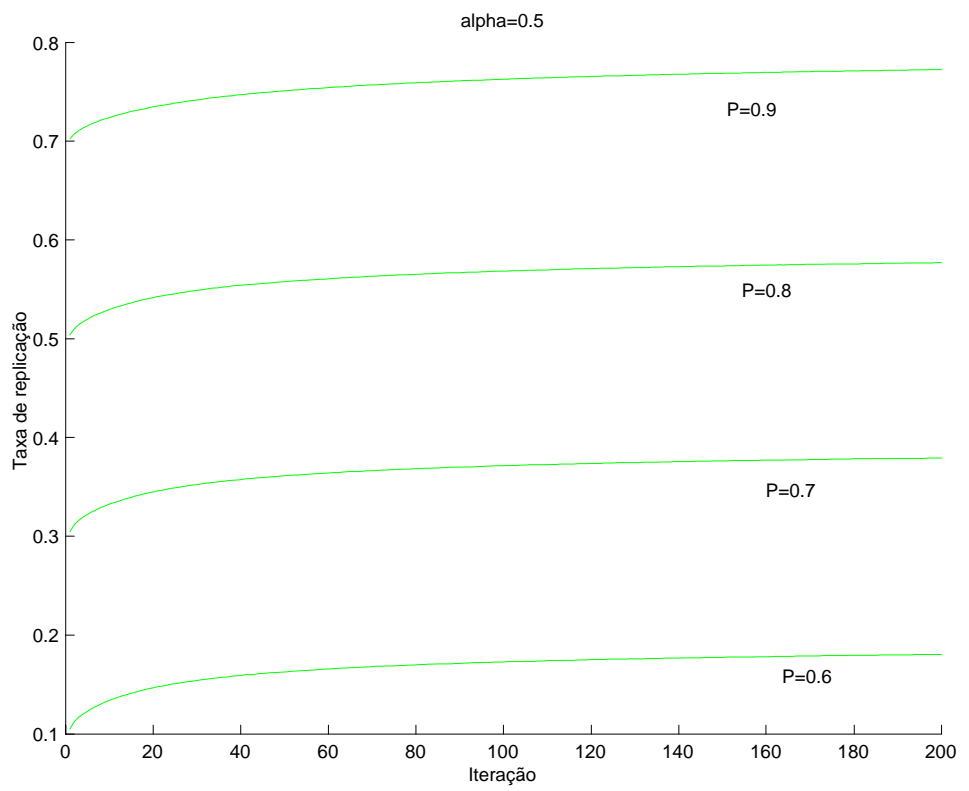

Figura 4.17. Dependência da taxa de replicação com a variação do parâmetro $P$ (pulso retangular). 


\subsection{Comparação com os dados experimentais}

Fizemos ajustes de nossa solução analítica para os dados experimentais publicados em [Novella 1995a]. Consideramos dois resultados diferentes do experimento, de maneira que ajustamos a primeira parte da nossa solução (equação (4.3) para a equação (3.10), referente à condição inicial (3.22) para um conjunto de dados o que aparentemente encontra-se ainda na fase de crescimento linear, e a outro conjunto de dados que apresenta um limite assintótico, onde ajustamos a segunda parte de nossa solução, ou seja, após o segundo choque (equação $(4.4))$.

Isto porque não é claro, e não há um método experimental definido, para se obter o instante em que há a mudança no comportamento da taxa de replicação da população de vírus tal como é observado e comentado pelos autores do trabalho experimental, e que portanto não pode ser facilmente quantificado.

De fato, os autores afirmam que esta transição ocorre quando a população que está evoluindo atinge a "neutralidade", ou seja, sua taxa de replicação se iguala à taxa de replicação da população wild type. Porém, para nós, este fato deve ser uma coincidência, uma vez que a população wild type é apenas uma população padrão, utilizada para se quantificar a taxa de replicação relativa: sua taxa de replicação não varia no tempo, e portanto não deve interferir na dinâmica da população que evolui.

Os ajustes foram feitos utilizando-se o programa Origin 6.1.

A seguir, mostramos na figura (4.18) ajustes obtidos para os parametros $a$ e $b$ utilizando 2 réplicas do experimento, dados presentes em Novella 1995a. Fizemos uma escolha

É interessante notar que os dados experimentais para o comportamento da taxa de replicação possuem uma grande variação, especialmente para tempos longos, cujas possíveis razões são comentadas em um trabalho de Isabel Novella (1999).

A primeira, é que a reprodutibilidade dos experimentos para medição da variação da taxa de replicação não seriam confiáveis ou dependeriam de outros fatores, e não apenas do fitness da população. Porém estes experimentos foram reproduzidos com resultados similares por outros grupos, o que é um possível argumento contra esta hipótese [Duarte 1993]. 


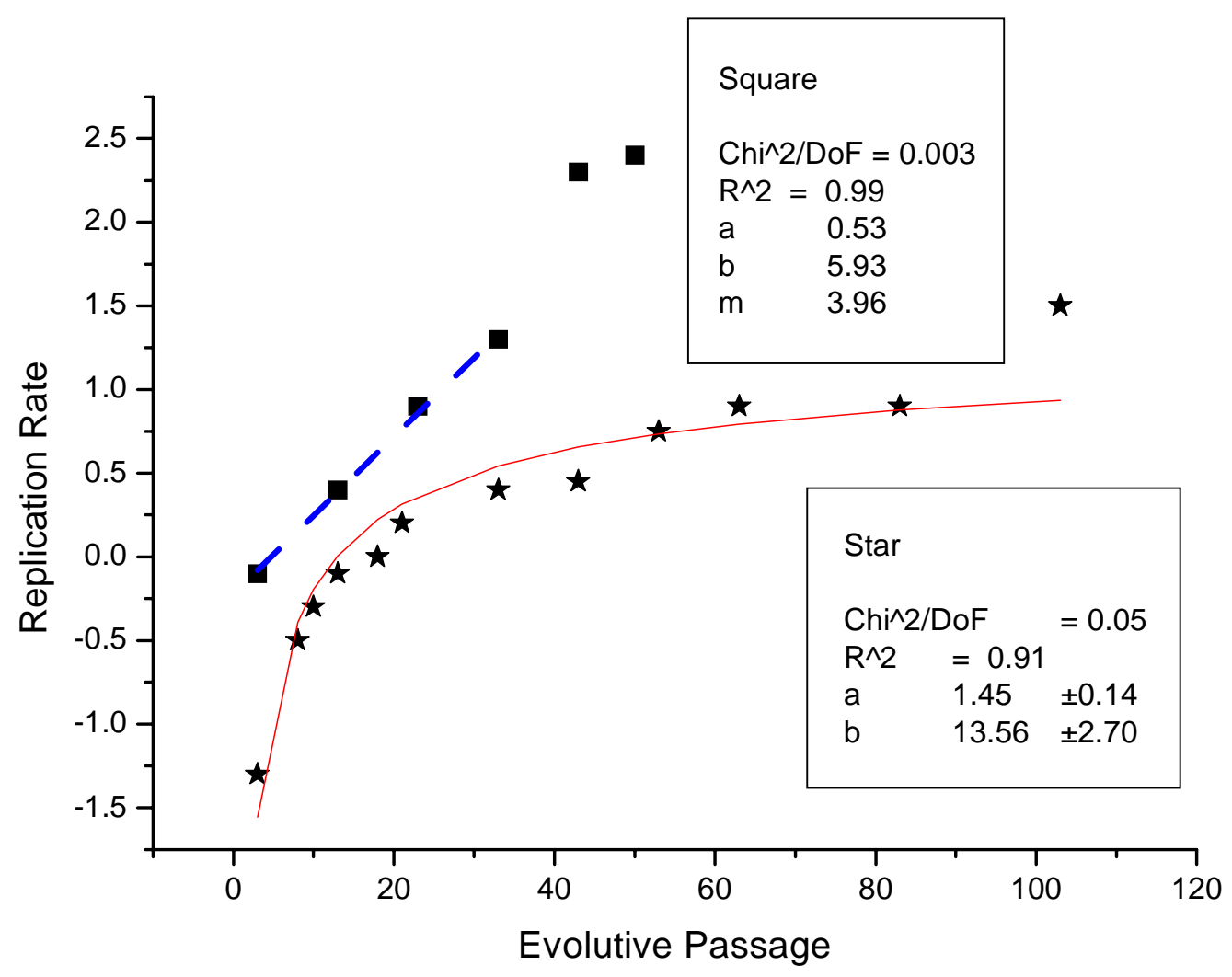

Figura 4.18. Ajuste das soluções (4.3 e 4.4) com os dados experimentais. Conjunto quadrados: um crescimento linear. Conjunto estrelas: crescimento polinomial, com limite assintótico finito.

Outra possível razão para a grande variação da taxa de replicação para tempos longos é o fato de que, nesta situação, os vírus possuem altas taxas de replicação, o que geraria muita variação (diversidade) quando nas passagens evolutivas.

No momento em que a alíquota de uma determinada passagem evolutiva é selecionada, devido a efeitos de amostragem na preparação das misturas de vírus selvagem com o vírus que evolui, é provável que naquela amostra não estejam presentes sub-populações mais representativas da população, dado que o que está sendo medido é apenas uma sub-população de toda população que evolui. Isto deve se aliar ao fato de que na população deve haver uma baixa 
concentração de vírus com alto fitness na população, como foi sugerido experimentalmente em outro trabalho [Duarte 1994].

Porém, segundo a autora, esta variação não é suficiente para explicar a magnitude das flutuações observadas no experimento.

Outro possível fator que pode estar envolvido na grande variação dos dados nesta região é a presença de Defective Interfering Particles (DIPs). DIPs são partículas viróticas que perderam parte de seu genoma, o que as impossibilita de se replicar por si próprias, dependendo de um vírus "sadio", ou seja, com genoma completo, para se replicar, quando numa coinfecção. Isto acaba comprometendo a replicação dos vírus sadios, uma vez que sua replicação poderia ser mais efetiva se o vírus defeituoso não estivesse lá.

Segundo a autora, a presença destas partículas não foi especificamente testada, porém existem fatores indiretos que indicam que, se houvesse DIPs na população, elas não se acumulariam a um limite em que poderiam causar interferência no experimento.

Por último, a taxa de replicação da população pode decrescer por efeitos de bottleneck. O proceso de bottlenecking, como já vimos, é devido a fixação de mutações deletérias na população, independentemente de sua taxa de replicação. Isto se deve ao chamado deriva genética (random drift), processo no qual a população varia sua taxa de replicação não por seleção natural, e, sim, por processos aleatórios.

Este efeito dá-se normalmente quando o tamanho da população não é relativamente grande para carregar uma boa representação da população tal como esta se encontrava no final da passagem evolutiva anterior (1 a 30 vírus por passagem), de maneira que os indivíduos mais adaptados podem ser perdidos quando na retirada da alíquota que compõe a nova passagem evolutiva.

Este processo, como dissemos anteriormente, é chamado de catraca de Muller (Muller's ratchet) [Muller 1964]. Este efeito nunca havia sido observado em grandes populações de vírus, tais como as envolvidas no experimento em questão $\left(2 \times 10^{5}\right.$ partículas infecciosas $)$. 
No entanto, segundo a autora, quando o fitness da população de vírus é da ordem de 10 a 15, efeitos de bottlenecking são esperados, apesar do tamanho das populações envolvidas em cada infecção ("large passages").

Isto foi analisado experimentalmente em outro artigo [Novella 1995b], onde a autora relaciona o fitness de uma população com o tamanho crítico da mesma para que efeitos de bottlenecking comecem a se tornar importantes.

Segundo este estudo, para uma população infecciosa de $2 \times 10^{5}$ indivíduos, efeitos de bottleneck começam a influenciar a evolução da população quando o fitness chega a um determinado valor crítico, o que é consistente com o observado nos experimentos que levam as passagens adiante.

Portanto, a autora identifica este processo como principal suspeito de ser o responsável pelas quedas de fitness sofridas pela população nas passagens. Esta queda estaria relacionada, então, com um processo aleatório, em que os indivíduos mais aptos seriam perdidos, em uma situação onde o processo de deriva genética é mais forte do que o processo de seleção natural.

Porém, logo depois o fitness da população volta a crescer, dado que as condições ambientais são as mesmas. É provável que a população alcance outro limite assintótico, devido ao aparecimento de novas cepas na população, com genótipos diferentes. Isto foi observado experimentalmente [Novella 1999], e equivale, em nosso trabalho, a diferentes valores do parâmetro $P$.

A conclusão é de que quando uma população chega a altos valores de fitness, dependendo do tamanho da população envolvida uma região de incerteza na evolução é alcançada. Esta incerteza vem do fato de haver uma maior probabilidade de ocorrência de mutações deletérias quando os vírus alcançam altos valores de fitness.

Isto significa, em outras palavras, que estas populações, por terem tamanho finito, estão sujeitas não apenas aos processos determinísticos de seleção natural pura, mas estão também sujeitos a processos estocásticos, chamados de deriva genética [Millstein 2002]. 



\section{CAPíTULO 5}

\section{Conclusões}

Quantificar e poder fazer previsões para a evolução de uma população de vírus é de extrema valia, pois estes seres estão presentes na natureza, afetam as populações humanas, e estão cada vez mais presentes em procedimentos laboratoriais, onde são estocados, manipulados e reproduzidos. Em todas estas situações, estas populações extremamente heterogêneas modificam-se evoluem, e estes processos afetam a vida humana de forma significativa.

Os experimentos que visam quantificar esta evolução são relativamente novos, e extremamente inventivos, dado que pretendem medir uma grandeza que se modifica incessantemente com o tempo: não existe nenhum equipamento capaz de medir instantaneamente a taxa de replicação de uma população de vírus, o que retoma a questão: como medir uma característica de uma população que evolui?

Mesmo tomando todas precauções para controlar rigorosamente o ambiente em que ocorre a evolução, efeitos estocásticos irão sempre representar uma barreira para a reprodutibilidade exata dos experimentos.

Em nosso trabalho, derivamos uma equação para a evolução da distribuição $C(x, t)$ de indivíduos com fenótipo $x$ no instante $t$, presentes na população de vírus, sujeita a um processo evolutivo. Trata-se de uma equação diferencial parcial de primeira ordem quasilinear, que foi resolvida analiticamente pelo método das características. As soluções para a taxa de replicação para certas condições iniciais são compostas por duas funções para diferentes regiões de tempo. Isto é devido à quasi-linearidade da equação, e é evidenciado pela ocorrência de choques entre as correspondentes curvas características.

Este resultado remete de maneira especial aos dados experimentais, também compostos por dois "regimes"temporais. 
O instante em que ocorre a mudança de regime da taxa de replicação (e que caracteriza a região transiente das soluções), e o comportamento desta são funções tanto das diferentes condições iniciais, como também de um parâmetro que está relacionado com características intrínsecas das populações de vírus (parâmetro $a=\Gamma(2 P-1)$ ), assim como um parâmetro relacionado com a interação parasita-hospedeiro (parâmetro $b=4 \Gamma \alpha$ ).

Desta maneira, o modelo é capaz também de fazer previsões e sugerir novos experimentos, que visam o moldar a evolução de populações de vírus.

Entendemos que nosso modelo segue o experimento laboratorial de maneira singular e inédita, sendo capaz, inclusive, de sugerir que a virulência da população seja representada por um parâmetro $\alpha$, independente do seu fenótipo $x$. Inspirados pelo experimento, utilizamos uma equação de continuidade (equação (3.10)), e a dinâmica contemplada leva em conta as concentrações relativas de indivíduos de diferentes componentes, que julgamos ser a quantidade que governa a dinâmica da taxa de replicação da população.

A expressão analítica para a variação da taxa de replicação média possibilitou o ajuste dos dados experimentais para esta grandeza.

Os trabalhos teóricos anteriores ao nosso ([Tsimring 1996] e [Aafif 1998]), que visam modelar o mesmo experimento, embora pertençam ao mesmo âmbito conceitual (processos markovianos), diferem na escolha das probabilidades de transição entre os componentes da população. No trabalho de Aafif (1998) estas grandezas são funções da taxa de replicação, enquanto em nosso trabalho são descritas em termos das concentrações de cada componente.

Essas diferenças refletem-se no comportamento da taxa de replicação da população de vírus, e, em particular, na maneira com que esta tende a um limite finito no regime assintótico.

O comportamento evolutivo do fenótipo (e a taxa de replicação) de uma população de vírus é extremamente importante de ser compreendido, uma vez que populações de vírus são cada vez mais comumente manipuladas em procedimentos laboratoriais, e, embora os vírus não sejam considerados seres vivos por parte da comunidade científica, é inegável que eles evoluem: modificam-se, de maneira que nunca se pode ter certeza de que determinada 
porção de vírus que está estocada e rotulada em um frasco realmente corresponde ao que este rótulo diz.

O desenvolvimento científico que permita conhecer um pouco mais sobre os princípios que regem a dinâmica da evolução das populações de vírus, tanto in vivo, como in vitro, pode representar, para a sociedade, uma ferramenta para melhor enfrentar os desafios da saúde, da medicina, da produção alimentar, e, portanto, da qualidade de vida. 



\section{Apêndice A}

Neste apêndice demonstraremos a transformação da equação discreta de nosso modelo para a equação contínua, quando no limite em que o tempo entre as passagens do processo markoviano tende a zero, assim como a unidade de fenótipo, levando a uma situação em que o processo temporal é contínuo, assim como as diferenças entre os fenótipos.

Consideramos a seguinte equação de recorrência que relaciona a concentração $C_{(i+1) \tau}(k \lambda)$ de partículas com fenótipo $k \lambda$ no instante $i \tau$ :

$C_{(i+1) \tau}(k \lambda)=\left[P-\alpha C_{i \tau}((k-1) \lambda)\right] C_{i \tau}((k-1) \lambda)+\left[(1-P)+\alpha C_{i \tau}((k+1) \lambda)\right] C_{i \tau}((k+1) \lambda)$

Obtemos a respectiva equação mestra subtraindo $C_{i \tau}(k \lambda)$ da equação (5.1) e dividindo por $\tau$. 


$$
\begin{aligned}
\frac{C_{(i+1) \tau}(k \lambda)-C_{i \tau}(k \lambda)}{\tau}= & \frac{P}{\tau}\left[C_{i \tau}((k-1) \lambda)-C_{i \tau}((k+1) \lambda)\right]+\frac{C_{i \tau}((k+1) \lambda)-C_{i \tau}(k \lambda)}{\tau}+ \\
& +\frac{\alpha}{\tau}\left[C_{i \tau}^{2}((k+1) \lambda)-C_{i \tau}^{2}((k-1) \lambda)\right]+ \\
& \left.+\frac{P}{\tau}\left[C_{i \tau}(k \lambda)-C_{i \tau}(k \lambda)\right]+\frac{\alpha}{\tau}\left[C_{i \tau}^{2}(k \lambda)-C_{i \tau}^{2}(k \lambda)\right] \quad \text { (termos somados }\right) \\
= & \frac{P \lambda}{\tau}\left[\frac{C_{i \tau}((k-1) \lambda)-C_{i \tau}(k \lambda)-C_{i \tau}((k+1) \lambda)+C_{i \tau}(k \lambda)}{\lambda}\right]+ \\
& +\frac{\alpha \lambda}{\tau}\left[\frac{C_{i \tau}((k+1) \lambda) C_{i \tau}((k+1) \lambda)-C_{i \tau}(k \lambda) C_{i \tau}(k \lambda)}{\lambda}\right]+ \\
& +\frac{\alpha \lambda}{\tau}\left[\frac{C_{i \tau}(k \lambda) C_{i \tau}(k \lambda)-C_{i \tau}((k-1) \lambda) C_{i \tau}((k-1) \lambda)}{\lambda}\right]+ \\
& \\
& \frac{\lambda}{\tau}\left[\frac{C_{i \tau}((k+1) \lambda)-C_{i \tau}(k \lambda)}{\lambda}\right] \\
& \\
& \\
& \\
& \\
&
\end{aligned}
$$

O limite contínuo da equação acima é obtido para $\lambda \rightarrow 0$ e $\tau \rightarrow 0, \operatorname{com} \frac{\lambda}{\tau} \rightarrow \Gamma$, com os seguintes limites: 
$(5.2)$

$$
\frac{C_{i \tau}((k-1) \lambda)-C_{i \tau}(k \lambda)-C_{i \tau}((k+1) \lambda)+C_{i \tau}(k \lambda)}{\lambda} \rightarrow-2 \frac{\partial}{\partial x} C(x, t)
$$

$$
\frac{C_{i \tau}^{2}((k+1) \lambda)-C_{i \tau}^{2}(k \lambda)}{\lambda} \rightarrow \frac{\partial}{\partial x} C^{2}(x, t)
$$

$$
\frac{C_{i \tau}^{2}(k \lambda)-C_{i \tau}^{2}((k-1) \lambda)}{\lambda} \rightarrow \frac{\partial}{\partial x} C^{2}(x, t)
$$

$$
\frac{C_{i \tau}((k+1) \lambda)-C_{i \tau}(k \lambda)}{\lambda} \rightarrow \frac{\partial}{\partial x} C(x, t)
$$

com

$$
k \lambda \rightarrow x
$$

$$
i \tau \rightarrow t
$$

e

$$
\lambda \rightarrow d x
$$

$$
\tau \rightarrow d t
$$

portanto:

$(5.10)$

$$
\frac{\partial C}{\partial t}=\Gamma \frac{\partial}{\partial x}\left[(1-2 P) C+2 \alpha C^{2}\right]
$$





\section{Apêndice B}

Neste apêndice introduzimos o método das características para solução analitica de equações diferenciais parciais de primeira ordem.

No caso mais simples de uma EDP, trata-se uma equação do tipo:

$$
\frac{\partial w}{\partial t}+c \frac{\partial w}{\partial x}=0
$$

Onde $c$ é uma constante, com uma condição inicial:

$$
w(x, 0)=f(x)
$$

O método das características consiste em comparar a EDP (5.11) com a derivada total em relação ao tempo da função $w(x, t)$, supondo que esta é medida por referencial que não observa mudanças na função $w(x, t)$. A função $x(t)$ para o referencial que satifaz isto é chamada de função característica.

Para a função $w$, a regra da cadeia implica que:

$$
\frac{d}{d t} w(x(t), t)=\frac{\partial w}{\partial t}+\frac{d x}{d t} \frac{\partial w}{\partial x}
$$

Comparando a equação diferencial (5.11) com a derivada total da função (5.13), identificamos:

$$
\left\{\begin{array}{l}
\frac{d w(x, t)}{d t}=0 \quad \Longrightarrow \quad w(x, t)=w\left(x_{0}, 0\right) \\
\frac{d x(t)}{d t}=c \quad \Longrightarrow \quad x(t)=c t+x_{0}
\end{array}\right.
$$


O que significa que $w(x(t), t)$ é constante para um observador que se move com velocidade $c$.

Neste sentido, a equação diferencial (5.11) foi substituída por duas equações ordinárias $(5.14)$

Integrando a equação para $x(t)$ em (3.20), obtemos a função característica:

$$
x(t)=c t+x_{0}
$$

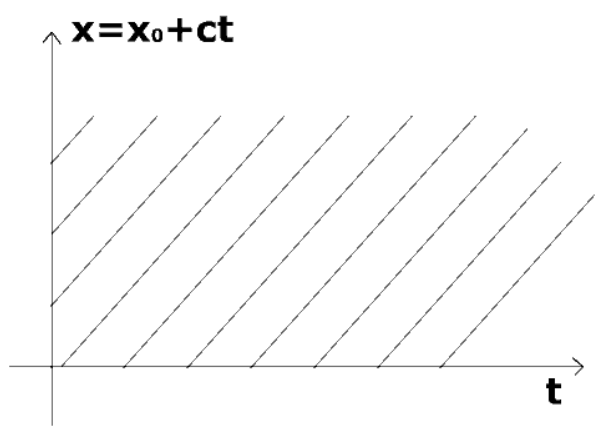

Figura 5.1. Família de características definido por (5.15).

Que é a equação para uma família de curvas (retas, no caso), para diferentes $x_{0} \mathrm{~s}$, ao longo das quais, caminhando com velocidade $c$, não se observa variação de $w(x, t)$ como mostra a Figura (5.1).

Estas curvas são chamadas de família de características, ou simplesmente características.

O procedimento final para resolver a equação é escrever $x_{0}$ em função de $x$ e $t$, e então voltar para a condição inicial do problema.

Desta maneira, a solução final será:

$$
w(x, t)=w_{0}\left(x_{0}(x, t), 0\right)
$$

Como exemplo, podemos resolver pelo método das características a equação de continuidade (5.11), com uma condição inicial pulso quadrado (5.18). 
Neste caso, as características são dadas por:

$$
x=c t+x_{0}, \forall t
$$

Com a seguinte condição inicial:

$$
w(x, 0)= \begin{cases}0, & x \leq 0 \\ 1, & 0<x \leq 1 \\ 0, & x>1\end{cases}
$$

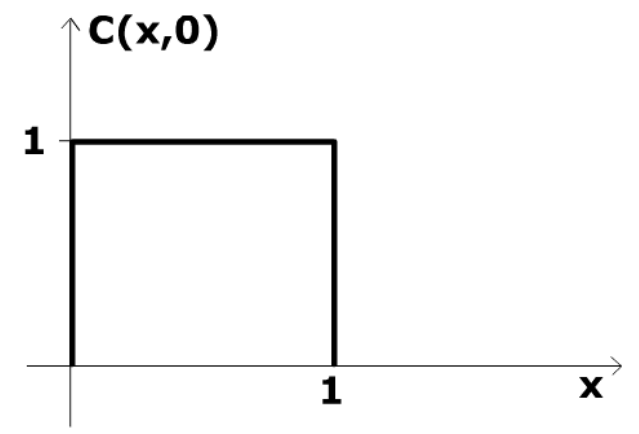

Figura 5.2. Condição inicial referente à equação (5.18).

A Figura (5.2) ilustra a condição inicial (5.18).

Comparando com a derivada total da função $w$,

$$
\frac{d}{d t} w(x(t), t)=\frac{\partial w}{\partial t}+\frac{d x}{d t} \frac{\partial w}{\partial x}
$$

identificamos: 


$$
\left\{\begin{array}{l}
\frac{d}{d t} w(x(t), t)=0 \quad \Longrightarrow \quad w(x(t), t)=w_{0}\left(x_{0}(x, t), 0\right) \\
\frac{d x}{d t}=c \quad \Longrightarrow \quad x(t)=x_{0}+c t
\end{array}\right.
$$

Que leva às seguintes características:

$$
x\left(x_{0}, t\right)=x_{0}+c t, \forall x_{0}, t
$$

de onde determinamos,

$$
x_{0}(x, t)=x-c t, \forall x, t
$$

Podemos então montar a solução de (5.11), através das características, voltando nas condições iniciais.

$$
w(x, t)=w_{0}\left(x_{0}(x, t), 0\right)= \begin{cases}0, & x \leq c t \\ 1, & c t<x \leq 1+c t \\ 0, & x>1+c t\end{cases}
$$

Esta solução está representada na Figura (5.3).

Podemos perceber também, pela Figura (5.3), que a variância de $x$ é constante:

$$
\sigma_{x}^{2}(t)=\int_{c t}^{1+c t} x^{2} d x-\left(\int_{c t}^{1+c t} x d x\right)^{2}=\frac{1}{12}
$$




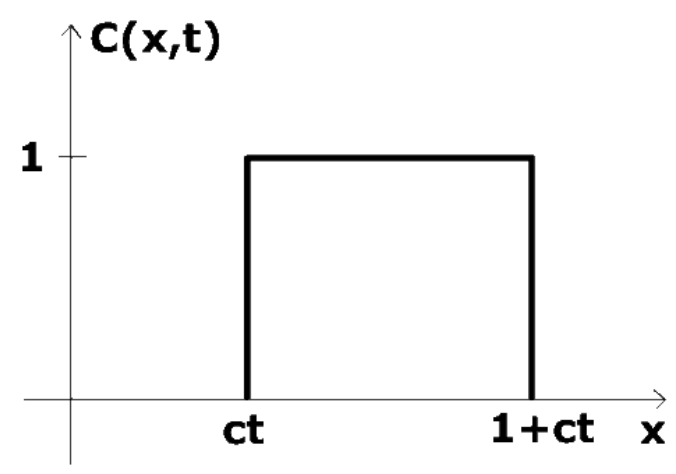

FIGURA 5.3

\subsubsection{Médias $x$ Características.}

Para esta distribuição inicial normalizada, e no caso da equação de conservação com $c$ constante, a média de $x$ sempre coincide com a característica "média"inicial (característica que emana da média da distribuição inicial (5.18)).

No caso, a média espacial é dada por

$$
<x>(t)=\frac{\int_{-\infty}^{+\infty} x w(x, t) d x}{\int_{-\infty}^{+\infty} w(x, t) d x}=\int_{c t}^{1+c t} x[1] d x=\frac{(1+c t)^{2}}{2}+\frac{(c t)^{2}}{2}=\frac{1}{2}+c t
$$

Que coincide com a característica "média"inicial, ou seja,

$$
x_{c}(t)=\frac{1}{2}+c t
$$

\subsubsection{Equações Quasi-lineares.}

O procedimento introduzido até agora diz respeito a equações cujo termo que multiplica a derivada espacial é constante. Veremos a seguir como proceder em casos em que isto não ocorre.

No caso do nosso modelo, trata-se de uma equação quasi-linear homogênea, do tipo: 


$$
\frac{\partial w(x, t)}{\partial t}+c(w, x, t) \frac{\partial w(x, t)}{\partial x}=0
$$

Cuja quasi-linearidade é devida ao termo que multiplica a derivada espacial, função das variáveis $x$ e $t$ e da própria função $w(x, t)$.

Não se trata de uma equação diferencial não-linear, uma vez que ela é linear em suas derivadas parciais.

A solução é analoga ao caso linear, utilizando-se o mesmo procedimento de comparar e identificar os termos entre a equação (5.26) e a derivada total de $w(x, t)$ :

$$
\left\{\begin{array}{l}
\frac{d w(x, t)}{d t}=0 \\
\frac{d x(t)}{d t}=c(w, x, t)
\end{array}\right.
$$

Ou seja, desta maneira a equação diferencial parcial (5.26) se reduz ao sistema de equações diferenciais ordinárias (5.27).

A integral da equação para $x(t)$ em (5.27)

$$
x=c\left(f\left(x_{0}\right)\right) t+x_{0}
$$

leva à família de trajetórias especiais definidas pela condição inicial ao longo das quais não se observa variação em $w(x, t)$, e é chamada de família das característica, ou simplesmente características.

Uma característica que emana de $x=x_{0}$ é determinada utilizando-se a condição inicial $w(x, 0)=f\left(x_{0}\right)$. Ao longo desta característica, a solução $w(x, t)$ muda de acordo com a equação para $w(x, t)$ em (5.27). Outras condições iniciais levam a outras características, o que gera a família de características para a determinada condição inicial. 
No caso de condições iniciais descontínuas, podem ocorrer ondas de rarefação ou choque, dependendo da forma das descontinuidades, que faz com que as características, não mais paralelas, se cruzem ou se distanciem com o tempo.

\subsubsection{Ondas de rarefação.}

É o caso de condições iniciais que levam a características que começam no mesmo ponto mas tem diferentes velocidades de propagação (diferentes derivadas), de maneira que as características se distanciam com o tempo, como indica a Figura (5.4).

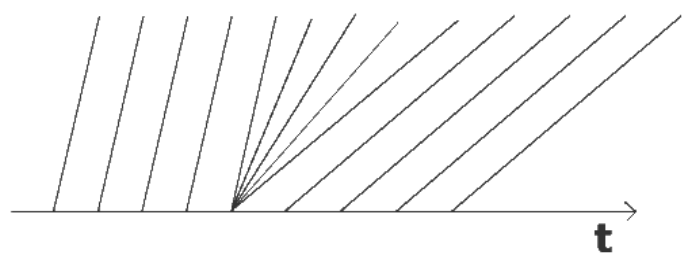

Figura 5.4. Ondas de rarefação: curvas que emanam de um determinado $x_{0}$ com diferentes inclinações.

Neste caso, a solução da equação é dada diretamente pela característica no ponto onde começa a região de rarefação. Utilizando a equação (5.28):

$$
c_{\text {raref. }}\left(f\left(x_{0}\right)\right)=\frac{x-x_{0}}{t}
$$

\subsubsection{Ondas de choque.}

No caso de equações quasi-lineares também é comum que as características se intersectem.

Isto ocorre quando duas características, uma partindo de $x=x_{1}$ e a outra de $x=x_{2}$, se intersectam em um momento posterior se $c\left(w\left(x_{1}, 0\right)\right)>c\left(w\left(x_{2}, 0\right)\right)$, ou seja, ocorre quando características com determinada condição inicial tem velocidade de propagação maior do que outras com condição inicial superior, como indica a Figura (5.5). 


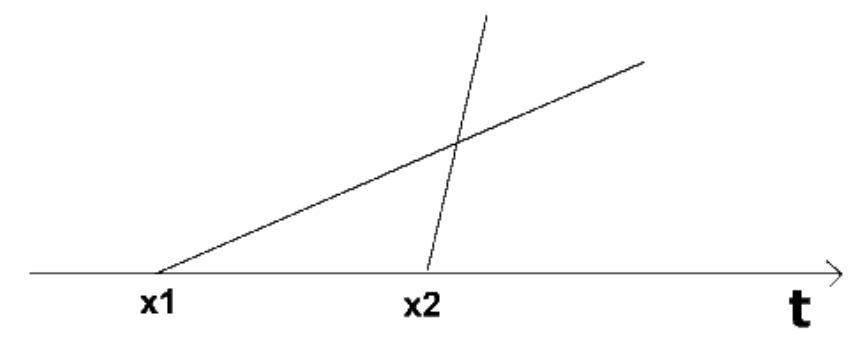

Figura 5.5. Ondas de choque: Características que emanam de diferentes $x_{0} \mathrm{~s}$ em $t=0$ e se interceptam em um tempo posterior.

No instante em que as características se intersectam, a solução da equação assume dois valores, cada um dada por uma das características, e a solução torna-se inválida. Isto se deve a um problema da própria equação diferencial, e não do método das características, já que este é justificado matematicamente.

O que se faz é assumir que a densidade, assim como a velocidade, tem uma descontinuidade, que será chamada de onda de choque, ou choque.

O choque ocorre em uma posição $x_{s}$ que se propaga no tempo. Chamemos de $x_{s^{+}}$e $x_{s^{-}}$ a posição do choque nos dois lado da descontinuidade.

Utilizando uma analogia com a equação de continuidade:

$$
\frac{\partial w}{\partial t}+\frac{\partial q}{\partial x}=0
$$

$q$ deve ser interpretado como a corrente.

Ocorre que, sendo uma equação de conservação, $w(x, t)$ deve ser conservada mesmo na descontinuidade. Em outras palavras, o fluxo relativo ao choque de um lado da descontinuidade deve ser o mesmo que o do outro lado:

$$
q_{+}^{r}-q_{-}^{r}=0
$$

Ou seja, a corrente de um lado do choque deve ser igual à corrente do outro lado.

Definimos: 


$$
q_{ \pm}^{r}=w_{ \pm} u_{ \pm}^{r}
$$

como sendo a corrente relativa, com

$$
u_{ \pm}^{r}=u_{ \pm}-\frac{d x_{s}}{d t}
$$

a velocidade relativa das características em cada um dos dois lados, onde $u_{ \pm}(t)$ é a velocidade das características em cada um dos dois lados do choque.

Então, de (5.31):

$$
w\left(x_{s^{+}}, t\right)\left[u\left(x_{s^{+}}, t\right)-\frac{d x_{s}}{d t}\right]=w\left(x_{s^{-}}, t\right)\left[u\left(x_{s^{-}}, t\right)-\frac{d x_{s}}{d t}\right]
$$

$\mathrm{Ou}$,

$$
\frac{d x_{s}}{d t}=\frac{w\left(x_{s^{+}}, t\right) u\left(x_{s^{+}}, t\right)-w\left(x_{s^{-}}, t\right) u\left(x_{s^{-}}, t\right)}{w\left(x_{s^{+}}, t\right)-w\left(x_{s^{-}}, t\right)} \equiv \frac{[q]}{[w]}
$$

Portanto a velocidade de choque é proporcional ao salto da descontinuidade do fluxo pelo salto de descontinuidade da densidade da quantidade conservada.

No caso de condições iniciais descontínuas, o choque ocorre logo no primeiro instante, como veremos no exemplo a seguir.

5.0.3. Equação de Burguers (não-viscosa). Como exemplo de uma equação diferencial parcial homogênea resolvida pelo método das características utilizaremos a equação de Burguers não difusiva, que é dada por:

$$
\frac{\partial C}{\partial t}+\frac{\partial}{\partial x}\left(\frac{C^{2}}{2}\right)=0
$$

$\mathrm{Ou}$

$$
\frac{\partial C}{\partial t}+C \frac{\partial C}{\partial x}=0
$$


ou ainda

$$
\frac{\partial C}{\partial t}=-\frac{\partial}{\partial x} F(C)
$$

onde

$$
F(C)=\frac{C^{2}}{2}
$$

Para resolve-la pelo método das características começamos comparando a equação com a derivada total da função,

$$
\frac{d}{d t} C(x(t), t)=\frac{\partial C}{\partial t}+\frac{d x}{d t} \frac{\partial C}{\partial x}=0
$$

identificando:

$$
\left\{\begin{array}{l}
\frac{d}{d t} C(x(t), t)=0 \rightarrow C(x, t)=C\left(x_{0}, 0\right) \\
\frac{d x}{d t}=C \rightarrow x(t)=x_{0}+C\left(f\left(x_{0}\right)\right) t
\end{array}\right.
$$

As características são dadas por:

$$
x(t)=x_{0}+C\left(f\left(x_{0}\right)\right) t
$$

No caso, escolhemos a seguinte condição inicial:

$$
C(x, 0)= \begin{cases}0, & x \leq 0 \\ 1, & 0<x \leq 1 \\ 0, & x>1\end{cases}
$$

A Figura (5.6) ilustra a condição inicial (5.43). 


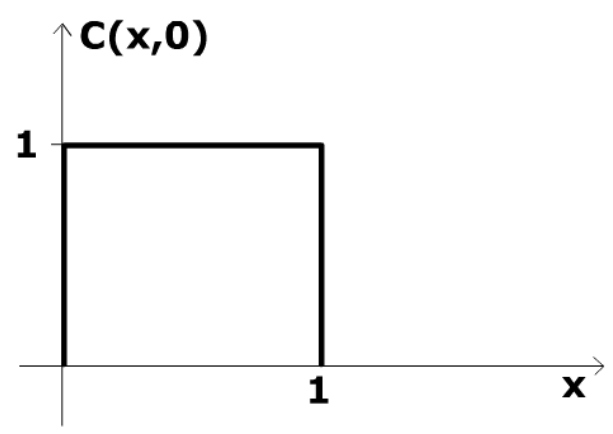

Figura 5.6. Condição inicial referente à equação (5.43).

Que leva às seguintes características:

$$
x(t)=\left\{\begin{array}{l}
x_{0}, \quad x_{0} \leq 0 \\
x_{0}+t, \quad 0<x_{0} \leq 1 \\
x_{0}, \quad x_{0}>1
\end{array}\right.
$$

$\mathrm{Ou}$

$$
x_{0}(t)=\left\{\begin{array}{l}
x, \quad x \leq 0 \\
x-t, \quad t<x \leq t+1 \\
x, \quad x>1
\end{array}\right.
$$

A Figura (5.7) mostra as características descritas por (5.44).

Em $t=0$, vemos, pela Figura (5.7) que há uma zona de choque em $x_{0}=1$ (as características se interceptam) e outra de rarefação em $x_{0}=0$.

As características que emanam de $x_{0}=0$ são dadas por (5.42):

$$
x=C t
$$




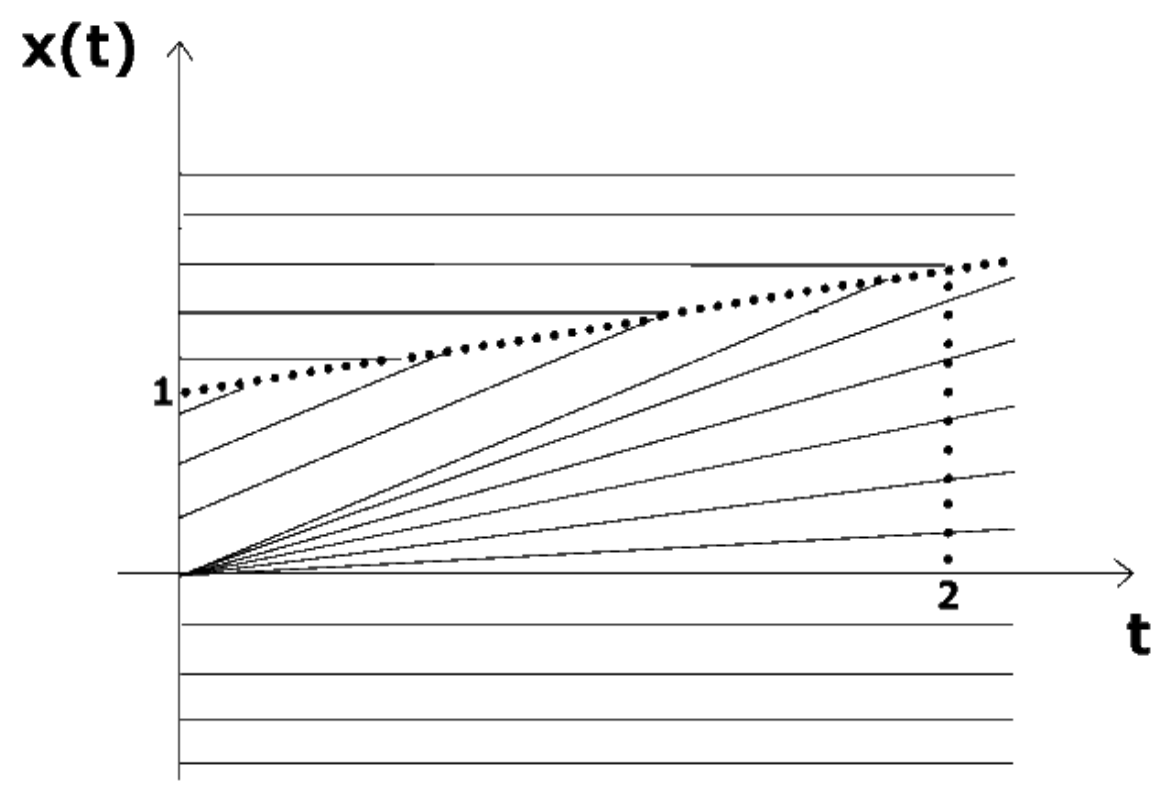

FigurA 5.7. Características da equação (5.42) referentes à condição inicial (5.36)

Logo, nesta região,

$$
C(x, t)=\frac{x}{t}
$$

Já a onda de choque, que começa em $x_{1 s}(0)=1$, se move de acordo com (5.35):

$$
\begin{gathered}
\frac{d x_{1 s}}{d t}=\frac{F\left(C_{l}\right)-F\left(C_{r}\right)}{C_{l}-C_{r}}=\frac{\left(\frac{1}{2}\right)^{2}-(0)^{2}}{1-0}=\frac{1}{4} \\
\therefore \quad x_{1 s}=x_{1 s}(0)+\frac{1}{4} t=1+\frac{1}{4} t
\end{gathered}
$$

Onde $F(C)$ é a função definida em (5.39), $C_{l}=1$ e $C_{r}=0$ são os valores que $C(x, t)$ assume nas regiões definidas pelas curvas características que emanam de $0<x_{0} \leq 1$ e $x_{0}>1$, respectivamente, vide Figura 5.7.

Há um segundo choque, que ocorre quando a região de rarefação encontra a solução do primeiro choque, ou,

$$
1+\frac{1}{4} t_{2 s}=t_{2 s} \rightarrow t_{2 s}=\frac{4}{3}
$$


Este choque se dará em

$$
x_{1 s}(2)=x_{2 s}=x_{1 s}(0)+\frac{1}{2}(t)=1+\frac{1}{2}(2)=2
$$

A segunda onda de choque é dada por

$$
\frac{d x_{2 s}(t)}{d t}=\frac{\left[\frac{1}{2}\left(\frac{x_{2 s}(t)}{t}\right)^{2}-(0)^{2}\right]}{\frac{x_{2 s}(t)}{t}}=\frac{1}{2} \frac{x_{2 s}(t)}{t}
$$

$$
\rightarrow \frac{d x_{2 s}(t)}{x_{2 s}(t)}=\frac{d t}{2 t} \rightarrow \ln \left(\frac{x_{2 s}(t)}{x_{2 s}\left(t_{2 s}\right)}\right)=\ln \left(\sqrt{\frac{t}{t_{2 s}}}\right)
$$

$$
\therefore x_{2 s}=x_{2 s} \sqrt{\frac{t}{t_{2 s}}}=2 \sqrt{\frac{t}{2}}=\sqrt{2 t}
$$

Onde $F(C)$ é a função definida em (5.39), $C_{l}=\frac{x_{2 s}(t)}{t}$ e $C_{r}=0$ são as soluções $C(x, t)$ referentes à região de rarefação (definida pelas curvas que emanam de $x_{0}=0$ ) e a região definida pelas curvas características que emanam de $x_{0}>1$, respectivamente.

Podemos então escrever a solução, voltando nas condições iniciais, através das características.

A solução é dividida em duas partes, uma antes e outra depois do segundo choque.

Para $t<t_{2 s}$ : 


$$
C(x, t)= \begin{cases}0, & x \leq 0 \\ \frac{x}{t}, & 0<x \leq t \\ 1, & t<x \leq 1+\frac{1}{2} t \\ 0, & x>1+\frac{1}{2} t\end{cases}
$$

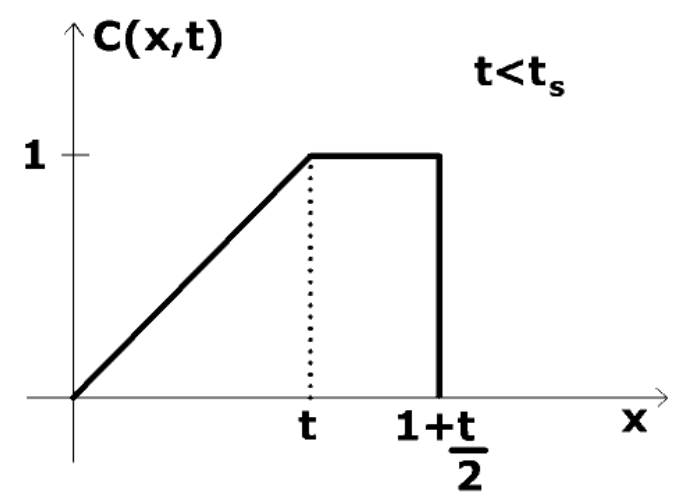

Figura 5.8. Solução da equação (5.36) com a condição inicial ( 5.6) para $t<t_{s}$.

A Figura (5.8) ilustra a condição inicial (5.54).

Para $t>t_{2 s}$ :

$$
C(x, t)=\left\{\begin{array}{c}
0, x \leq 0 \\
\frac{x}{t}, 0<x \leq \sqrt{2 t} \\
0, x>\sqrt{2 t}
\end{array}\right.
$$

A Figura (5.9) ilustra a condição inicial (5.55). 


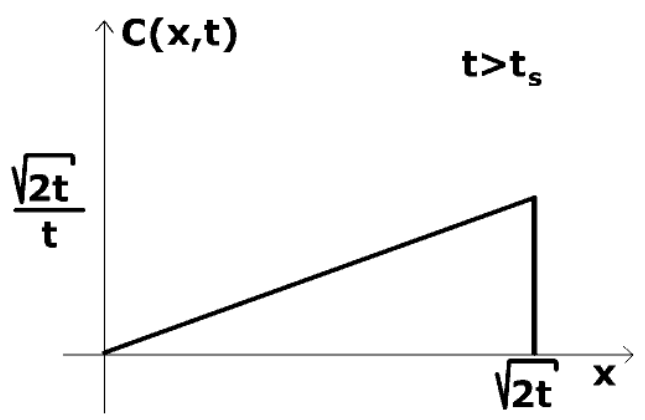

Figura 5.9. Solução da equação (5.36) com a condição inicial ( 5.6) para $t>t_{s}$.

A equação de Burguers é uma equação de conservação, logo deve ser normalizada para qualquer instante, ou seja, se integrarmos a solução em $x$, devemos ter um resultado independente do tempo. Isto deve valer todos os instantes, ou seja, para antes e depois do segundo choque:

$$
\frac{\partial}{\partial t} \int c(x, t) d x=0
$$

Para $t<t_{2 s}:$

$$
A_{1}=\int_{-\infty}^{+\infty} C(x, t) d x=\int_{0}^{t}\left[\frac{x}{t}\right] d x+\int_{t}^{1+\frac{1}{2} t}[1] d x=\frac{1}{t}\left[\frac{x^{2}}{2}\right]_{0}^{t}+[x]_{t}^{1+\frac{1}{2} t}
$$

$$
=\frac{1}{t} \frac{t^{2}}{2}+1+\frac{1}{2} t-t=1+t-t=1, \forall t
$$

Para $t>t_{2 s}:$

$$
A_{2}=\int_{-\infty}^{+\infty} C(x, t) d x=\int_{0}^{\sqrt{2 t}}\left[\frac{x}{t}\right] d x=\frac{1}{t}\left[\frac{x^{2}}{2}\right]_{0}^{\sqrt{2 t}}=\frac{1}{t} \frac{\sqrt{2 t}^{2}}{2}=\frac{2 t}{2 t}=1, \forall t
$$

O que prova que as soluções permanecem normalizadas no tempo. 


\subsubsection{Relação Médias $\times$ Características.}

No caso de equações diferenciais parciais lineares a média da solução sempre coincide com a característica, porém no caso de equações quasi-lineares isto nem sempre ocorre.

No caso da solução da equação de Burguers não viscoso, por exemplo, para a condição inicial pulso quadrado, a média só coincide na segunda parte da solução, ou seja, depois do segundo choque.

Na primeira parte elas diferem no grau do polinômio, como veremos a seguir.

Para $t<t_{2 s}$ :

$$
<x>(t)=\frac{\int_{-\infty}^{+\infty} x C(x, t) d x}{\int_{-\infty}^{+\infty} C(x, t) d x}=\int_{0}^{t} x\left[\frac{x}{t}\right] d x+\int_{t}^{1+\frac{1}{2} t} x[1] d x=\frac{1}{t}\left[\frac{x^{3}}{3}\right]_{0}^{t}+\left[\frac{x^{2}}{2}\right]_{t}^{1+\frac{1}{2} t}
$$

$$
=\frac{1}{t} \frac{t^{3}}{3}+\frac{1}{2}\left(1+\frac{1}{2} t\right)-\frac{t^{2}}{2}=\frac{t^{2}}{3}+\frac{t^{2}+t+\frac{1}{4}-t^{2}}{2}=\frac{t^{2}}{3}+\frac{t}{2}+\frac{1}{8}
$$

Que não coincide com a característica "média":

$$
x_{1}(t)=1+\frac{1}{2} t
$$

Para $t>t_{2 s}:$

$$
<x>(t)=\frac{\int_{-\infty}^{+\infty} x C(x, t) d x}{\int_{-\infty}^{+\infty} C(x, t) d x}=\int_{0}^{\sqrt{2 t}} x\left[\frac{x}{t}\right] d x=\frac{1}{t}\left[\frac{x^{3}}{3}\right]_{0}^{\sqrt{2 t}}=\frac{1}{t} \frac{\sqrt{2 t}^{3}}{3}=\frac{2}{3} \sqrt{2 t}
$$

Que coincide com a característica "média"apenas no grau do polinômio:

$$
x_{2}(t)=\sqrt{2 t}
$$

Lembrando que com característica "média"queremos dizer a característica que emana da média da distribuição inicial do problema.

Portanto, através destes exemplos de soluções de equações lineares e quasi-lineares, descritos neste apêndice, podemos inferir que a média espacial de uma função só coincide com a 
"característica média"da mesma quando a função provém de uma equação diferencial parcial linear. 



\section{Apêndice $\mathbf{C}$}

Solução da equação para o segundo choque da condição rankine do pulso retangular.

Trata-se uma equação do tipo:

$$
\frac{\partial x}{\partial t}=x g(t)+f(t)
$$

Sendo que $g(t)$ e $f(t)$ são funções contínuas.

Encontramos a solução da equação (5.65) através da seguinte manipulação matemática [Guidorizzi 1987]:

$$
\begin{aligned}
\frac{\partial}{\partial t}\left[x e^{-\int g(t) d t}\right] & =\frac{\partial x}{\partial t} e^{-\int g(t) d t}-x g(t) e^{-\int g(t) d t} \\
& =\left[\frac{\partial x}{\partial t}-x g(t)\right] e^{-\int g(t) d t}
\end{aligned}
$$

Isto é,

$$
\frac{\partial}{\partial t}\left[x e^{-\int g(t) d t}\right]=\left[\frac{\partial x}{\partial t}-x g(t)\right] e^{-\int g(t) d t}
$$

A igualdade acima nos indica um caminho para obtermos a solução geral da equação.

No caso,

$$
\frac{\partial x}{\partial t}-x g(t)=f(t)
$$

Multiplicando a equação (5.68) pelo fator integrante $e^{-\int g(t) d t}$, obtemos:

$$
\left[\frac{\partial x}{\partial t}-x g(t)\right] e^{-\int g(t) d t}=f(t) e^{-\int g(t) d t}
$$


$\mathrm{Ou}$,

$$
\frac{\partial}{\partial t}\left[x e^{-\int g(t) d t}\right]=f(t) e^{-\int g(t) d t}
$$

Daí,

$$
x e^{-\int g(t) d t}=A+\int f(t) e^{-\int g(t) d t} d t
$$

$\mathrm{Ou}$,

$$
x(t)=A e^{\int g(t) d t}+e^{\int g(t) d t} \int f(t) e^{\int g(t) d t} d t
$$

No caso,

$$
\frac{d x_{2 s}}{d t}=\frac{x_{2 s}}{2 t}+\frac{a t-\Delta-m}{2 t}
$$

onde identificamos:

$$
\left\{\begin{array}{c}
g(t)=\frac{x_{2 s}}{2 t} \\
f(t)=\frac{a t-\Delta-m}{2 t}
\end{array}\right.
$$

Logo:

$$
e^{\int g(t) d t}=\sqrt{t}
$$

e

$$
e^{-\int g(t) d t}=\frac{\sqrt{t}}{t}
$$

O que nos leva a solução:

$$
x_{2 s}(t)=A \sqrt{t}+\sqrt{t}\left[\int \frac{1}{\sqrt{t}}\left(\frac{a t-\Delta-m}{2 t}\right) d t\right]
$$

$$
=A \sqrt{t}+a t+(\Delta+m)
$$

Encontramos $A$ à partir da condição inicial $t_{2 s}=\frac{2 m}{b n}$ : 


$$
x_{2 s}\left(\frac{2 m}{b n}\right)=\Delta-m+\frac{2 a m}{b n}
$$

(5.78)

$$
\therefore A=-\sqrt{2 b n m t}=-\sqrt{2 b t}
$$

E portanto

$$
x_{2 s}(t)=a t-\sqrt{2 b t}+\Delta+m
$$





\section{Referências}

Aafif, A., Lin, J. 1998. Selection-mutantion of RNA víruses. Physical Review E, 57:24712474 .

Ayala, F. J. 1971. Competition Between Species: Frequency Dependence. Science. 171:820-824.

Baake, E., Baake M and Wagner. 1997. Ising Quantum Chain is Equivalent to a Model of Biological Evolution. Physical Review Letters 78:559-562.

Bell, Graham. 1997. The Basics of Selection. Chapman and Hall USA.

Bull, J. J. Virulence, 1994. International Journal of Organic Evolution. V48 número 5.

Burch, Christina, Chao L. 2000. Evolvability of an RNA Virus is Determined by its Mutational Neighbourhood. Nature 406:625-628.

Chao, L. 1990. Fitness of RNA Virus decreased by Muller's Ratchet. Nature 348:454-455.

Chao, L. et al. 2000. Kin Selection and Parasite Virulence: Higher and Lower Virulence with Higher and Lower Selection. Q. Rev. Biol. 75:261-275.

Clarke, David K., E. A. Duarte, A. Moya, S. F. Elena, E. Domingo, and J Holland. 1993. Genetic Bottlenecks and Population Passages Cause Profound Fitness Differences in RNA Viruses. Jounal of Virology 67:222.

Clarke, David K. Duarte E. A., Elena S. F., Moya A., Domingo E., Holland J. 1994. The Red Queen Reigns in the Kingdom of RNA Viruses. Proc. Natl. Acad. Sci. USA. 91:4821-4824.

Darwin, Francis. 2000. The Autobiography of Charles Darwin (Great Minds Series). Prometheus Books.

Darwin, Charles. 2002. A origem das Espécies. Editora Itatiaia. Belo Horizonte. quarta edição. Tradução de Eugênio Amado. 
Darwin, Charles. 1979. The Origin of Species by Means of Natural Selection. Gramercy Books.

Davies, Paul. 2000. O Quinto Milagre- Em Busca da Origem da Vida. Companhia das letras.

Domingo, E., Holland, J. J. 1997. RNA Virus Mutations and Fitness for Survival. Annu. Rev. Microbiol. 51:151-178.

Domingo, E., Eric Baranowski, Carmen M. Ruiz-Jarabo, Ana M. Martín-Hernández, Juan C. Sáiz, and Cristina Escarmís. 1998. Quasispecies Structure and Persistence of RNA Viruses. Emerging Infectious Deseases 4:521-527.

Duarte, E., D. Clarke, A. Moya, E. Domingo e J. Holland. 1992. Rapid Fitness losses in mammalian RNA Virus Clones due to Muller's Ratchet. Proc. Natl. Acad. Sci. USA. 89:6015-6019.

Duarte, E., Clarke D. K., Moya A., Elena S. F., Domingo E., Holland J. 1993. Many Trillionfold Amplification of single RNA vírus particles Fails to overcome the Muller's Ratchet Effect. Jounal of Virology 67:3620-3623.

Duarte, E., Novella I. S., Ledesma S., Clarke D. K., Moya A., Elena S. F., Domingo E., Holland J. 1994. Subclonal components of consensus fitness in an RNA vírus clone. Jornal of Virology 68:4295-4301.

Ebert, D. 1998. Experimental Evolution of Parasites. Science 282:1432-1435.

Eigen, Manfred. 1979. The Hipercycle - A Principle of Natural Self Organization. Springer-Verlag, New York. NY.

Eigen, Manfred. 1986. The Physics of Molecular Evolution. Chem. Scr. 26B13-16.

Eigen, Manfred. 1987. The Physics of Evolution. Chimia 41:195.

Eigen, Manfred. 1992. Steps Towards Life. Oxford University Press.

Eigen, Manfred. 1996. On the nature of Quasispecies. Trends in Microbiology. 4:216-218.

Elena, S. F. et al. 1996. Evolution of Fitness in Experimental Populations of Vesicular Stomatitis Virus. Genetics 142:673-679. 
Elena, S. F. et al. 1997. Frequency-dependent Selection in a Mammalian RNA vírus. Evolution 51:984-987.

Enders, J., S. Katz, M. Milovanovic, e A. Holloway. 1960. Studies on an Attenuated Measles Virus Vaccine. N. England J. Med. 263:153-159.

Evans, L.C. 1999. Partial Differential Equations, Graduate Studies in Mathematics, Vol. 19. American Mathematical Society, Providence, Rhode Island.

Figueiredo, Djairo Guedes de. 1997. Equações Diferenciais Aplicadas. IMPA.

Goel, Narendras e Richter-Dyn, Nira. 1974. Stochastic Models in Biology. New York: Academic Press.

Gould, Stephen Jay. 2004. O Polegar do Panda. Martins Fontes.

Guidorizzi, Hamilton Luiz. 1987. Um curso de cálculo - Vol 1. Livros Técnicos e Científicos S.A.

Haberman, R. 1998. Elementary applied partial differential equations. Prentice Hall.

Hamming, Richard W. 1980. Coding and information theory, Prentice-Hall, Englewood Cliffs.

Herre, E. A. 1993. Population Structure and the Evolution of Virulence in Nematode Parasites of Fig Wasps. Science 259:1442-1445.

Hofbauer, Josef. 1988. The theory of evolution and dynamical systems: mathematical aspects of selection. Cambridge University Press.

Holland, John J. 1982. Rapid Evolution of RNA Genomes. Science. 215:1577.

Holland, John J.1991. Quantitation of Relative Fitness and Great Adaptability of Clonal Populations of RNA Viruses. Journal of Virology, 65:2960-2967.

Hood, M. E. 2002. Dynamics of Multiple Infection and Within-Host Competition by the Anther-Smut Pathogen. The American Naturalist. 162:122-133.

Kessler, David A., H. Levine, D. Ridgway and L. S. Tsimring, 1997. Evolution on a Smooth Landscape, J. Stat. Phys. 87:519-544. 
Lázaro, E., Cristina Escarmís, Esteban Domingo, e Susanna C. Manrubia. 2002. Modeling Genome Fitness Evolution Associated with Serial Bottleneck Events: Evidence of Stationary States of Fitness. Jornal of Virology 76:8675-8681.

Lensky, Richard, Bennett A. F., Dao K. M. 1990. Rapid Evolution in Response to HighTemperature Selection. Letters to Nature 364:79-81.

Lensky, Richard et al. 1994. The Evolution of Virulence in Parasites and Pathogens: Reconciliation Between Two Competing Hypoteses. Jornal of Theoretical Biology 169:253365.

Lensky, Richard et al. 2004. Long-Term Experimental Evolution in Escherichia coli. I. Adaption and Divergence during 2000 Generations. The American Naturalist 138:1315-1341.

Levin, S., Pimentel, D. 1981. Selection of Intermediate Rates of Increase in Parasite-Host Systems. The American Naturalist 117:308-315.

Lotka, A. J. 1956. Elements of Mathematical Biology. New York, Dover Publications.

Mandelbrot, Benoit B. 1983. The fractal Gemometry of Nature, Freeman, New York.

Martell, Maria et al. 1992. Hepatitis C Virus (HCV) Circulates as a Population of Different bit Closely Related Genomes: Quasispecies Nature of HCV Genome Distribution. Journal of Virology 66:3225-3229.

Martinez, M. A., Carrillo C, Gonzalez-Candelas F, Moya A, Domingo E, Sobrino F. 1991. Fitness Alteration of Foot-and-mouth Disease Virus: Measaurement of Adaptability of Viral Quasispecies. Journal of Virology 66:3557-3565.

Mayr, Ernst. 1963. Animal species and evolution. Cambridge : Belknap Press of Harvard University Press.

Millstein, Roberta. 2002. Are random drift and natural selection conceptually distinct? Biology \& Philosophy 17(2):33-53.

Montrol, E. W., Lebowitz, J. L. 1979. On an Enriched Collection of Stochastic Processes, in Fluctuation Phenomena. Elsevier Science Publishers BV.

Muller, H. J. 1964. The relation of recombination to mutatitonal advance. Mutat. Res. $1: 2$. 
Novella, I. et al. 1995a. Exponencial increases of RNA fitness during large population transitions. Proc. Natl. Acad. Sci. USA 92:5841.

Novella, I., Elena SF, Moya A, Domingo E, Holland J. 1995b. Size of Bottleneck Leading to Fitness Loss is determined by Initial Population Fitness. Jornal of Virology 69:2869-2872.

Novella, I. Clarke D. K., Quer J., Duarte E. A., Lee C. H., Weaver S. C., Elena S. F., Moya A., Domingo E., Holland J. 1995c. Extreme Fitness Differences in Mammalian and Insect Hosts After Persistent Replication of Vesicular Stomatitis Virus. Jornal of Virology, 69:6805-6809.

Novella, I. et al. 1999. Exponencial Fitness Gains of RNA Virus Populations Are Limited by Bottleneck Effects. Journal of Virology 73:1668-1671.

Nowak, M.A., May, R. M. 1994. Superinfection and the evolution of parasite virulence. Proc. R. Soc. Lond. B Biol Sci. 255:81-9.

Overbaugh, J., Charles Bangham. 2001. Selection Forces and Constraints on Retroviral Sequence variation. Science 292:1106-1109.

Parvin, Jeffrey D., Moscona A., Pan W. T., Leider J. M., Palese P. 1986. Measurement of the Mutation Rates of Animal Viruses: Influenza A Virus and Poliovírus Type 1. Journal of Virology 59:377-383.

Pickering, J. et al. 2000. Sex Ratio and Virulence in two Species of Lizard Malaria Parasites. Evol. Ecology Res. 2:171-184.

Quer, J., Huerta R., Novella I. S., Tsimring L., Domingo E., Holland J. 1997. Reproducible Non-linear Population Dynamics and Critical Points During Replicative Competitions of RNA Virus Quasispecies. Journal of Molecular Biology 264:465-471.

Read, A. F., Taylor L. H. 2001. The Ecology of Genetically Diverse Infections. Science 292:1099-1102.

Rouzine, Igor M. 2002. The Solitary Wave of Assexual Evolution. PNAS 100:587-592.

Rouzine, Igor M. 2001. Transition Between Stochastic Evolution and Determinstic Evolution in the Presence of Selection: Genereal Theory and Application to Virology. Microbiology and Molecular Biology Reviews. 
Saakian, David, Hu, Chin-Kun. 2004. Eigen Model as a Quantum Spin Chain: Exact Dynamics. Physical Review E 69:021913-1.

Sabin, A. B., L. Boulger. 1973. History of Sabin Attenuated Poliovirus Oral Vacine Strains. J. Biol. Stand. 1:115-118.

Saldaña, J., Elena, S., Solé, R. 2003. Coinfection and Superinfection in RNA Virus Population: a Selection-mutation Model. Mathematical Biosciences 183:153-160.

Schrödinger, Erwin. 1997. O que é Vida? Fundação Editora da UNESP.

Schneider, W. L. e Marilyn J. Roossinck. 2000. Evolutionary Related Sindbis-Like Plant Viruses Maintain Different Levels of Population Diversity in a Common Host. Journal of Virology 74:3130-3134.

Schneider, W. L. e Roossinck M. J. 2001. Genetic Diversity in RNA Virus Quasispecies is Controlled by Host-Virus Interactions. Journal of Virology, 75:6566-6571.

Solé, R. V., Ferrer R., Gonzalez-Garcia I., Quer J., Domingo E. 1999. Red Queen Dynamics Competition and Critical Points in a Model of RNA Virus Quasispecies. Journal of Virology 198:47-59.

Steinhauer, D. A., Holland, J. J. 1987. Rapid Evolution of RNA víruses. Ann. Rev. Microbiol. 41:409-433.

Strauss, J. e E. Strauss. 1988. Evolution of RNA Viruses. Annu Rev. Microbiol. 42:657-683.

Thelier, M. e H. Smith. 1937. Use of Yellow Fever Virus Modified by In Vitro Cultuvation for Humam Immunization. J. Exp. Med. 65:767-800

Tsimring, L., H. Levine. 1996. RNA Virus Evolution via a Fitness-Space Model. Physical Review Letters. 76:23

Tomé, Tânia e Oliveira, Mário José de. 2001. Dinâmica Estocástica e Irreversibilidade. EDUSP.

Turner, P., Chao L. 1998. Sex and the Evolution of Intrahost Competition in RNA Virus $\phi 6$. Genetics 150:523-532.

Valen, Van. 1973. A new evolutionary law. Evol. Theory 1: 1-30. 
West, S. A. 2002. Cooperation, Virulence and Siderophore Production in Bacterial Parasites. Proc. R. Soc. Lond. B. 270:37-44. 